Supporting Information for:

\title{
Understanding Molecular Factors that Determine Performance in the Rare Earth (TriNOx) Separations System
}

\author{
Bren E. Cole, Thibault Cheisson, $\neq$ Joshua J. M. Nelson, Robert F. Higgins, Michael R. \\ Gau, Patrick J. Carroll, and Eric J. Schelter* \\ P. Roy and Diana T. Vagelos Laboratories, Department of Chemistry, University of \\ Pennsylvania, 231 S 34th St., Philadelphia, Pennsylvania 19104, United States \\ ‡ Present address: Eramet Ideas, 1 avenue Albert Einstein, 78190 Trappes, France \\ *schelter@sas.upenn.edu
}

Number of Tables: 1

Number of Pages: 63

Number of Figures: 59

Number of Scheme: 17 


\section{Table of Contents}

Experimental Procedures $\quad$ S3

General Methods $\quad$ S3

Materials $\quad$ S3

X-Ray Crystallography $\quad$ S3

Inductively Coupled Plasma - Optical Emission Spectroscopy (ICP-OES) S4

Table S1. Instrumental and operating conditions for ICP-OES measurements $\quad$ S4

Cyclic Voltammetry $\quad$ S5

Synthetic Details $\quad$ S5

Scheme S1. Preparation of tris(2-bromo-4-tert-butyl)benzylamine from 2-bromo-4-tert-butyl-1-

methylbenzene. $\quad$ S5

Synthesis of (2-bromo-4-tert-butyl)benzylbromide $\quad$ S5

Synthesis of tris(2-bromo-4-tert-butyl)benzylamine $\quad$ S6

Scheme S2. Synthesis of tris(2-tert-butylhydroxylamine-4-tertbutyl)benzylamine $\left(\mathrm{H}_{3} \mathrm{TriNOx}^{\mathrm{tBu}}\right) . \quad \mathrm{S} 6$

Scheme S3. Preparation of (2-bromo-5-phenyl)benzylbromide from 2-bromobenzoic acid. $\quad$ S7

Synthesis of methyl-2-bromo-5-iodobenzoate $\quad S 7$

$\begin{array}{ll}\text { Synthesis of methyl-2-bromo-5-phenylbenzoate } & \text { S7 }\end{array}$

$\begin{array}{ll}\text { Synthesis of } 2 \text { bromo-5-phenylbenzyl alcohol } & 57\end{array}$

Synthesis of 2-bromo-5-phenylbenzyl bromide $\quad$ S8

Scheme S4. Preparation of tris(2-bromo-5-phenyl)benzylamine from (2-bromo-5-
phenyl)benzylbromide.

Synthesis of bis(2-bromo-5-phenyl)benzylamine $\quad$ S8

Synthesis of tris(2-bromo-5-phenyl)benzylamine $\quad$ S9

Scheme S5. Synthesis of tris(2-tert-butylhydroxylamine-5-phenyl)benzylamine $\left(\mathrm{H}_{3} \mathrm{TriNOx}^{\mathrm{Ph}}\right) . \quad \mathrm{S9}$

Scheme S6. Synthesis of 2-bromo-4-(trifluoromethyl)benzylamine from 4-(trifluoromethyl)aniline. S10

Synthesis of 2-bromo-4-(trifluoromethyl)aniline $\quad$ S10

Synthesis of 2-bromo-4-(trifluoromethyl)iodobenzene $\quad$ S10

Synthesis of 2-bromo-4-(trifluoromethyl)benzaldehyde $\quad$ S10

Synthesis of 2-bromo-4-(trifluoromethyl)benzylamine $\quad$ S11

Scheme S7. Synthesis of tris(2-bromo-4-trifluoromethyl)benzylamine from 2-bromo-4-

Synthesis of tris(2-bromo-4-trifluoromethyl)benzylamine

Scheme S8. Synthesis of tris(2-tert-butylhydroxylamine-4-trifluoromethyl)benzylamine $\left(\mathrm{H}_{3} \mathrm{TriNOx}^{\mathrm{CF} 3}\right)$

\begin{tabular}{l}
$\mathrm{S} 12$ \\
\hline
\end{tabular}

Scheme S9. Synthesis of $R E\left(\operatorname{TriNOx}^{\mathrm{R}}\right)(\mathrm{THF})_{\mathrm{x}}$ complexes $\left(\mathrm{x}=1\right.$ for $\mathrm{R}=\mathrm{Ph}, \mathrm{CF}_{3} ; \mathrm{x}=0$ for $\left.\mathrm{R}={ }^{t} \mathrm{Bu}\right)$.

Scheme S10. Synthesis of Nd(TriNOxtBu).

Scheme S11. Synthesis of Dy(TriNOx $\left.{ }^{\mathrm{tB}}\right)$.

Scheme S12. Synthesis of $\left[\mathrm{Nd}\left(\operatorname{TriNOx}^{\mathrm{BBu}}\right)\right]_{2}$. $\quad \mathrm{S} 14$

Scheme S13. Synthesis of $\mathrm{Nd}\left(\mathrm{TriNOx}^{\mathrm{Ph}}\right)(\mathrm{THF}) . \quad \mathrm{S} 14$

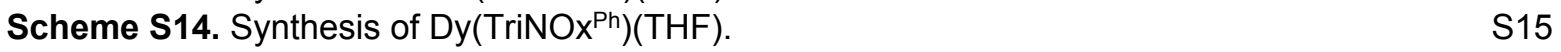

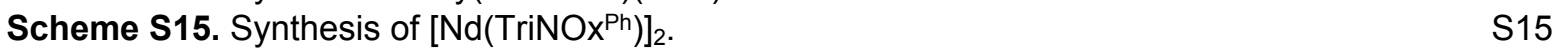

Scheme S16. Synthesis of $\mathrm{Nd}\left(\mathrm{TriNOx}^{\mathrm{CF} 3}\right)$ (THF). $\quad$ S16

Scheme S17. Synthesis of Dy(TriNOx $\left.{ }^{\mathrm{CF}}\right)(\mathrm{THF})$. $\quad \mathrm{S} 16$

$\begin{array}{ll}\text { NMR Spectra } & \text { S17 }\end{array}$

Electrochemistry and Correlation Studies $\quad$ S50

$\begin{array}{ll}\text { References } & \text { S63 }\end{array}$ 


\section{Experimental Procedures}

\section{General Methods}

Unless otherwise noted, all reactions and manipulations were performed under an inert atmosphere $\left(\mathrm{N}_{2}\right)$ using standard Schlenk techniques or in a Vacuum Atmospheres, Inc. Nexus II drybox equipped with equipped with a molecular sieves 13X/Q5 Cu-0226S catalyst purifier system. Glassware was oven-dried for at least three hours at $150{ }^{\circ} \mathrm{C}$ prior to use. ${ }^{1} \mathrm{H}$ NMR spectra were obtained on a Bruker DMX-300 Fourier transform NMR spectrometer while operating at a ${ }^{1} \mathrm{H}$ frequency of $300 \mathrm{MHz} .{ }^{13} \mathrm{C}\left\{{ }^{1} \mathrm{H}\right\}$ and ${ }^{19} \mathrm{~F}\left\{{ }^{1} \mathrm{H}\right\}$ NMR spectra were obtained on a UNI 400 instrument while operating at ${ }^{13} \mathrm{C}$ and ${ }^{19} \mathrm{~F}$ frequencies of 100.6 and $376.3 \mathrm{MHz}$ respectively. Chemical shifts were recorded in units of parts per million and referenced against residual proteo solvent peaks for ${ }^{1} \mathrm{H}$ NMR and characteristic solvent peaks for ${ }^{13} \mathrm{C}$ NMR. Elemental analyses were performed on a Costech ECS 4010 Analyzer. Inductively Coupled Plasma - Optical Emission Spectroscopy (ICP-OES) analysis was performed at the University of Pennsylvania Earth \& Environmental Science Dept. on a Spectro Genesis ICP-OES Spectrometer. Attenuated Total Reflectance Fourier-Transform Infrared (ATR FT-IR) spectra were obtained on a Perkin Elmer Spectrum Two spectrometer. High-resolution mass spectrometry (HRMS) measurement analyses were conducted on either a Waters GCT Premier, time-of-flight, GCMS with electron ionization (EI), or an LCT Premier XE, time-of-flight, LCMS with electrospray ionization (ESI). Samples were taken up in a suitable solvent for analysis. The signals were mass measured against an internal lock mass reference of perfluorotributylamine (PFTBA) for EI-GCMS, and leucine enkephalin for ESI-LCMS. Waters software calibrates the instruments, and reports measurements, by use of neutral atomic masses. The mass of the electron is not included.

\section{Materials}

Tetrahydrofuran, diethyl ether, dimethoxyethane, benzene, toluene, dichloromethane, hexanes, pentane, and acetonitrile were purchased from Fisher Scientific. All solvents were sparged with dry argon for 30 minutes and dried using a commercial two-column solvent purification system comprising columns packed with Q5 reactant and neutral alumina, respectively (benzene, toluene, dichloromethane, hexanes, pentane, acetonitrile), or two columns of neutral alumina (THF, $\mathrm{Et}_{2} \mathrm{O}$, and DME). $\mathrm{CDCl}_{3}, \mathrm{C}_{6} \mathrm{D}_{6}$, pyridine- $d_{5}$, thf- $d_{8}, \mathrm{CD}_{3} \mathrm{OD}$, and acetone- $d_{6}$ were purchased from Cambridge Isotope Laboratories, Inc. and stored over $4-\AA$ molecular sieves prior to use. Potassium bis(trimethylsilyl)amide, neodymium(III) chloride, europium(III) chloride, dysprosium(III) chloride, and yttrium(III) chloride were purchased from Sigma Aldrich and used as received. $\mathrm{RE}\left[\mathrm{N}\left(\mathrm{Si}\left(\mathrm{CH}_{3}\right)_{3}\right)_{2}\right]_{3}(\mathrm{RE}=\mathrm{Nd}, \mathrm{Eu}, \mathrm{Dy}, \mathrm{Y}),{ }^{1}$ were synthesized according to literature procedures.

\section{X-Ray Crystallography}

X-ray intensity data for $\mathrm{H}_{3}$ TriNOx $\left.^{\mathrm{CF}_{3}}, \quad\left[\mathrm{Nd}(\mathrm{TriNOx})^{\mathrm{tBu}}\right)\right]_{2}, \quad \mathrm{Nd}\left(\mathrm{TriNOx}{ }^{\mathrm{Ph}}\right)(\mathrm{THF}), \quad$ and

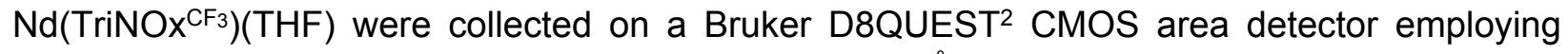
graphite-monochromated Mo-Ka radiation $(\lambda=0.71073 \AA)$ at $100(1) \mathrm{K}$. X-ray intensity data for

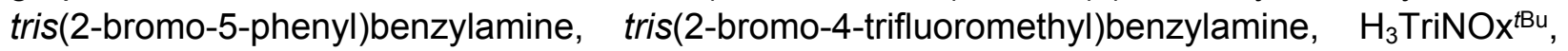
$\mathrm{H}_{3}$ TriNOx $^{\mathrm{Ph}}$, $\mathrm{Nd}\left(\right.$ TriNOx $\left.^{\mathrm{tBu}}\right)$, Dy(TriNOx $\left.{ }^{\mathrm{tBu}}\right)$, Dy(TriNOx $\left.{ }^{\mathrm{CF}_{3}}\right)(\mathrm{THF})$, were collected on a Bruker APEXII ${ }^{3}$ CCD area detector employing graphite-monochromated Mo-Ka radiation $(\lambda=0.71073 \AA)$ at $100(1) \mathrm{K}$. In all cases, rotation frames were integrated using SAINT, ${ }^{4}$ producing a listing of unaveraged $\mathrm{F}^{2}$ and $\sigma\left(\mathrm{F}^{2}\right)$ values. The intensity data were corrected for Lorentz and polarization 
effects and for absorption using SADABS. ${ }^{5} \mathrm{H}_{3}$ TriNOx $^{\mathrm{Ph}}, \mathrm{H}_{3}$ TriNOx $^{\mathrm{CF}} 3$, $\mathrm{Nd}\left(\mathrm{TriNOx}{ }^{\mathrm{tBu}}\right)$, $\left.\left[\mathrm{Nd}(\mathrm{TriNOx})^{\mathrm{tBu}}\right)\right]_{2}, \mathrm{Nd}\left(\mathrm{TriNOx}^{\mathrm{Ph}}\right)(\mathrm{THF})$, and $\mathrm{Nd}\left(\mathrm{TriNO}^{\mathrm{CF}}\right)(\mathrm{THF})$ were solved by direct methods using SHELXT. ${ }^{6}$ tris(2-bromo-5-phenyl)benzylamine, tris(2-bromo-4-trifluoromethyl)benzylamine, $\mathrm{H}_{3}$ TriNOx $^{t \mathrm{Bu}}$, Dy $\left(\right.$ TriNOx $\left.^{\mathrm{tBu}}\right)$, and $\mathrm{Dy}\left(\mathrm{TriNOx}^{\mathrm{CF}}\right)(\mathrm{THF})$ were solved by direct methods using SHELXS. ${ }^{7}$ Refinement was by full-matrix least squares based on $\mathrm{F}^{2}$ using SHELXL-2016-2018. ${ }^{8}$ All reflections were used during refinements. Non-hydrogen atoms were refined anisotropically. All single crystal solid state structures are depicted as thermal ellipsoid plots at the $40 \%$ probability levels. Hydrogen atoms, interstitial solvent molecules, and the tert-butyl group of the hydroxylamine moiety are depicted in wireframe for clarity.

\section{Inductively Coupled Plasma - Optical Emission Spectroscopy (ICP-OES)}

Inductively coupled plasma optical emission spectroscopy was conducted on a Spectro Genesis ICP-OES spectrometer (SPECTRO Analytical Instruments $\mathrm{GmbH}$, Kleve, Germany) equipped with an integrated three channel peristaltic pump and a ASX-260 auto-sampler (CETAC Technologies, Omaha, NE, USA). Samples solutions were delivered to the nebulizer using a Mod Lichte spray chamber and single-use PVC PT-2140PF tubing (Precision Glassblowing, Centennial, CO, USA). Each data acquisition was preceded by a 35 second rinse sequence at different pump speeds. Other relevant parameters were previously optimized to give the smallest RSD and are summarized in Table S1.

Table S1. Instrumental and operating conditions for ICP-OES measurements

\begin{tabular}{ll}
\hline Instrument conditions & \\
\hline Forward power $(\mathrm{W})$ & 1350 \\
Plasma gas flow rate $\left(\mathrm{L} \mathrm{min}^{-1}\right)$ & 13.50 \\
Auxiliary gas flow rate $\left(\mathrm{L} \mathrm{min}^{-1}\right)$ & 1.00 \\
Nebulizer flow rate $\left(\mathrm{L} \mathrm{min} \mathrm{min}^{-1}\right)$ & 0.90 \\
& $\mathrm{Nd} 430.358$ \\
& Eu 381.967 \\
Wavelengths $(\mathrm{nm})$ & Dy 364.540 \\
& Y 371.030 \\
\hline
\end{tabular}

Sulfuric acid (Fisher, Certified ACS Plus grade), hydrogen peroxide (Fisher, $30 \%$ solution in water), and distilled-deionized water (Milli-Q, $18.2 \mathrm{M} \Omega \mathrm{cm}$, Millipore) were used for sample preparation and dilution. Samples were prepared by digestion in a (3:1) $\mathrm{H}_{2} \mathrm{SO}_{4}: \mathrm{H}_{2} \mathrm{O}_{2}$ mixture at $100{ }^{\circ} \mathrm{C}$ for 1 hour, followed by dilution to a concentration of ca. $10 \% \mathrm{H} \mathrm{H}_{2} \mathrm{SO}_{4}$ to limit matrix effects. Analytical plasma standard solutions were obtained from Alfa Aesar (Specpure ${ }^{\circledR}, 1000$ ppm $\mathrm{RE}_{2} \mathrm{O}_{3}$ in $5 \% \mathrm{HNO}_{3}$ ).

Calibrations were performed before each set of measurements using a range of 7 standardized solutions (125-0.025 ppm). Calibration curves were confirmed to have $R^{2}>0.999$ for the selected elements. Potential instrumental drift was monitored by continuously measuring $\mathrm{Ar}$ lines at 430.010 and $404.442 \mathrm{~nm}$; absence of drift was finally confirmed by measuring a standardized solution at the end of each measurement session. The following wavelengths $(\mathrm{nm})$ were used for element quantifications and reviewed for the absence of interferences: 364.540 (Dy), 430.358 $(\mathrm{Nd}), 381.967(\mathrm{Eu}), 371.030(\mathrm{Y})$ and were consistent with literature recommendations. The wavelengths selected had the highest signal intensity, in agreement with the literature, ${ }^{9}$ and were the most relevant for the studied range of concentrations.

Separation factors were calculated as the ratio of distribution coefficients between REs using 
data obtained from ICP-OES analysis ${ }^{54}(D=$ distribution coefficient, $S F=$ separation factor, $E F=$ enrichment factor, $n=$ moles):

$$
\begin{gathered}
D_{R E}=\frac{[R E]_{\text {solid }}}{[R E]_{\text {filtrate }}} \\
S F_{R E 2 / R E 1}=\frac{D_{R E 2}}{D_{R E 1}}=\frac{\frac{[R E 2]_{\text {solid }}}{[R E 2]_{\text {filtrate }}}}{\frac{[R E 1]_{\text {solid }}}{[R E 1]_{\text {filtrate }}}}=\frac{[R E 2]_{\text {solid }}}{[R E 2]_{\text {filtrate }}} \times \frac{[R E 1]_{\text {filtrate }}}{[R E 1]_{\text {solid }}} \\
E F_{\text {filtrate }}=\frac{n_{R E 1, \text { filtrate }}}{n_{R E 2, \text { filtrate }}} \\
E F_{\text {solid }}=\frac{n_{R E 2, \text { solid }}}{n_{R E 1, \text { solid }}}
\end{gathered}
$$

Note: Enrichment factors were calculated in the precipitation-based separation method as a metric for the purity of the RE of interest within a single phase.

\section{Cyclic Voltammetry}

All experiments were performed under an inert atmosphere $\left(\mathrm{N}_{2}\right)$ in a drybox with electrochemical cells that consisted of a $4 \mathrm{~mL}$ vial, glassy carbon disk ( $3 \mathrm{~mm}$ diameter) working electrode, a platinum-wire counterelectrode, and a silver wire plated with $\mathrm{AgCl}$ as a quasi-reference electrode. The working electrode surface was polished prior to each set of experiments. Potentials recorded in THF were referenced versus ferrocene, which was added as an internal standard for calibration at the end of each run. Solutions employed during $\mathrm{CV}$ studies were approximately $3 \mathrm{mM}$ in analyte and $100 \mathrm{mM}$ in $\left[{ }^{n} \mathrm{Pr}_{4} \mathrm{~N}\right]\left[\mathrm{BAr}_{4}\right]$. All data were collected in a positive-feedback IR compensation mode. The THF solution cell resistances were measured prior to each run to ensure resistances $(\lesssim 500 \Omega)$.

\section{Synthetic Details}

Scheme S1. Preparation of tris(2-bromo-4-tert-butyl)benzylamine from 2-bromo-4-tert-butyl-1methylbenzene.<smiles>Cc1ccc(Br)cc1Br</smiles>

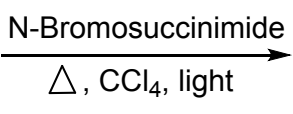<smiles>CC(C)(O)CC(=O)NCc1ccc(Br)cc1Br</smiles><smiles>CC(C)(C)c1ccc(CN(Cc2ccc(C(C)(C)C)cc2Br)Cc2ccc(C(C)(C)C)cc2Br)c(Br)c1</smiles>

\section{Synthesis of (2-bromo-4-tert-butyl)benzylbromide}

(2-bromo-4-tert-butyl)benzylbromide was synthesized according to a procedure adapted from Mallory et al. ${ }^{10}$ 2-bromo-4-tert-butyl-1-methylbenzene $(18.7 \mathrm{~g}, 105 \mathrm{mmol}, 1$ equiv.) and $N$ bromosuccinimide (23.8 g, $105 \mathrm{mmol}, 1$ equiv.) were stirred in $150 \mathrm{~mL}$ of carbon tetrachloride, 
which was refluxed overnight. The reaction mixture was allowed to cool and then filtered over a medium porosity glass frit. Volatiles were removed from the filtrate under reduced pressure to give a colorless liquid (30.0 g, 94\%). Characterization by ${ }^{1} \mathrm{H}$ NMR spectroscopy was consistent with the reported data.

\section{Synthesis of tris(2-bromo-4-tert-butyl)benzylamine}

tris(2-bromo-4-tert-butyl)benzylamine was synthesized according to a procedure adapted from Fox et al. ${ }^{11}$ (2-bromo-4-tert-butyl)benzylbromide $(6.00 \mathrm{~g}, 19.6 \mathrm{mmol}, 3.0$ equiv.) was stirred in ethanol to dissolve all solids. Ammonium hydroxide (29\%) (2.22 g, $63.4 \mathrm{mmol}, 9.7$ equiv.) was added to solution and the reaction mixture was stirred at room temperature for 2 days, producing a white solid. The precipitate was collected by filtration, rinsed with $2 \times 15 \mathrm{~mL}$ ethanol, and dried under reduced pressure overnight to yield a white solid $(3.85 \mathrm{~g}, 85 \%)$. ${ }^{1} \mathrm{H}$ NMR (ppm, $d_{8}$-thf, 300 $\mathrm{MHz}): \delta=7.68(\mathrm{~d}, \mathrm{~J}=8.1 \mathrm{~Hz}, 3 \mathrm{H}), 7.56(\mathrm{~d}, \mathrm{~J}=1.9 \mathrm{~Hz}, 3 \mathrm{H}), 7.25(\mathrm{dd}, \mathrm{J}=8.1,1.4 \mathrm{~Hz}, 3 \mathrm{H}), 3.78$ $(\mathrm{s}, 6 \mathrm{H}), 1.27$ (s, 27H). ${ }^{13} \mathrm{C}$ NMR (ppm, $d_{8}$-thf, $\left.400 \mathrm{MHz}\right): \delta=152.5,136.0,130.3,129.9,125.4$, 124.4, 58.4, 35.0, 31.3. IR: $v=2962,1549,1493,1480,1440,1387,1360,1273,1261,1147$, 1130, 1114, 1035, 984, 882, 860, 835, 722, 707, $602 \mathrm{~cm}^{-1}$. HRMS: (ESI) m/z calc. for $\mathrm{C}_{33} \mathrm{H}_{43} \mathrm{Br}_{3} \mathrm{~N}$ $(\mathrm{M}+\mathrm{H}): 690.0946$, found: 690.0947 .

Scheme S2. Synthesis of tris(2-tert-butylhydroxylamine-4-tertbutyl)benzylamine $\left(\mathrm{H}_{3} \mathrm{TriNOx}^{t \mathrm{Bu}}\right)$.

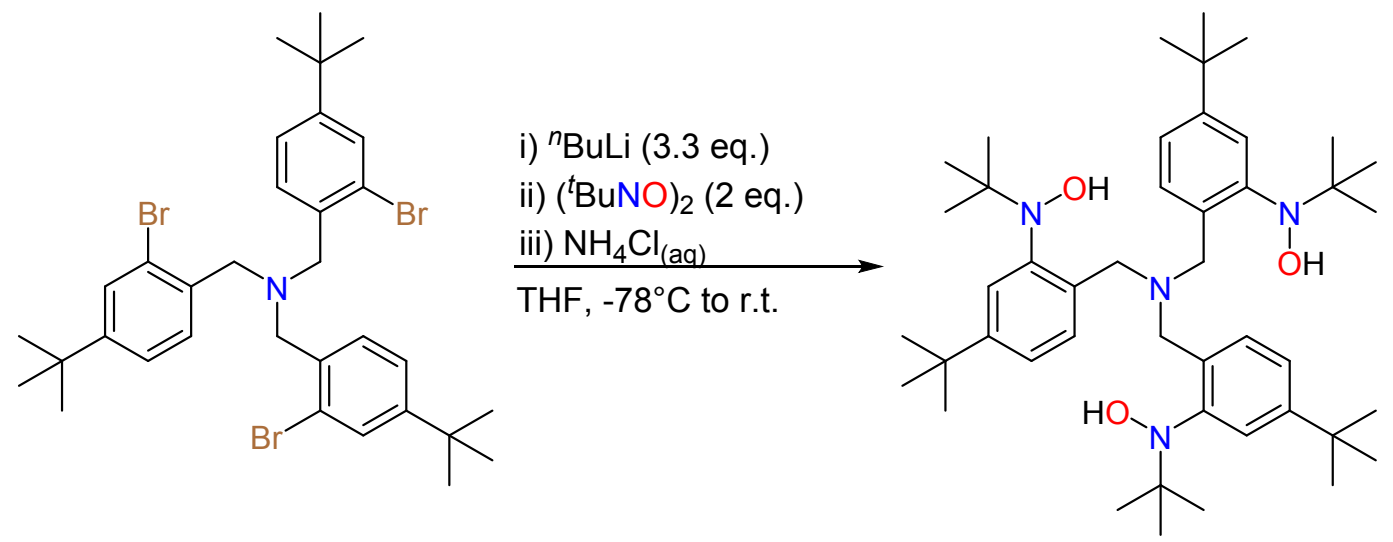

Tris(2-bromo-4-tertbutyl)benzylamine ( $2.00 \mathrm{~g}, 2.89 \mathrm{mmol}, 1$ equiv.) was dissolved in hot THF (100 $\mathrm{mL}$ ) and added to a $200 \mathrm{~mL}$ Schlenk flask equipped with a magnetic stir bar. The flask was placed under atmosphere and cooled to $-78{ }^{\circ} \mathrm{C}$. A $1.6 \mathrm{M}$ solution of $n$-butyllithium complex in hexanes (5.95 mL, $9.53 \mathrm{mmol}, 3.3$ equiv.) was added dropwise and the reaction was stirred for 3 hours. A THF solution $(10 \mathrm{~mL})$ of 2-methyl-2-nitrosopropane dimer $(1.01 \mathrm{~g}, 5.78 \mathrm{mmol}, 2$ equiv.) was added and the reaction was gradually warmed to room temperature and stirred for 3 hours. The reaction was quenched with a saturated aqueous ammonium chloride solution. The organic portion was extracted with $3 \times 50 \mathrm{~mL}$ diethyl ether. The combined organics were dried over magnesium sulfate and volatiles removed under reduced pressure, yielding a yellow solid. Single crystals were grown from a hot hexanes solution allowed to cool to room temperature $(1.15 \mathrm{~g}, 56 \%)$. ${ }^{1} \mathrm{H}$ NMR (ppm, $d_{5}$-pyr, $\left.300 \mathrm{MHz}\right): \delta=8.47(\mathrm{~s}, 3 \mathrm{H}), 7.53(\mathrm{~d}, \mathrm{~J}=1.9 \mathrm{~Hz}, 3 \mathrm{H}), 7.16(\mathrm{q}, \mathrm{J}=7.9 \mathrm{~Hz}, 6 \mathrm{H}), 3.61(\mathrm{~s}, 6 \mathrm{H})$, $1.28(\mathrm{~s}, 27 \mathrm{H}), 0.82(\mathrm{~s}, 27 \mathrm{H}) .{ }^{13} \mathrm{C}$ NMR $\left(\mathrm{ppm}, \mathrm{CDCl}_{3}, 400 \mathrm{MHz}\right): \delta=150.6,149.1,132.0,131.9$, 124.4, 122.2, 59.0, 56.2, 34.6, 31.4, 26.7. IR: $v=3355,2962,1606,1462,1385,1361,1273$, 1250, 1205, 1102, 1077, 950, 900, 859, 822, 723, 655, 624, 559, $521 \mathrm{~cm}^{-1}$. HRMS: (ESI) m/z calc. for $\mathrm{C}_{45} \mathrm{H}_{73} \mathrm{~N}_{4} \mathrm{O}_{3}(\mathrm{M}+\mathrm{H}): 717.5683$, found: 717.5687. Anal. calc. for $\mathrm{C}_{45} \mathrm{H}_{72} \mathrm{~N}_{4} \mathrm{O}_{3}: \mathrm{C}, 75.37 ; \mathrm{H}$, 10.12; N, 7.81. Found: C, 75.64; H, 9.73; N, 7.67. 
Scheme S3. Preparation of (2-bromo-5-phenyl)benzylbromide from 2-bromobenzoic acid.

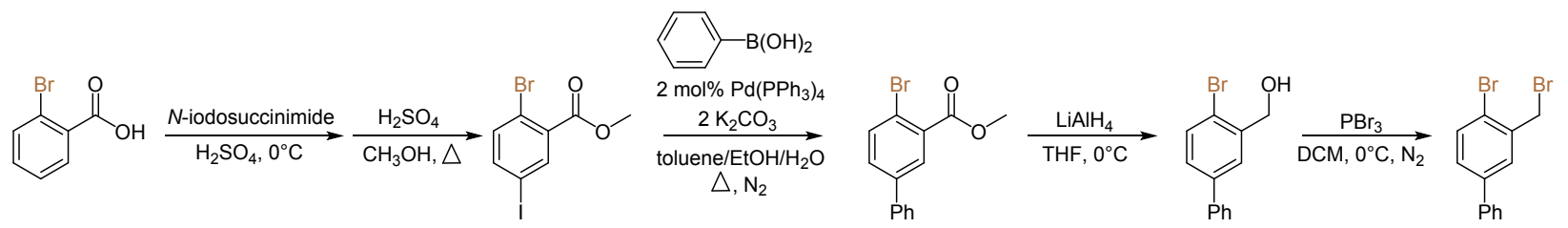

\section{Synthesis of methyl-2-bromo-5-iodobenzoate}

Methyl-2-bromo-5-iodobenzoate was synthesized according to a procedure adapted from Dahl et al. ${ }^{12}$ 2-bromobenzoic acid $(6.00 \mathrm{~g}, 29.8 \mathrm{mmol}, 1$ equiv.) was dissolved in $70 \mathrm{~mL}$ conc. sulfuric acid and chilled to $0{ }^{\circ} \mathrm{C}$ in an ice bath. $\mathrm{N}$-iodosuccinimide $(6.72 \mathrm{~g}, 29.8 \mathrm{mmol}, 1$ equiv.) was then added over $15 \mathrm{~min}$. and the reaction was stirred for $5 \mathrm{~h}$. The reaction was then poured over ice and extracted with $3 \times 100 \mathrm{~mL}$ EtOAc. The combined organics were washed with $1 \times 50 \mathrm{~mL}$ of $10 \%$ $\mathrm{Na}_{2} \mathrm{~S}_{2} \mathrm{O}_{3}, 2 \times 50 \mathrm{~mL} \mathrm{H} \mathrm{H}_{2}$, and $1 \times 50 \mathrm{~mL}$ brine. The organics were then dried over magnesium sulfate (anhyd.) and filtered, and volatiles were removed under reduced pressure to yield a pale yellow solid (9.2 g, 95\%). The crude 2-bromo-5-iodobenzoic acid (9.2 g, $26.1 \mathrm{mmol}, 1$ equiv.) was dissolved in $200 \mathrm{~mL}$ methanol and $4 \mathrm{~mL}$ conc. sulfuric acid was added. The reaction mixture was refluxed overnight. The reaction was then cooled, diluted with $200 \mathrm{~mL} \mathrm{H}_{2} \mathrm{O}$, and extracted with 3 $\times 50 \mathrm{~mL}$ diethyl ether. The combined organics were washed with $50 \mathrm{~mL} \mathrm{Na}_{2} \mathrm{~S}_{2} \mathrm{O}_{3}, 50 \mathrm{~mL} \mathrm{H}_{2} \mathrm{O}$, and $2 \times 50 \mathrm{~mL}$ brine. The organics were dried with magnesium sulfate, filtered, and volatiles were removed under reduced pressure. White crystals formed upon standing at room temperature (9.05 g, 89\%). Characterization by ${ }^{1} \mathrm{H}$ NMR spectroscopy was consistent with the reported data.

\section{Synthesis of methyl-2-bromo-5-phenylbenzoate}

Methyl-2-bromo-5-phenylbenzoate was synthesized according to a procedure adapted from Duggan et al. ${ }^{13}$ Methyl-2-bromo-5-iodobenzoate (10.0 g, $29.3 \mathrm{mmol}, 1$ equiv.), phenylboronic acid (3.57 g, $29.2 \mathrm{mmol}, 0.95$ equiv.), and potassium carbonate (8.12 g, $58.7 \mathrm{mmol}$, 2 equiv.) were stirred in a mixture of toluene $(200 \mathrm{~mL})$, ethanol $(50 \mathrm{~mL})$, and water $(25 \mathrm{~mL})$. The reaction flask was sparged with nitrogen for $30 \mathrm{~min}$. Tetrakis(triphenylphosphine)palladium $(0.068 \mathrm{~g}, 0.59 \mathrm{mmol})$ was added to the reaction under a stream of nitrogen. The reaction was sparged with nitrogen for $15 \mathrm{~min}$, followed by refluxing overnight. The reaction mixture was cooled to room temperature, then partitioned between $200 \mathrm{~mL}$ toluene and $100 \mathrm{~mL} \mathrm{H} \mathrm{H}_{2} \mathrm{O}$. The combined organics were washed with $2 \times 100 \mathrm{~mL}$ brine, dried over magnesium sulfate, filtered, and volatiles were removed under reduced pressure, yielding an orange oil. The residue was purified by chromatography (10\% to $25 \%$ EtOAc:hexanes) to give an orange oil $(6.02 \mathrm{~g}, 62 \%)$. Characterization by ${ }^{1} \mathrm{H}$ NMR spectroscopy was consistent with the reported data.

\section{Synthesis of 2 bromo-5-phenylbenzyl alcohol}

2-bromo-5-phenylbenzyl alcohol was synthesized according to a procedure adapted from Duggan et al. ${ }^{13}$ A suspension of lithium aluminum hydride $(1.26 \mathrm{~g}, 33.2 \mathrm{mmol}, 0.75$ equiv.) in $80 \mathrm{~mL}$ anhydrous THF was prepared in an atmosphere of nitrogen and cooled to $0{ }^{\circ} \mathrm{C}$. Next, a THF solution of methyl-2-bromo-5-phenylbenzoate (12.9 g, $44.3 \mathrm{mmol}, 1$ equiv.) was added dropwise to the reaction mixture under a stream of nitrogen. The mixture was stirred at $0{ }^{\circ} \mathrm{C}$ for $40 \mathrm{~min}$, followed by an additional 20 min stirring at room temperature. The reaction mixture was quenched by dropwise addition of $1.2 \mathrm{~mL} \mathrm{H}_{2} \mathrm{O}, 1.2 \mathrm{~mL} 15 \%$ sodium hydroxide solution, and $3.6 \mathrm{~mL} \mathrm{H}_{2} \mathrm{O}$. EtOAc $(100 \mathrm{~mL})$ was added to the solution, and the mixture was filtered over Celite, with rinses 
of EtOAc. The organic filtrates were dried over anhydrous magnesium sulfate, filtered, and volatiles were removed under reduced pressure to yield a white solid (11.4 $\mathrm{g}, 98 \%)$. Characterization by ${ }^{1} \mathrm{H}$ NMR spectroscopy was consistent with the reported data.

\section{Synthesis of 2-bromo-5-phenylbenzyl bromide}

2-bromo-5-phenylbenzyl alcohol $(6.00 \mathrm{~g}, 22.8 \mathrm{mmol}, 1.0$ equiv.) was stirred in $150 \mathrm{~mL}$ of dichloromethane, and the resulting solution was cooled to $0{ }^{\circ} \mathrm{C}$ and sparged with nitrogen for 15 minutes. Afterwards, phosphorus tribromide $(6.79 \mathrm{~g}, 25.1 \mathrm{mmol}, 1.1$ equiv.) was added dropwise under nitrogen flow and the reaction was stirred at room temperature overnight. The reaction was quenched by the careful addition of a saturated sodium carbonate solution $(150 \mathrm{~mL})$. The solution was extracted with $3 \times 150 \mathrm{~mL}$ dichloromethane, washed with $2 \times 150 \mathrm{~mL}$ brine, and dried over magnesium sulfate. Volatiles were removed, and the sample was dried under reduced pressure overnight to yield a white solid $(6.2 \mathrm{~g}, 83 \%)$. ${ }^{1} \mathrm{H}$ NMR $\left(\mathrm{ppm}, \mathrm{CDCl}_{3}, 300 \mathrm{MHz}\right): \delta=7.67(\mathrm{~d}, \mathrm{~J}=$ $11.9 \mathrm{~Hz}, 1 \mathrm{H}), 7.66(\mathrm{~d}, \mathrm{~J}=12.9 \mathrm{~Hz}, 1 \mathrm{H}), 7.59(\mathrm{t}, \mathrm{J}=1.8 \mathrm{~Hz}, 1 \mathrm{H}), 7.56(\mathrm{~d}, \mathrm{~J}=1.2 \mathrm{~Hz}, 1 \mathrm{H}), 7.47(\mathrm{~s}$, $1 \mathrm{H}), 7.46(\mathrm{dt}, \mathrm{J}=20.9,1.5 \mathrm{~Hz}, 1 \mathrm{H}), 7.45(\mathrm{~s}, 1 \mathrm{H}), 7.41(\mathrm{~d}, \mathrm{~J}=2.5 \mathrm{~Hz}, 1 \mathrm{H}), 7.38(\mathrm{~d}, \mathrm{~J}=2.2 \mathrm{~Hz}, 1 \mathrm{H})$, 4.67 (s, 2H). ${ }^{13} \mathrm{C}$ NMR (ppm, $\mathrm{CDCl}_{3}, 500 \mathrm{MHz}$ ): $\delta=141.3,139.4,137.4,133.8,130.0,129.1$, 128.8, 128.0, 127.1, 123.5, 33.5. IR: $v=1469,1446,1433,1390,1214,1190,1075,1056,1027$, 1020, 894, 829, 756, 727, 714, 695, 649, 570, 545, $520 \mathrm{~cm}^{-1}$. HRMS: (ESI) m/z calc. for $\mathrm{C}_{13} \mathrm{H}_{11} \mathrm{Br}_{2} \mathrm{~N}(\mathrm{M}+\mathrm{H}): 323.9149$, found: 323.9155 .

Scheme S4. Preparation of tris(2-bromo-5-phenyl)benzylamine from (2-bromo-5phenyl)benzylbromide.

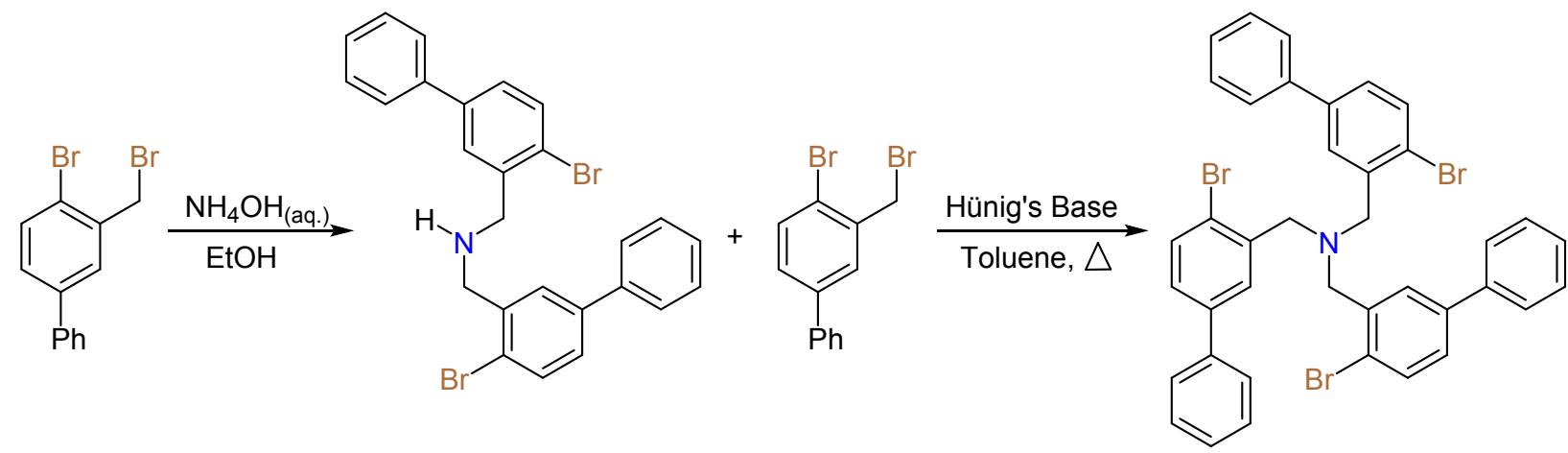

\section{Synthesis of bis(2-bromo-5-phenyl)benzylamine}

2-bromo-5-phenylbenzyl bromide (4.00 g, $12.3 \mathrm{mmol}, 2.0$ equiv.) was dissolved in $100 \mathrm{~mL}$ ethanol and allowed to cool to room temperature. Ammonium hydroxide $(29 \%)(1.51 \mathrm{~g}, 42.9 \mathrm{mmol}, 7.0$ equiv.) was added to solution and the reaction mixture was stirred for 2 days, producing a white solid. The precipitate was collected by filtration, washed with ethanol, and dried under reduced pressure overnight to yield a white solid $(2.2 \mathrm{~g}, 70 \%) .{ }^{1} \mathrm{H}$ NMR $\left(\mathrm{ppm}, d_{8}\right.$-thf, $\left.400 \mathrm{MHz}\right): \delta=7.90$ $(\mathrm{d}, \mathrm{J}=1.9 \mathrm{~Hz}, 2 \mathrm{H}), 7.61(\mathrm{t}, \mathrm{J}=7.0 \mathrm{~Hz}, 4 \mathrm{H}), 7.55(\mathrm{~d}, \mathrm{~J}=8.3 \mathrm{~Hz}, 1 \mathrm{H}), 7.51(\mathrm{dd}, \mathrm{J}=7.8,1.6 \mathrm{~Hz}$, $1 \mathrm{H}), 7.41(\mathrm{dd}, \mathrm{J}=7.8,2.4 \mathrm{~Hz}, 1 \mathrm{H}), 7.39(\mathrm{t}, \mathrm{J}=7.7 \mathrm{~Hz}, 4 \mathrm{H}), 7.31(\mathrm{~d}, \mathrm{~J}=7.2 \mathrm{~Hz}, 2 \mathrm{H}), 7.27(\mathrm{~m}$, overlapping, $1 \mathrm{H}), 4.00(\mathrm{~d}, \mathrm{~J}=6.7 \mathrm{~Hz}, 4 \mathrm{H}), 2.42(\mathrm{q}, \mathrm{J}=6.7 \mathrm{~Hz}, 1 \mathrm{H}) .{ }^{13} \mathrm{C}$ NMR $\left(\mathrm{ppm}, d_{8}\right.$-thf, 400 $\mathrm{MHz}): \delta=141.2,140.9,133.5,129.4,129.1,128.1,127.5,127.4,123.4,53.5$. IR: $v=2981,1463$, 1448, 1383, 1334, 1183, 1139, 1108, 1075, 1054, 1024, 999, 960, 889, 832, 815, 758, 735, 716, $694 \mathrm{~cm}^{-1}$. HRMS: (ESI) m/z calc. for $\mathrm{C}_{26} \mathrm{H}_{22} \mathrm{Br}_{2} \mathrm{~N}(\mathrm{M}+\mathrm{H}): 506.0119$, found: 506.0119 . 


\section{Synthesis of tris(2-bromo-5-phenyl)benzylamine}

bis(2-bromo-5-phenyl)benzylamine (2.27 g, $4.48 \mathrm{mmol}, 1.0$ equiv.) and 2-bromo-5-phenylbenzyl bromide (1.46 g, $4.48 \mathrm{mmol}, 1.0$ equiv.) were stirred in $100 \mathrm{~mL}$ of toluene. $N, N$ diisopropylethylamine (Hünig's base) $(0.70 \mathrm{~g}, 5.4 \mathrm{mmol}, 1.2$ equiv.) was added to the solution, and the reaction was refluxed overnight. Volatiles were removed, and the resulting residue was triturated with dichloromethane. The precipitate was collected by filtration and dried under reduced pressure overnight to yield a white solid $(2.55 \mathrm{~g}, 75 \%)$. ${ }^{1} \mathrm{H}$ NMR (ppm, $d_{8}$-thf, $\left.400 \mathrm{MHz}\right)$ : $\delta=8.11(\mathrm{~d}, \mathrm{~J}=2.2 \mathrm{~Hz}, 3 \mathrm{H}), 7.55(\mathrm{~d}, \mathrm{~J}=8.2 \mathrm{~Hz}, 3 \mathrm{H}), 7.51(\mathrm{dd}, \mathrm{J}=7.6,1.6 \mathrm{~Hz}, 6 \mathrm{H}), 7.37$ (dd, J = 8.2, $2.3 \mathrm{~Hz}, 3 \mathrm{H}), 7.25$ (m, overlapping, 9H), 4.00 (s, 6H). ${ }^{13} \mathrm{C}$ NMR (ppm, $d_{8}$-thf, $400 \mathrm{MHz}$ ): $\delta=$ 141.1, 140.5, 139.4, 133.7, 129.7, 129.5, 128.1, 127.7, 127.3, 123.8, 59.1. IR: $v=2981,1466$, 1447, 1386, 1372, 1181, 1139, 1120, 1076, 1055, 1026, 970, 892, 830, 821, 757, 728, 693, 524, $469 \mathrm{~cm}^{-1}$. HRMS: (ESI) m/z calc. for $\mathrm{C}_{39} \mathrm{H}_{31} \mathrm{Br}_{3} \mathrm{~N}(\mathrm{M}+\mathrm{H}): 750.0007$, found: 750.0020 .

Scheme S5. Synthesis of tris(2-tert-butylhydroxylamine-5-phenyl)benzylamine $\left(\mathrm{H}_{3} \mathrm{TriNOx}^{\mathrm{Ph}}\right)$.
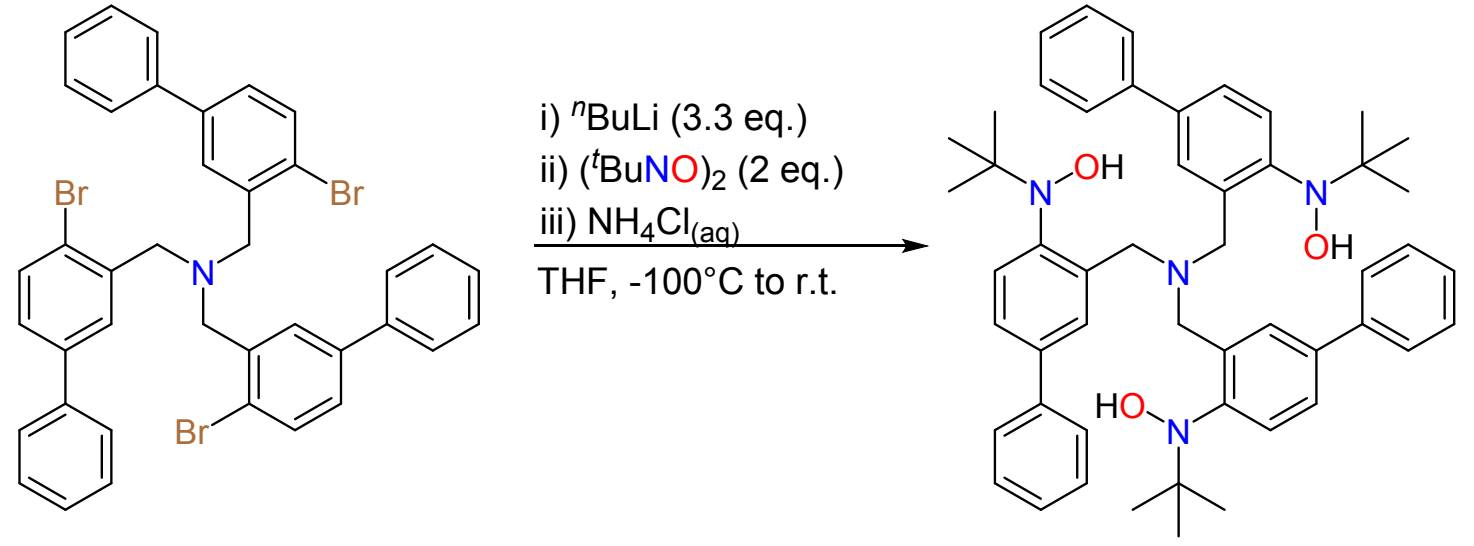

Tris(2-bromo-5-phenyl)benzylamine (3.00 g, $3.99 \mathrm{mmol}, 1$ equiv.) was dissolved in hot THF (500 $\mathrm{mL}$ ) and added to a $1 \mathrm{~L}$ Schlenk flask equipped with a magnetic stir bar. The flask was placed under atmosphere and cooled to $-100{ }^{\circ} \mathrm{C}$. A $1.6 \mathrm{M}$ solution of $n$-butyllithium complex in hexanes (8.2 $\mathrm{mL}, 13.2 \mathrm{mmol}, 3.3$ equiv.) was added dropwise and the reaction was stirred for 3 hours. A THF solution ( $10 \mathrm{~mL}$ ) of 2-methyl-2-nitrosopropane dimer ( $1.39 \mathrm{~g}, 7.97 \mathrm{mmol}, 2$ equiv.) was added and the reaction was gradually warmed to room temperature and stirred for 3 hours. The reaction was quenched with a saturated aqueous ammonium chloride solution. The organic portion was extracted with $3 \times 50 \mathrm{~mL}$ diethyl ether. The combined organics were dried over magnesium sulfate and volatiles removed under reduced pressure, yielding a white solid. Single crystals were grown from an acetonitrile solution cooled to $-25^{\circ} \mathrm{C}(2.05 \mathrm{~g}, 65 \%) .{ }^{1} \mathrm{H}$ NMR $\left(p p m, \mathrm{C}_{6} \mathrm{D}_{6}, 400 \mathrm{MHz}\right): \delta=$ $7.85(\mathrm{~s}, 3 \mathrm{H}), 7.72(\mathrm{~d}, \mathrm{~J}=5.0 \mathrm{~Hz}, 3 \mathrm{H}), 7.66(\mathrm{~s}, 3 \mathrm{H}), 7.60(\mathrm{~d}, \mathrm{~J}=4.1 \mathrm{~Hz}, 6 \mathrm{H}), 7.42$ (d, J = $5.4 \mathrm{~Hz}$, $3 \mathrm{H}), 7.24(\mathrm{~s}, 6 \mathrm{H}), 3.92(\mathrm{~s}, 6 \mathrm{H}), 1.01(\mathrm{~s}, 27 \mathrm{H}) .{ }^{13} \mathrm{C}$ NMR (ppm, $\left.\mathrm{C}_{6} \mathrm{D}_{6}, 400 \mathrm{MHz}\right): \delta=149.1,141.4$, 138.8, 136.1, 130.4, 129.2, 127.5, 127.4, 126.6, 60.1, 56.0, 26.4. IR: $v=3363,2979,2869,1479$, 1450, 1386, 1356, 1204, 1132, 1099, 1053, 1027, 970, 944, 895, 838, 771, 755, 698, $527 \mathrm{~cm}^{-1}$. HRMS: (ESI) $\mathrm{m} / \mathrm{z}$ calc. for $\mathrm{C}_{51} \mathrm{H}_{61} \mathrm{~N}_{4} \mathrm{O}_{3}(\mathrm{M}+\mathrm{H})$ : 777.4744 , found: 777.4756 . Anal. calc. for $\mathrm{C}_{51} \mathrm{H}_{60} \mathrm{~N}_{4} \mathrm{O}_{3}$ : C, 78.83; $\mathrm{H}, 7.78 ; \mathrm{N}, 7.21$. Found: C, 78.38; $\mathrm{H}, 8.07 ; \mathrm{N}, 7.22$. 
Scheme S6. Synthesis of 2-bromo-4-(trifluoromethyl)benzylamine from 4(trifluoromethyl)aniline.

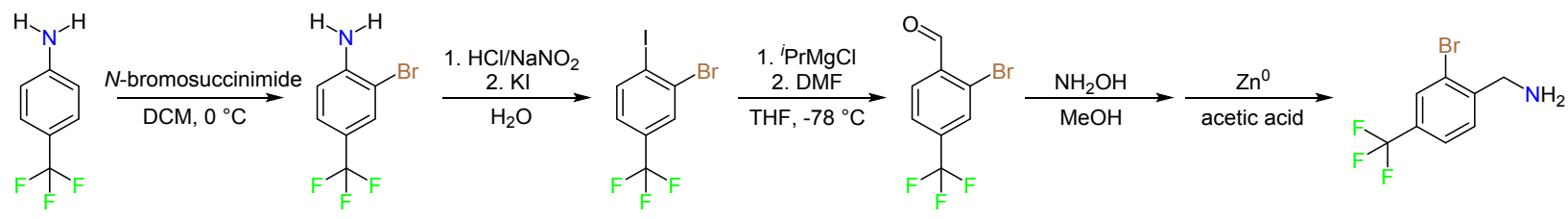

\section{Synthesis of 2-bromo-4-(trifluoromethyl)aniline}

2-bromo-4-(trifluoromethyl)aniline was synthesized according to a procedure adapted from Crousse et al. ${ }^{14}$ 4-(trifluoromethyl)aniline $(15.0 \mathrm{~g}, 93.1 \mathrm{mmol}, 1$ equiv.) was stirred in $150 \mathrm{~mL}$ dichloromethane and cooled to $0^{\circ} \mathrm{C}$ in an ice bath. $\mathrm{N}$-bromosuccinimide $(16.5 \mathrm{~g}, 94.0 \mathrm{mmol}, 1.01$ equiv.) was added to the reaction mixture over the course of 15 minutes. The reaction was stirred 20 minutes, then allowed to warm to room temperature and stirred for an additional 40 minutes. The reaction was quenched with dropwise addition of saturated sodium bicarbonate solution, followed by addition of $\mathrm{H}_{2} \mathrm{O}$. The sample was extracted with $2 \times 150 \mathrm{~mL}$ dichloromethane, washed with $150 \mathrm{~mL} \mathrm{H} \mathrm{H}_{2} \mathrm{O}$ and $2 \times 150 \mathrm{~mL}$ brine. The combined organics were dried over magnesium sulfate, filtered, and volatiles were removed under reduced pressure to yield a bright orange oil (20.3 g, 91\%). Characterization by ${ }^{1} \mathrm{H}$ NMR spectroscopy was consistent with the reported data.

\section{Synthesis of 2-bromo-4-(trifluoromethyl)iodobenzene}

2-bromo-4-(trifluoromethyl)iodobenzene was synthesized according to a procedure adapted from Jorgensen et al. ${ }^{15}$ 2-bromo-4-(trifluoromethyl)aniline $(20.9 \mathrm{~g}, 87.1 \mathrm{mmol}, 1$ equiv.) was added dropwise to $40 \mathrm{~mL}$ hydrochloric acid (\%) and cooled to $0{ }^{\circ} \mathrm{C}$ in an ice bath. An aqueous solution of sodium nitrite $\left(6.61 \mathrm{~g}, 95.8 \mathrm{mmol}, 1.1\right.$ equiv.) in $26 \mathrm{~mL} \mathrm{H}_{2} \mathrm{O}$ was added dropwise and the reaction was stirred 30 minutes. An aqueous solution of potassium iodide $(127.2 \mathrm{~g}, 766 \mathrm{mmol}$, 8.8 equiv.) in $150 \mathrm{~mL} \mathrm{H}_{2} \mathrm{O}$ was added to the reaction dropwise. The reaction mixture was allowed to warm to room temperature while stirring overnight. The reaction was extracted with $3 \times 150 \mathrm{~mL}$ hexanes, and the combined organics were washed with $2 \times 150 \mathrm{~mL} 1 \mathrm{M}$ sodium hydroxide solution, $2 \times 150 \mathrm{~mL}$ saturated sodium bisulfite solution, and $200 \mathrm{~mL}$ brine. The combined organics were dried over magnesium sulfate, filtered, and volatiles were removed under reduced pressure to yield an orange oil. The sample was purified by flash chromatography with $100 \%$ hexanes eluent, and the product was isolated as a pale pink liquid that crystallized upon standing $(22.8 \mathrm{~g}, 75 \%)$. Characterization by ${ }^{1} \mathrm{H}$ NMR spectroscopy was consistent with the reported data.

\section{Synthesis of 2-bromo-4-(trifluoromethyl)benzaldehyde}

2-bromo-4-(trifluoromethyl)benzaldehyde was synthesized according to a procedure adapted from Hall et al. ${ }^{16}$ 2-bromo-4-(trifluoromethyl)iodobenzene $(10.1 \mathrm{~g}, 28.8 \mathrm{mmol}$, 1 equiv.) was stirred in a 50:50 mixture of THF and diethyl ether under a stream of nitrogen. The solution was cooled to $-78{ }^{\circ} \mathrm{C}$ in a dry ice/acetone bath. A $3.0 \mathrm{M}$ solution of isopropylmagnesium bromide $(9.7 \mathrm{~mL}$, $29.1 \mathrm{mmol}, 1.01$ equiv.) in THF was added dropwise, and the reaction mixture was stirred for 2 hours cold. Anhydrous N,N-dimethylformamide $(6.6 \mathrm{~mL}, 86.3 \mathrm{mmol}, 3$ equiv.) was added dropwise, and the solution was allowed to warm to room temperature over 30 minutes while stirring. The reaction mixture was quenched by dropwise addition of sodium bicarbonate, followed by extraction with $3 \times 150 \mathrm{~mL}$ diethyl ether. The combined organics were washed with $2 \times 150$ $\mathrm{mL}$ brine, and $150 \mathrm{~mL} 1 \mathrm{M}$ lithium chloride solution. The combined organics were dried over magnesium sulfate, filtered, and volatiles removed under reduced pressure to yield an orange oil 
(6.4 g, 88\%). Characterization by ${ }^{1} \mathrm{H}$ NMR spectroscopy was consistent with the reported data.

\section{Synthesis of 2-bromo-4-(trifluoromethyl)benzylamine}

2-bromo-4-(trifluoromethyl)benzaldehyde $(4.18 \mathrm{~g}, 16.5 \mathrm{mmol}, 1$ equiv.) was stirred in $100 \mathrm{~mL}$ methanol. Hydroxylamine (50\%) $(0.601 \mathrm{~g}, 18.2 \mathrm{mmol}, 1.1$ equiv.) was added dropwise and the resulting solution was stirred 3 hours. Volatiles were removed under vacuum, partitioned between $200 \mathrm{~mL}$ ethyl acetate and $200 \mathrm{~mL}$ deionized water. Combined organics were washed with $2 \times 100$ $\mathrm{mL}$ deionized water, dried over magnesium sulfate and volatiles removed under vacuum. The resulting pale yellow residue was dissolved in $100 \mathrm{ml}$ glacial acetic acid and zinc powder (4.34 g, $66.1 \mathrm{mmol}, 4.1$ equiv.) was added and the reaction was stirred overnight. The reaction was quenched with sodium bicarbonate, extracted with $2 \times 200 \mathrm{~mL}$ ethyl acetate, washed with brine, and dried over magnesium sulfate. Volatiles were removed under reduced pressure to yield an orange oil $(3.41 \mathrm{~g}, 81 \%)$. ${ }^{1} \mathrm{H}$ NMR (ppm, $\left.\mathrm{CD}_{3} \mathrm{OD}, 300 \mathrm{MHz}\right): \delta=8.03(\mathrm{~s}, 1 \mathrm{H}), 7.79(\mathrm{~s}, 2 \mathrm{H}), 4.37$ (s, 2H). ${ }^{13} \mathrm{C} \mathrm{NMR}$ (ppm, $\mathrm{CD}_{3} \mathrm{OD}, 400 \mathrm{MHz}$ ): $\delta=138.5$ (s), 133.8 (q, J = 33.3 Hz), 132.4 (s), 131.2 (q, J = 3.9 Hz), 126.3 (q, J = 3.7 Hz), 125.6 (s), 124.4 (q, J = 272.0 Hz), 43.8 (s). ${ }^{19} \mathrm{~F} \mathrm{NMR} \mathrm{(ppm,}$ $\left.\mathrm{CD}_{3} \mathrm{OD}, 400 \mathrm{MHz}\right): \delta=-64.5$. IR: $v=2870,2829,2642,2616,1526,1402,1320,1273,1178$, 1149, 1119, 1077, 1047, 1016, 905, 895, 832, 820, 682, $623 \mathrm{~cm}^{-1}$. HRMS: (ESI) m/z calc. for $\mathrm{C}_{8} \mathrm{H}_{6} \mathrm{BrF}_{3} \mathrm{~N}(\mathrm{M}+\mathrm{H}): 251.9636$, found: 251.9608 .

Scheme S7. Synthesis of tris(2-bromo-4-trifluoromethyl)benzylamine from 2-bromo-4(trifluoromethyl)benzylamine

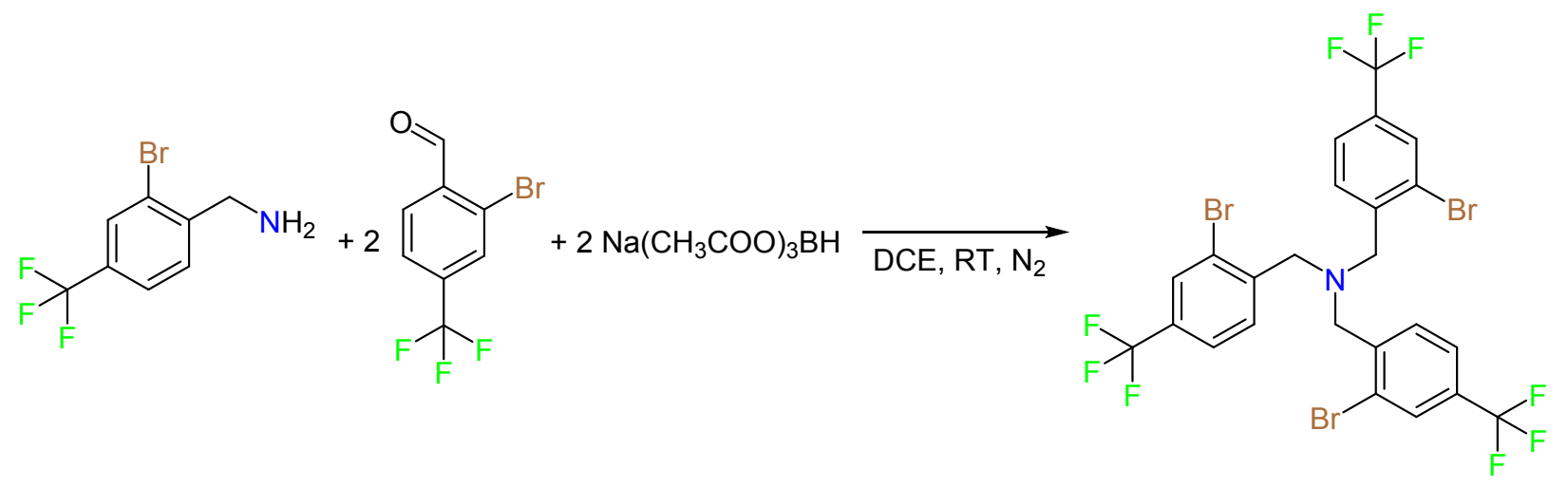

\section{Synthesis of tris(2-bromo-4-trifluoromethyl)benzylamine}

2-bromo-4-(trifluoromethyl)benzylamine (1.00 g, $3.94 \mathrm{mmol}, 1$ equiv.) and 2-bromo-4(trifluoromethyl)benzaldehyde $(2.00 \mathrm{~g}, 7.91 \mathrm{mmol}, 2.01$ equiv.) were stirred in $30 \mathrm{~mL}$ dichloroethane under nitrogen flow. Sodium triacetoxyborohydride (3.35 g, $15.7 \mathrm{mmol}, 4$ equiv.) was added slowly and the reaction mixture was stirred at room temperature overnight. The reaction was quenched with sodium bicarbonate, extracted with $3 \times 50 \mathrm{~mL}$ dichloromethane and dried over magnesium sulfate. Volatiles were removed under reduced pressure to yield a pale yellow oil that solidified upon standing. Recrystallization from a cold hexanes yielded a white solid (2.01 g, 70\%). ${ }^{1} \mathrm{H}$ NMR (ppm, $\left.\mathrm{CDCl}_{3}, 300 \mathrm{MHz}\right): \delta=7.78(\mathrm{~d}, \mathrm{~J}=0.9 \mathrm{~Hz}, 3 \mathrm{H}), 7.69$ (d, J = 8.1 Hz, $3 \mathrm{H}), 7.52$ (dd, J = 8.1, $1.1 \mathrm{~Hz}, 3 \mathrm{H}), 3.89(\mathrm{~s}, 6 \mathrm{H}) \cdot{ }^{13} \mathrm{C} \mathrm{NMR}$ (ppm, $\left.\mathrm{CDCl}_{3}, 400 \mathrm{MHz}\right): \delta=141.8$ (s), 131.3 (q, J = 33.2 Hz), 130.5 (s), 130.0 (q, J = 3.8 Hz), 124.5 (s), 124.4 (q, J = 3.7 Hz), 123.2 (q, $\mathrm{J}=272.6 \mathrm{~Hz}), 58.7$ (s). ${ }^{19} \mathrm{~F} \mathrm{NMR}\left(\mathrm{ppm}, \mathrm{CDCl}_{3}, 300 \mathrm{MHz}\right): \delta=-62.8 . \mathrm{IR}: \mathrm{v}=1612,1397,1271$, 1316, 1303, 1267, 1204, 1169, 1119, 1077, 1038, 983, 955, 911, 889, 833, 708, 691, 648, 638 $\mathrm{cm}^{-1}$. HRMS: (ESI) m/z calc. for $\mathrm{C}_{24} \mathrm{H}_{16} \mathrm{Br}_{3} \mathrm{~F}_{9} \mathrm{~N}(\mathrm{M}+\mathrm{H}): 725.8689$, found: 725.8679 . 
Scheme S8. Synthesis of tris(2-tert-butylhydroxylamine-4-trifluoromethyl)benzylamine $\left(\mathrm{H}_{3} \mathrm{TriNOx}^{\mathrm{CF}_{3}}\right)$

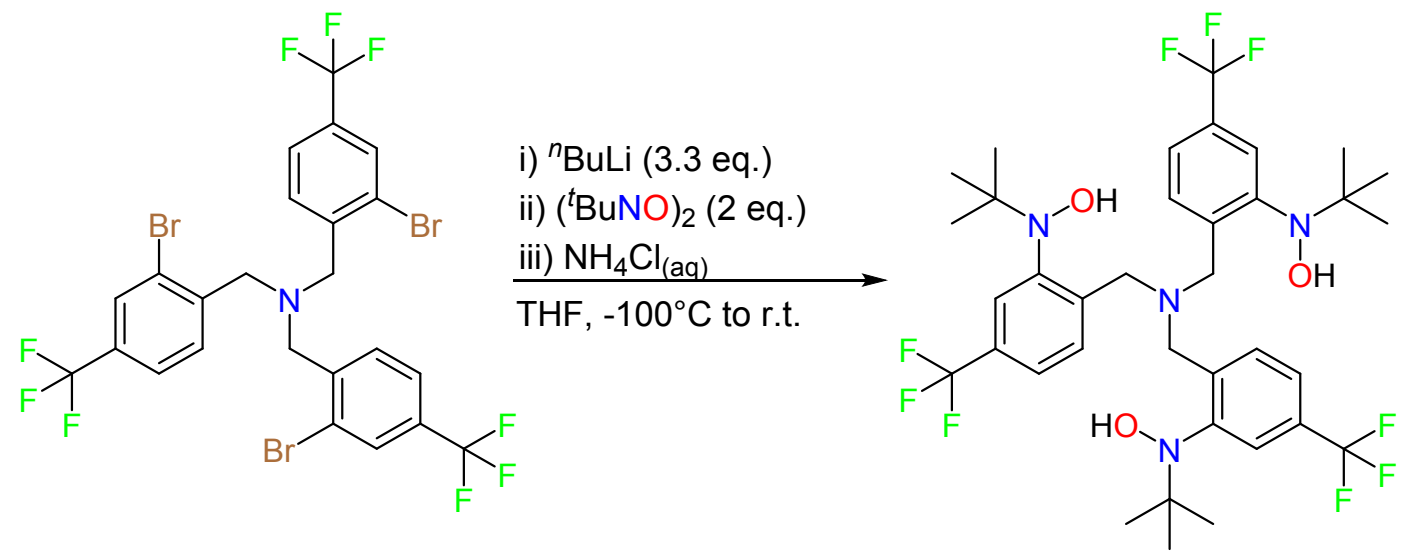

Tris(2-bromo-4-trifluoromethyl)benzylamine $(1.00 \mathrm{~g}, 1.37 \mathrm{mmol}, 1$ equiv.) was dissolved in THF $(50 \mathrm{~mL})$ and added to a $200 \mathrm{~mL}$ Schlenk flask equipped with a magnetic stir bar. The flask was placed under atmosphere and cooled to $-100{ }^{\circ} \mathrm{C}$. A $1.6 \mathrm{M}$ solution of $n$-butyllithium complex in hexanes (2.8 mL, $4.53 \mathrm{mmol}, 3.3$ equiv.) was added dropwise and the reaction was stirred for 3 hours. A THF solution ( $5 \mathrm{~mL}$ ) of 2-methyl-2-nitrosopropane dimer $(0.48 \mathrm{~g}, 2.75 \mathrm{mmol}$, 2 equiv.) was added and the reaction was gradually warmed to room temperature and stirred for 3 hours. The reaction was quenched with a saturated aqueous ammonium chloride solution. The organic portion was extracted with $3 \times 50 \mathrm{~mL}$ diethyl ether. The combined organics were dried over magnesium sulfate and volatiles removed under reduced pressure, yielding a yellow solid. Single crystals were grown from the slow evaporation of an acetone solution $(0.81 \mathrm{~g}, 78 \%)$. ${ }^{1} \mathrm{H}$ NMR (ppm, $d_{6}$-acetone, $\left.400 \mathrm{MHz}\right): \delta=8.02(\mathrm{~d}, \mathrm{~J}=8.1 \mathrm{~Hz}, 3 \mathrm{H}), 7.81(\mathrm{~s}, 3 \mathrm{H}), 7.73(\mathrm{~s}, 3 \mathrm{H}), 7.49(\mathrm{~d}, \mathrm{~J}=$ $7.4 \mathrm{~Hz}, 3 \mathrm{H}), 3.83(\mathrm{~s}, 6 \mathrm{H}), 1.04(\mathrm{~s}, 27 \mathrm{H}) .{ }^{13} \mathrm{C}$ NMR (ppm, $d_{6}$-acetone, $\left.400 \mathrm{MHz}\right): \delta=150.7(\mathrm{~s}), 141.4$ (s), 130.3 (s), 123.7 (q, J = 4.0 Hz), 122.7 (q, J = 3.8 Hz), 68.1 (s), 61.7 (s), 54.6 (s), 25.8 (s). ${ }^{19} \mathrm{~F}$ NMR (ppm, $d_{6}$-acetone, $400 \mathrm{MHz}$ ): $\delta=-63.0$. IR: $v=3250,2980,1412,1321,1251,1230,1167$, 1123, 1099, 1079, 1068, 983, 961, 948, 903, 830, 743, 717, 659, 643, $542 \mathrm{~cm}^{-1}$. HRMS: (ESI) $\mathrm{m} / \mathrm{z}$ calc. for $\mathrm{C}_{36} \mathrm{H}_{46} \mathrm{~F}_{9} \mathrm{~N}_{4} \mathrm{O}_{3}(\mathrm{M}+\mathrm{H}):$ 753.3426, found: 753.3433 .

Scheme S9. Synthesis of $R E\left(\operatorname{TriNOx}^{\mathrm{R}}\right)(\mathrm{THF})_{\mathrm{x}}$ complexes $\left(\mathrm{x}=1\right.$ for $\mathrm{R}=\mathrm{Ph}, \mathrm{CF}_{3} ; \mathrm{x}=0$ for $\mathrm{R}=$ $\left.{ }^{t} \mathrm{Bu}\right)$.

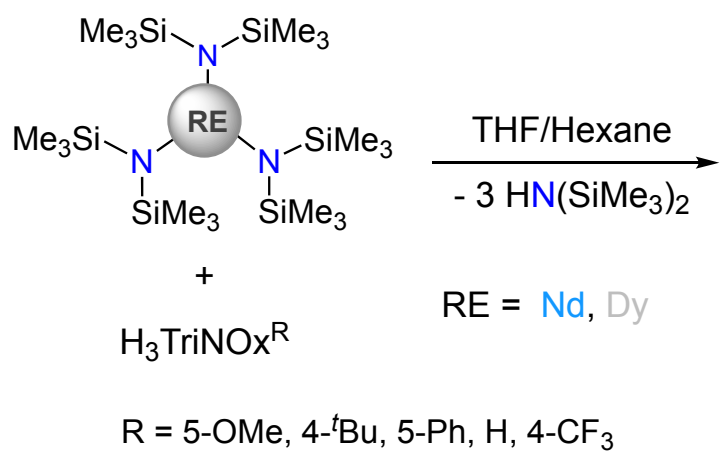

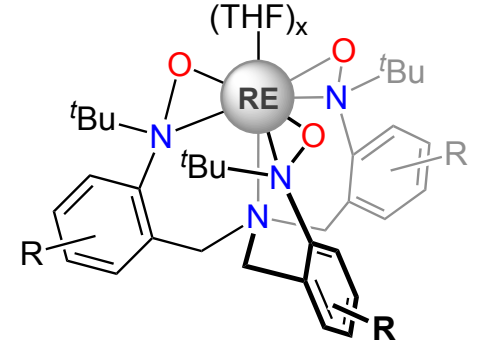

RE(TriNOx $\left.{ }^{R}\right)(\text { THF })_{x}(82-93 \%)$ $\mathrm{x}=0,1$ 
Scheme S10. Synthesis of $\mathrm{Nd}\left(\operatorname{TriNOx}^{\mathrm{tBu}}\right)$.
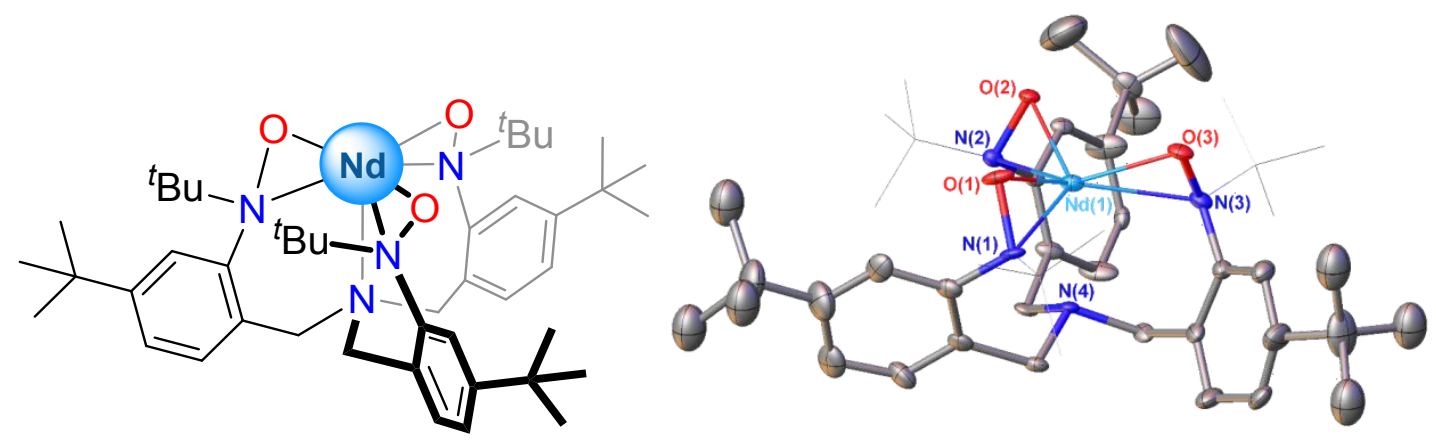

A THF solution of $\mathrm{H}_{3}$ TriNOx ${ }^{\text {tBu }}(0.100 \mathrm{~g}, 0.139 \mathrm{mmol}, 1$ equiv.) was added to a THF solution of $\mathrm{Nd}\left[\mathrm{N}\left(\mathrm{SiMe}_{3}\right)_{2}\right]_{3}(0.087 \mathrm{~g}, 0.139 \mathrm{mmol}, 1$ equiv.). The reaction mixture was stirred for 2 hours, and volatiles were removed under reduced pressure. Sample was stirred in acetonitrile and filtered, solid collected and dried under reduced pressure to yield a blue solid $(0.112 \mathrm{~g}, 93 \%)$. Single crystals were grown from a THF solution layered with hexanes. ${ }^{1} \mathrm{H}$ NMR $\left(\mathrm{ppm}\right.$, pyridine- $d_{5}, 300$ $\mathrm{MHz}$ ): $\delta=18.56$ (s, 3H), 6.98 (overlapping, 3H), $6.85(\mathrm{~s}, 27 \mathrm{H}), 3.04(\mathrm{~s}, 27 \mathrm{H}), 1.83(\mathrm{~d}, \mathrm{~J}=8.7 \mathrm{~Hz}$, $3 \mathrm{H}),-8.13(\mathrm{~s}, 3 \mathrm{H}),-12.46(\mathrm{~s}, 3 \mathrm{H})$. Anal. Calc. for $\mathrm{C}_{49} \mathrm{H}_{77} \mathrm{~N}_{4} \mathrm{NdO}_{4}$ : C, 63.26; $\mathrm{H}, 8.34 ; \mathrm{N}, 6.02$. Found: C, 63.43; H, 7.93; N, 5.80 .

Scheme S11. Synthesis of Dy $\left(\operatorname{TriNOx}^{\mathrm{tB} u}\right)$.
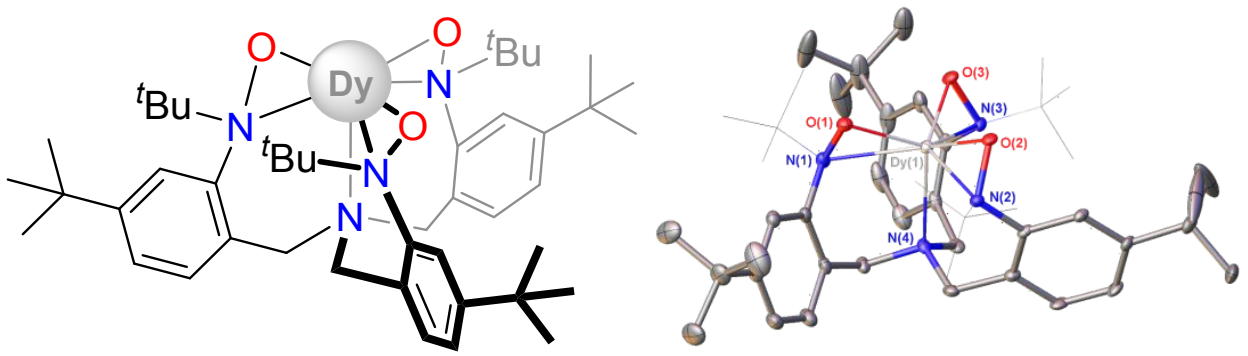

A THF solution of $\mathrm{H}_{3}$ TriNOx $^{\text {tBu }}(0.100 \mathrm{~g}, 0.139 \mathrm{mmol}, 1$ equiv. $)$ was added to a THF solution of $\mathrm{Dy}\left[\mathrm{N}\left(\mathrm{SiMe}_{3}\right)_{2}\right]_{3}(0.090 \mathrm{~g}, 0.139 \mathrm{mmol}, 1$ equiv.). The reaction mixture was stirred for 2 hours, filtered, rinsed with THF and dried under reduced pressure, affording a white solid $(0.111 \mathrm{~g}, 91 \%)$. Single crystals were grown from a chloroform solution layered with THF. ${ }^{1} \mathrm{H}$ NMR (ppm, pyridine$\left.d_{5}, 300 \mathrm{MHz}\right): \delta=222.81(\mathrm{~s}, 3 \mathrm{H}), 135.43(\mathrm{~s}, 27 \mathrm{H}), 40.52(\mathrm{~s}, 27 \mathrm{H}),-4.20(\mathrm{~s}, 3 \mathrm{H})$, $-103.40$ $(\mathrm{s}, 3 \mathrm{H}),-305.67$ (s, 3H), -360.95 (s, 3H). Anal. Calc. for $\mathrm{C}_{45} \mathrm{H}_{69} \mathrm{DyN}_{4} \mathrm{O}_{3} \cdot 4 \mathrm{CHCl}_{3}: \mathrm{C}, 43.47 ; \mathrm{H}, 5.43$; N, 4.14. Found: C, 43.37; H, 5.24; N, 3.93. 
Scheme S12. Synthesis of $\left[\mathrm{Nd}\left(\operatorname{TriNOx}{ }^{\sharp \mathrm{Bu}}\right)\right]_{2}$.

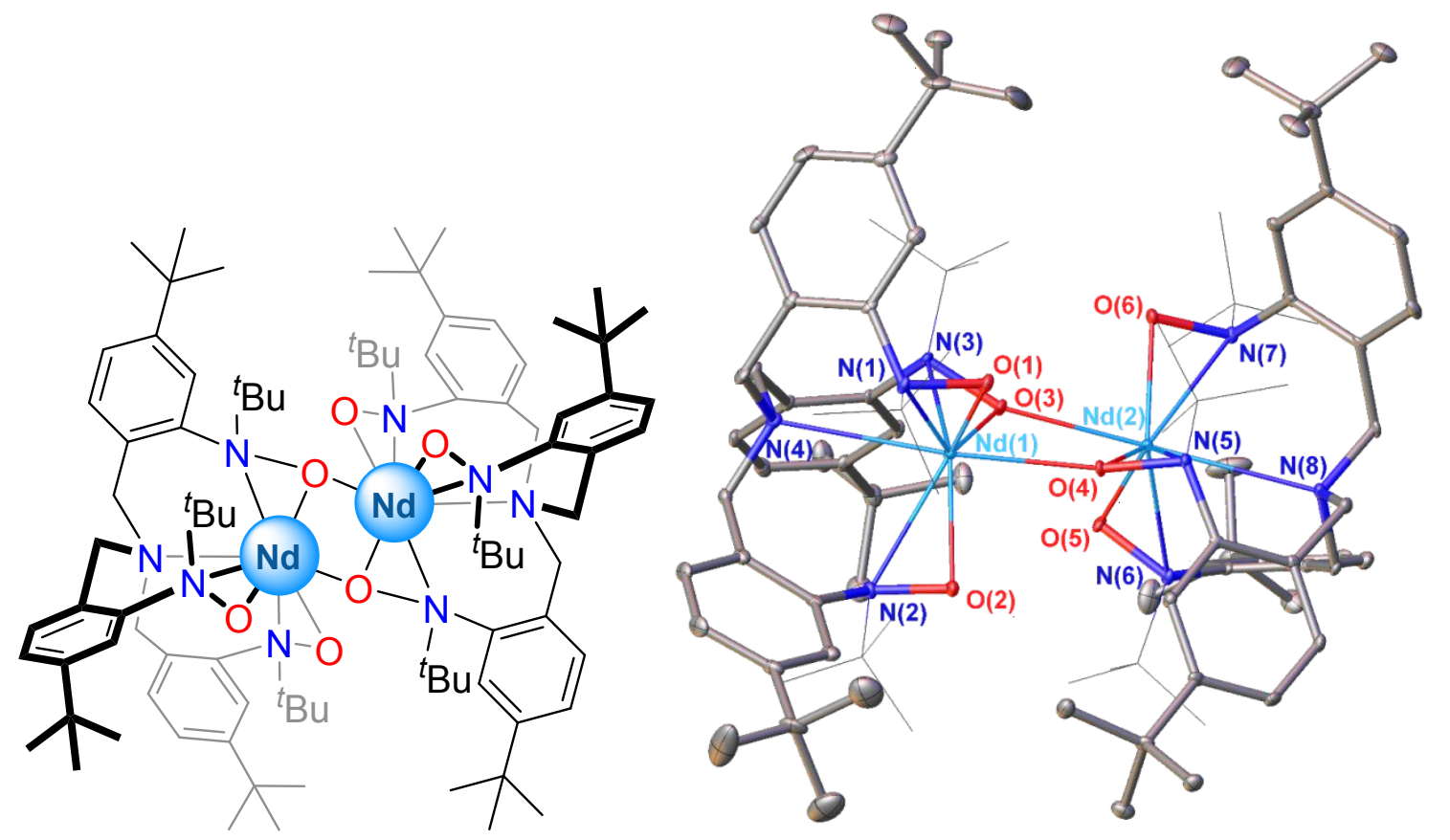

$\mathrm{Nd}\left(\operatorname{TriNO}{ }^{\mathrm{tBu}}\right)(0.200 \mathrm{~g}, 0.233 \mathrm{mmol})$ was dissolved in DME $(4 \mathrm{~mL})$ and volatiles were removed under reduced pressure to yield a blue solid $(0.178 \mathrm{~g}, 89 \%)$. Single crystals were grown from a slow evaporation of toluene solution.

Scheme S13. Synthesis of $\mathrm{Nd}\left(\operatorname{TriNOx}^{\mathrm{Ph}}\right)(\mathrm{THF})$.
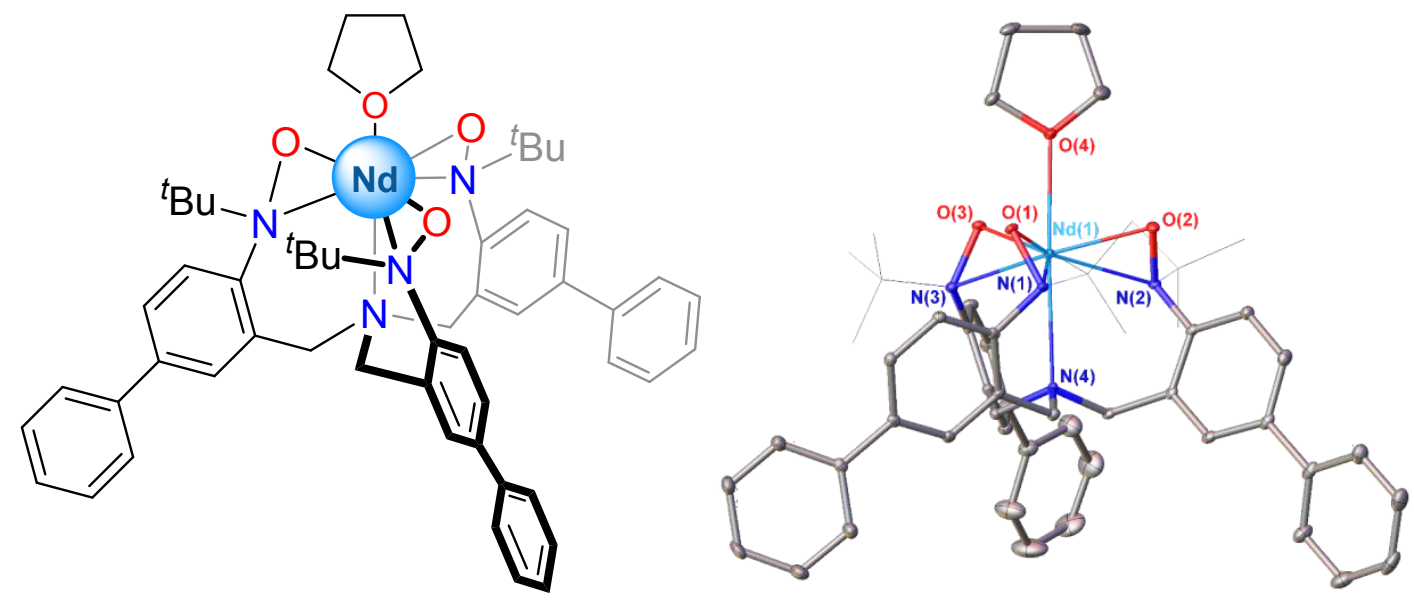

A THF solution of $\mathrm{H}_{3}$ TriNOx ${ }^{\text {Ph }}(0.100 \mathrm{~g}, 0.129 \mathrm{mmol}, 1$ equiv.) was added to a THF solution of $\mathrm{Nd}\left[\mathrm{N}\left(\mathrm{SiMe}_{3}\right)_{2}\right]_{3}(0.080 \mathrm{~g}, 0.129 \mathrm{mmol}, 1$ equiv. $)$. The reaction mixture was stirred for 2 hours, and volatiles were removed under reduced pressure. Sample was stirred in pentane and filtered, solid collected and dried under reduced pressure to yield a blue solid $(0.102 \mathrm{~g}, 82 \%)$. Single crystals were grown from a THF solution layered with hexanes. ${ }^{1} \mathrm{H}$ NMR (ppm, pyridine- $d_{5}, 400 \mathrm{MHz}$ ): $\delta=$ $17.80(\mathrm{~s}, 3 \mathrm{H}), 10.13(\mathrm{~s}, 3 \mathrm{H}), 7.47$ (d, J = 6.7 Hz, 6H), 7.38 (d, J = $11.2 \mathrm{~Hz}, 3 \mathrm{H}), 7.34$ (q, J = 9.8 $\mathrm{Hz}, 6 \mathrm{H}), 6.42(\mathrm{~s}, 27 \mathrm{H}), 2.46(\mathrm{~s}, 3 \mathrm{H}),-7.06(\mathrm{~s}, 3 \mathrm{H}),-11.14(\mathrm{~s}, 3 \mathrm{H})$. 
Scheme S14. Synthesis of Dy(TriNOxPh $)(T H F)$.

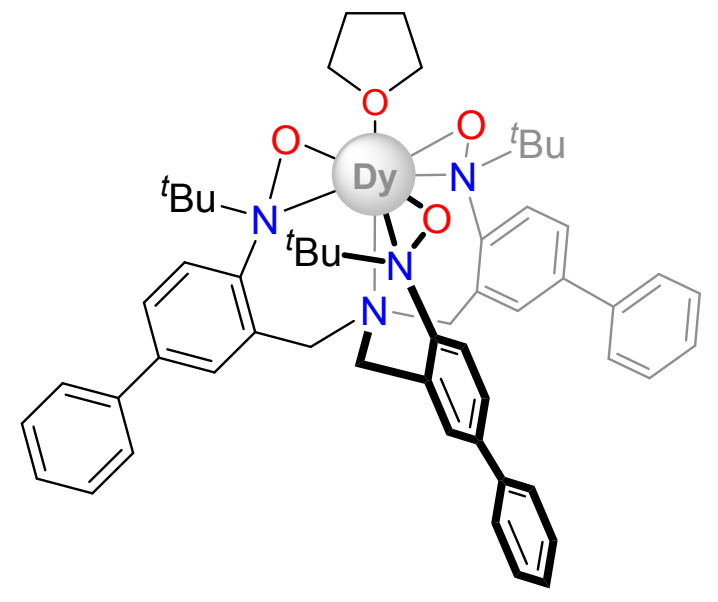

A THF solution of $\mathrm{H}_{3}$ TriNOx $^{\mathrm{Ph}}(0.100 \mathrm{~g}, 0.129 \mathrm{mmol}, 1$ equiv.) was added to a THF solution of $\mathrm{Dy}\left[\mathrm{N}\left(\mathrm{SiMe}_{3}\right)_{2}\right]_{3}(0.083 \mathrm{~g}, 0.129 \mathrm{mmol}, 1$ equiv.). The reaction mixture was stirred for 2 hours, filtered, rinsed with THF and dried under reduced pressure, affording a white solid $(0.110 \mathrm{~g}, 85 \%)$. Single crystals were grown from a chloroform solution layered with THF. ${ }^{1} \mathrm{H}$ NMR (ppm, pyridine$\left.d_{5}, 300 \mathrm{MHz}\right): \delta=360.46(\mathrm{~s}, 3 \mathrm{H}), 215.49(\mathrm{~s}, 3 \mathrm{H}), 133.99(\mathrm{~s}, 27 \mathrm{H}), 60.44(\mathrm{~s}, 3 \mathrm{H}),-0.78(\mathrm{~s}, 3 \mathrm{H})$, $-105.71(\mathrm{~s}, 3 \mathrm{H}),-304.89(\mathrm{~s}, 3 \mathrm{H}),-358.82(\mathrm{~s}, 3 \mathrm{H})$. Anal. Calc. for $\mathrm{C}_{55} \mathrm{H}_{65} \mathrm{DyN}_{4} \mathrm{O}_{4}: \mathrm{C}, 65.49 ; \mathrm{H}$, 6.50; N, 5.55. Found: C, 65.70; H, 6.46; N, 5.21.

Scheme S15. Synthesis of $\left[\mathrm{Nd}\left(\operatorname{TriNOx}^{\mathrm{Ph}}\right)\right]_{2}$.

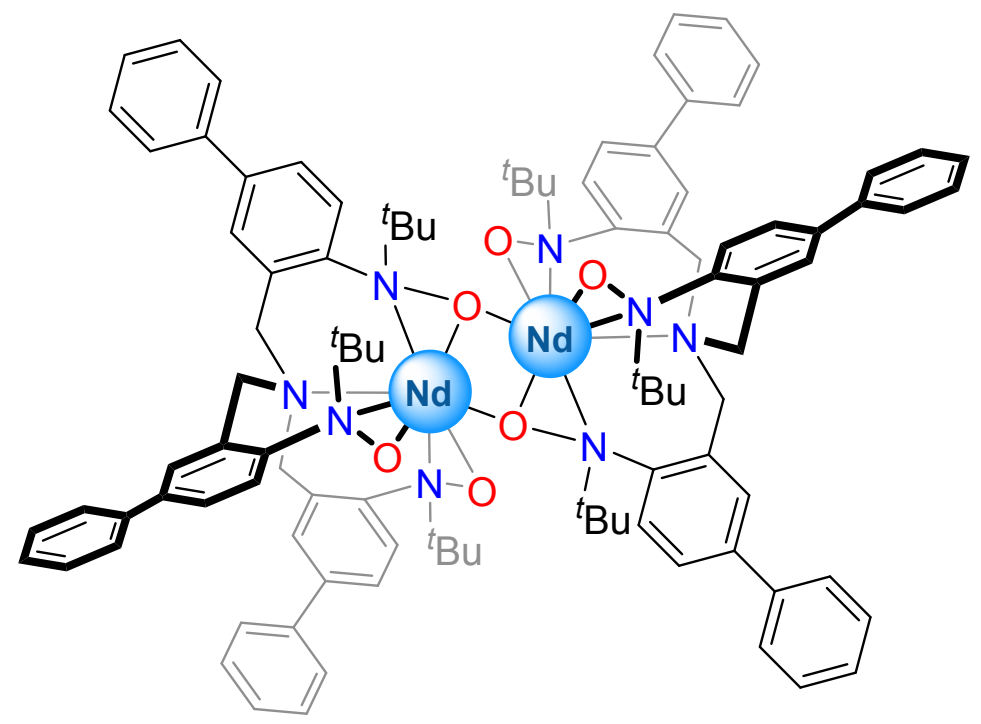

$\mathrm{Nd}\left(\right.$ TriNOx $\left.^{\mathrm{Ph}}\right)(\mathrm{THF})(0.200 \mathrm{~g}, 0.202 \mathrm{mmol})$ was dissolved in $4 \mathrm{~mL}$ toluene and volatiles were removed under reduced pressure to yield a blue solid $(0.167 \mathrm{~g}, 90 \%)$. Single crystals were grown from the slow evaporation of a toluene solution. ${ }^{1} \mathrm{H}$ NMR $\left(\mathrm{ppm}, \mathrm{C}_{6} \mathrm{D}_{6}, 300 \mathrm{MHz}\right)$ : $\delta=38.62(\mathrm{~s}$, 2H), 16.84 (s, 2H), 15.05 (s, 2H), 14.67 (s, 2H), 12.37 (s, 2H), $10.82(\mathrm{~s}, 2 \mathrm{H}), 8.70$ (broad, 18H), $8.05(\mathrm{~s}, 2 \mathrm{H}), 7.56(\mathrm{~d}, \mathrm{~J}=7.5 \mathrm{~Hz}, 2 \mathrm{H}), 7.36(\mathrm{dd}, \mathrm{J}=16.1,7.3 \mathrm{~Hz}, 4 \mathrm{H}), 7.06(\mathrm{~d}, \mathrm{~J}=6.8 \mathrm{~Hz}, 4 \mathrm{H})$, $6.97(\mathrm{~d}, \mathrm{~J}=7.8 \mathrm{~Hz}, 4 \mathrm{H}), 6.28(\mathrm{t}, \mathrm{J}=7.4 \mathrm{~Hz}, 4 \mathrm{H}), 6.09(\mathrm{t}, \mathrm{J}=7.3 \mathrm{~Hz}, 4 \mathrm{H}), 4.53(\mathrm{~d}, \mathrm{~J}=7.3 \mathrm{~Hz}, 4 \mathrm{H})$, $2.70(\mathrm{~s}, 18 \mathrm{H}), 0.83(\mathrm{~s}, 2 \mathrm{H}),-0.04(\mathrm{~s}$, overlapping, $2 \mathrm{H}),-0.16(\mathrm{~s}$, overlapping, $18 \mathrm{H}),-0.78(\mathrm{~s}, 2 \mathrm{H})$, $-5.61(\mathrm{~s}, 2 \mathrm{H}),-12.44(\mathrm{~s}, 2 \mathrm{H}),-13.64(\mathrm{~s}, 2 \mathrm{H}),-14.01(\mathrm{~s}, 2 \mathrm{H}),-16.08(\mathrm{~s}, 2 \mathrm{H}),-21.00(\mathrm{~s}, 2 \mathrm{H})$, 
Scheme S16. Synthesis of $\mathrm{Nd}\left(\mathrm{TriNOx}^{\mathrm{CF}_{3}}\right)(\mathrm{THF})$.
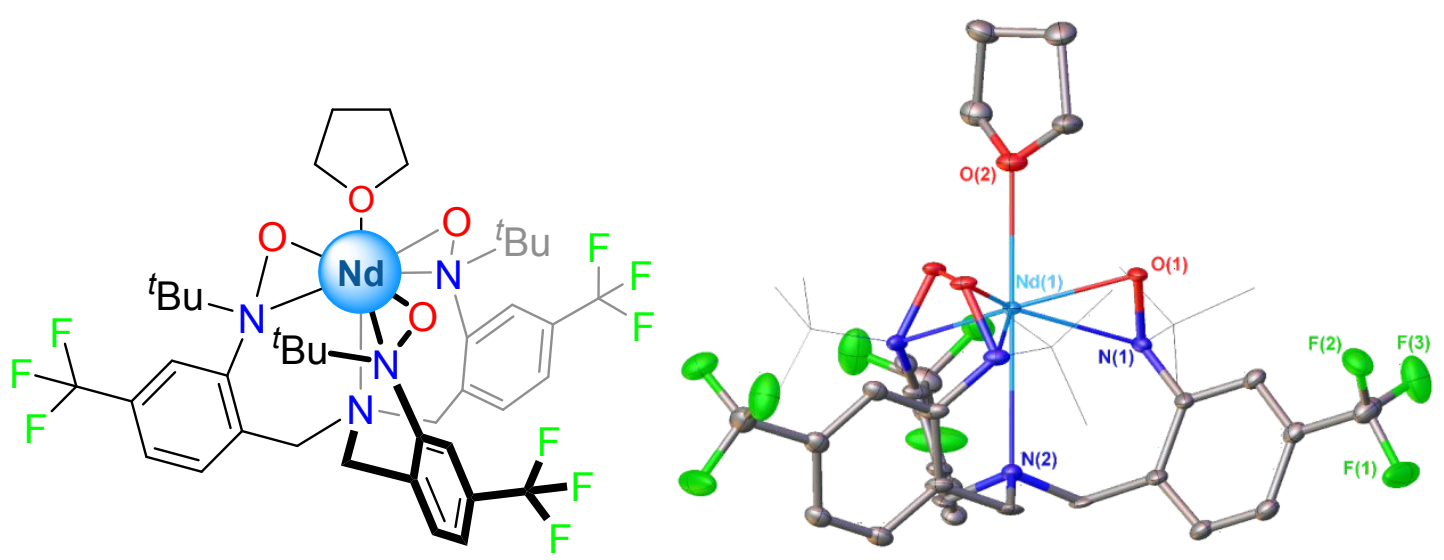

A THF solution of $\mathrm{H}_{3} \mathrm{TriNOx}^{\mathrm{CF} 3}(0.100 \mathrm{~g}, 0.133 \mathrm{mmol}, 1$ equiv.) was added to a THF solution of $\mathrm{Nd}\left[\mathrm{N}\left(\mathrm{SiMe}_{3}\right)_{2}\right]_{3}(0.083 \mathrm{~g}, 0.133 \mathrm{mmol}, 1$ equiv. $)$. The reaction mixture was stirred for 2 hours, and volatiles were removed under reduced pressure. Sample was stirred in benzene and filtered, solid collected and dried under reduced pressure to yield a blue solid $(0.108 \mathrm{~g}, 84 \%)$. Single crystals were grown from a THF solution layered with hexanes. ${ }^{1} \mathrm{H}$ NMR $\left(\mathrm{ppm}\right.$, pyridine- $\left.d_{5}, 400 \mathrm{MHz}\right): \delta=$ $19.26(\mathrm{~s}, 3 \mathrm{H}), 7.30(\mathrm{~d}, \mathrm{~J}=6.3 \mathrm{~Hz}, 3 \mathrm{H}), 6.98(\mathrm{~s}, 27 \mathrm{H}), 1.85(\mathrm{~d}, \mathrm{~J}=7.0 \mathrm{~Hz}, 3 \mathrm{H}),-8.44(\mathrm{~s}, 3 \mathrm{H})$, $-12.98(\mathrm{~s}, 3 \mathrm{H})$. ${ }^{19} \mathrm{~F}$ NMR (ppm, pyridine- $\left.d_{5}, 400 \mathrm{MHz}\right): \delta=-60.2$. Anal. Calc. for $\mathrm{C}_{40} \mathrm{H}_{50} \mathrm{~F}_{9} \mathrm{~N}_{4} \mathrm{NdO}_{4} \cdot \mathrm{C}_{6} \mathrm{H}_{6}: \mathrm{C}, 52.91 ; \mathrm{H}, 5.41 ; \mathrm{N}, 5.37$. Found: C, 53.44; H, 5.30; N, 6.03.

Scheme S17. Synthesis of Dy(TriNOx $\left.{ }^{\mathrm{CF} 3}\right)(\mathrm{THF})$.
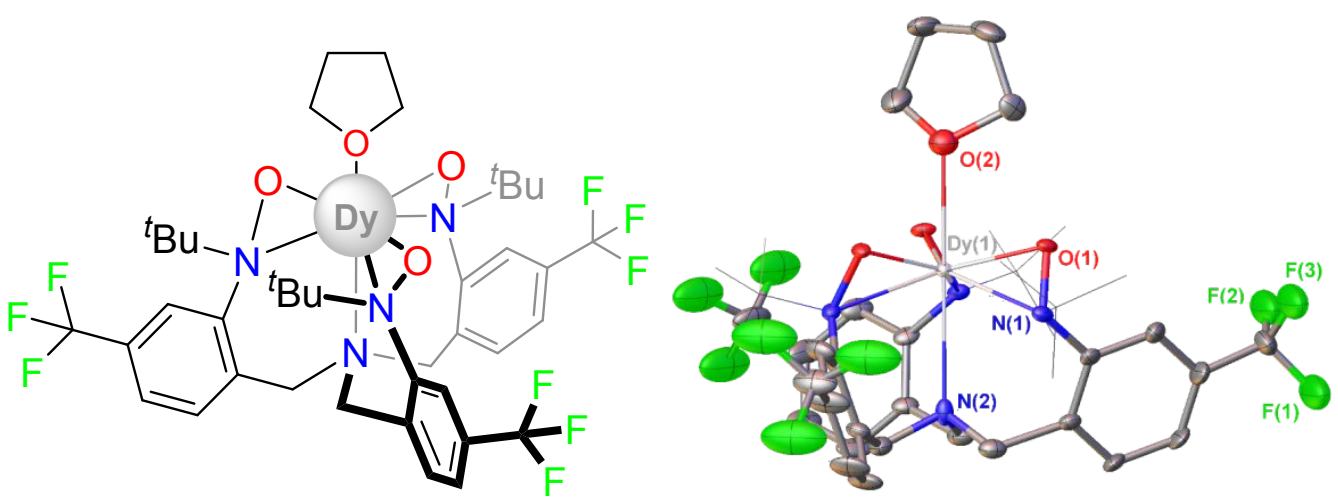

A THF solution of $\mathrm{H}_{3} \mathrm{TriNOx}^{\mathrm{CF} 3}$ ( $0.100 \mathrm{~g}, 0.133 \mathrm{mmol}$, 1 equiv.) was added to a THF solution of $\mathrm{Dy}\left[\mathrm{N}\left(\mathrm{SiMe}_{3}\right)_{2}\right]_{3}(0.086 \mathrm{~g}, 0.133 \mathrm{mmol}, 1$ equiv.). The reaction mixture was stirred for 2 hours, filtered, rinsed with THF and dried under reduced pressure, affording a white solid $(0.114 \mathrm{~g}, 87 \%)$. Single crystals were grown from a chloroform solution layered with THF. ${ }^{1} \mathrm{H}$ NMR (ppm, pyridine$\left.d_{5}, 300 \mathrm{MHz}\right): \delta=347.38(\mathrm{~s}, 3 \mathrm{H}), 236.30(\mathrm{~s}, 3 \mathrm{H}), 143.93(\mathrm{~s}, 27 \mathrm{H}),-4.58(\mathrm{~s}, 3 \mathrm{H}),-110.95(\mathrm{~s}, 3 \mathrm{H})$, -319.17 (s, 3H). ${ }^{19} \mathrm{~F} \mathrm{NMR}$ (ppm, pyridine- $d_{5}, 400 \mathrm{MHz}$ ): $\delta=-17.4$. Anal. Calc. for $\mathrm{C}_{40} \mathrm{H}_{50} \mathrm{DyF}_{9} \mathrm{~N}_{4} \mathrm{O}_{4}$ : C, 48.81; H, 5.12; N, 5.69. Found: C, 49.18; H, 5.37; N, 5.61. 


\section{NMR Spectra}

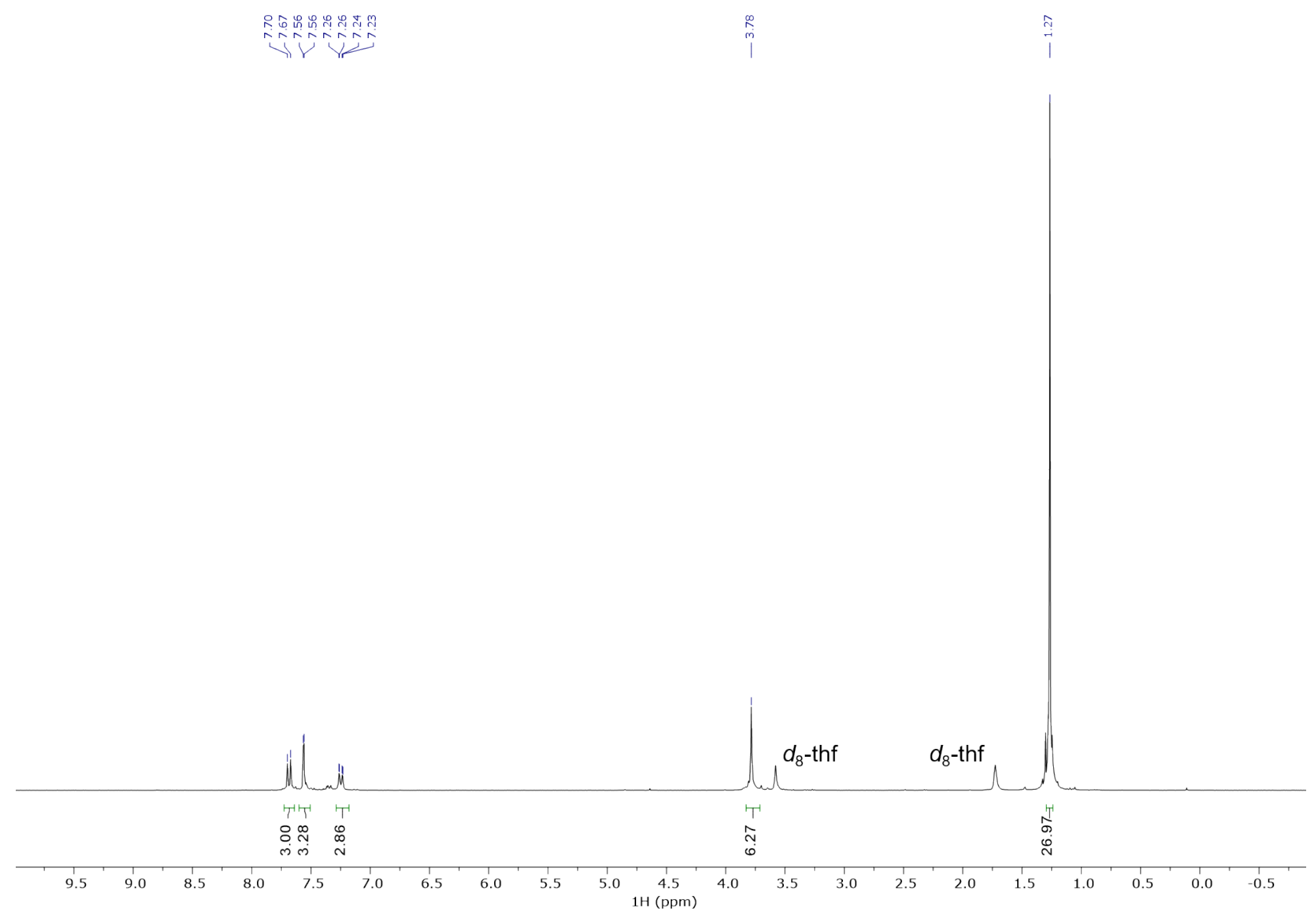

Figure S1. ${ }^{1} \mathrm{H}$ NMR spectrum of tris(2-bromo-4-tert-butyl)benzylamine in $d_{8}$-thf. 


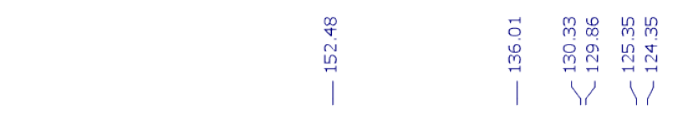

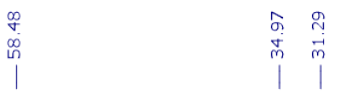
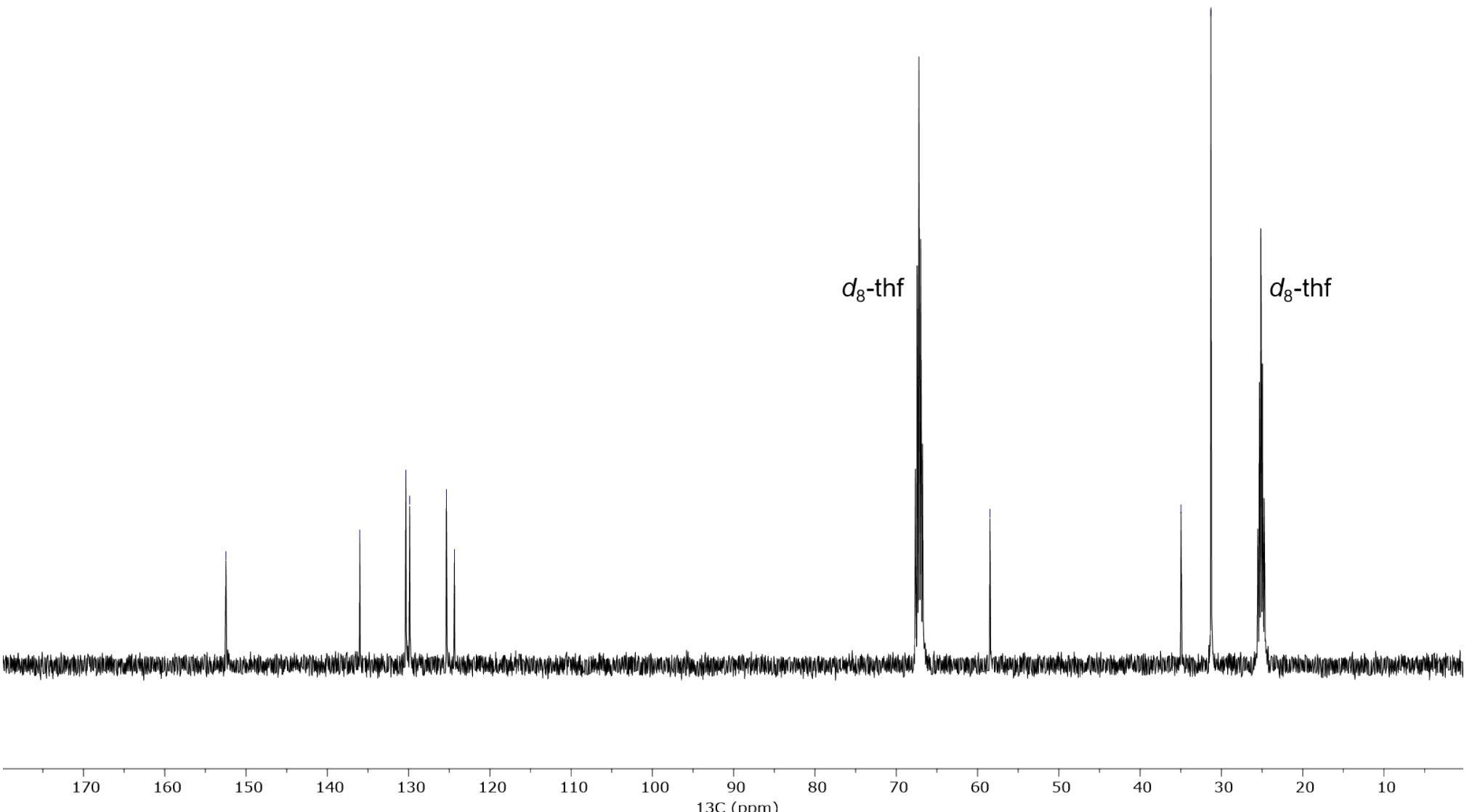

Figure S2. ${ }^{13} \mathrm{C}$ NMR spectrum of tris(2-bromo-4-tert-butyl)benzylamine in $d_{8}$-thf. 


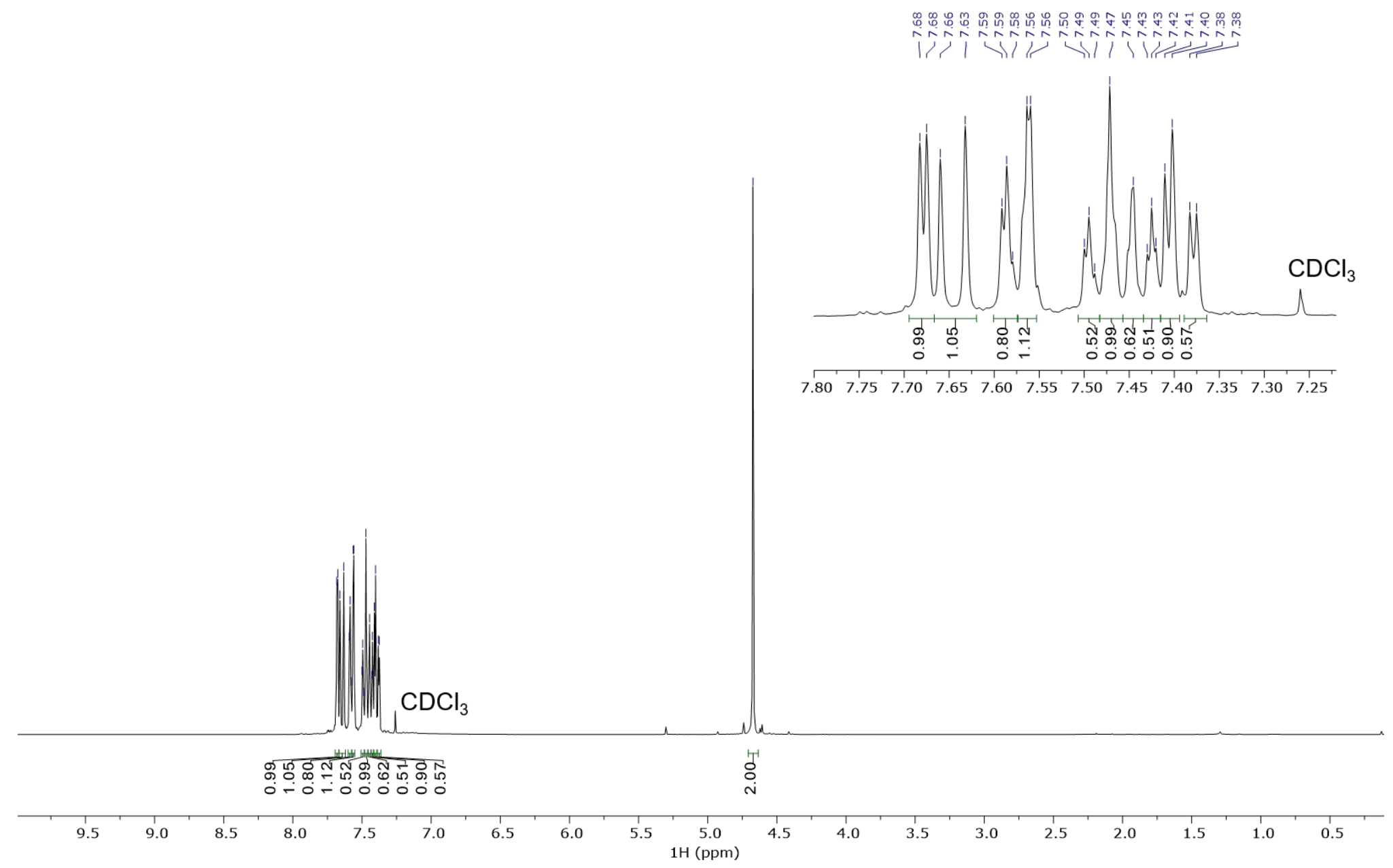

Figure S3. ${ }^{1} \mathrm{H}$ NMR spectrum of 2-bromo-5-phenylbenzyl bromide in $\mathrm{CDCl}_{3}$. 


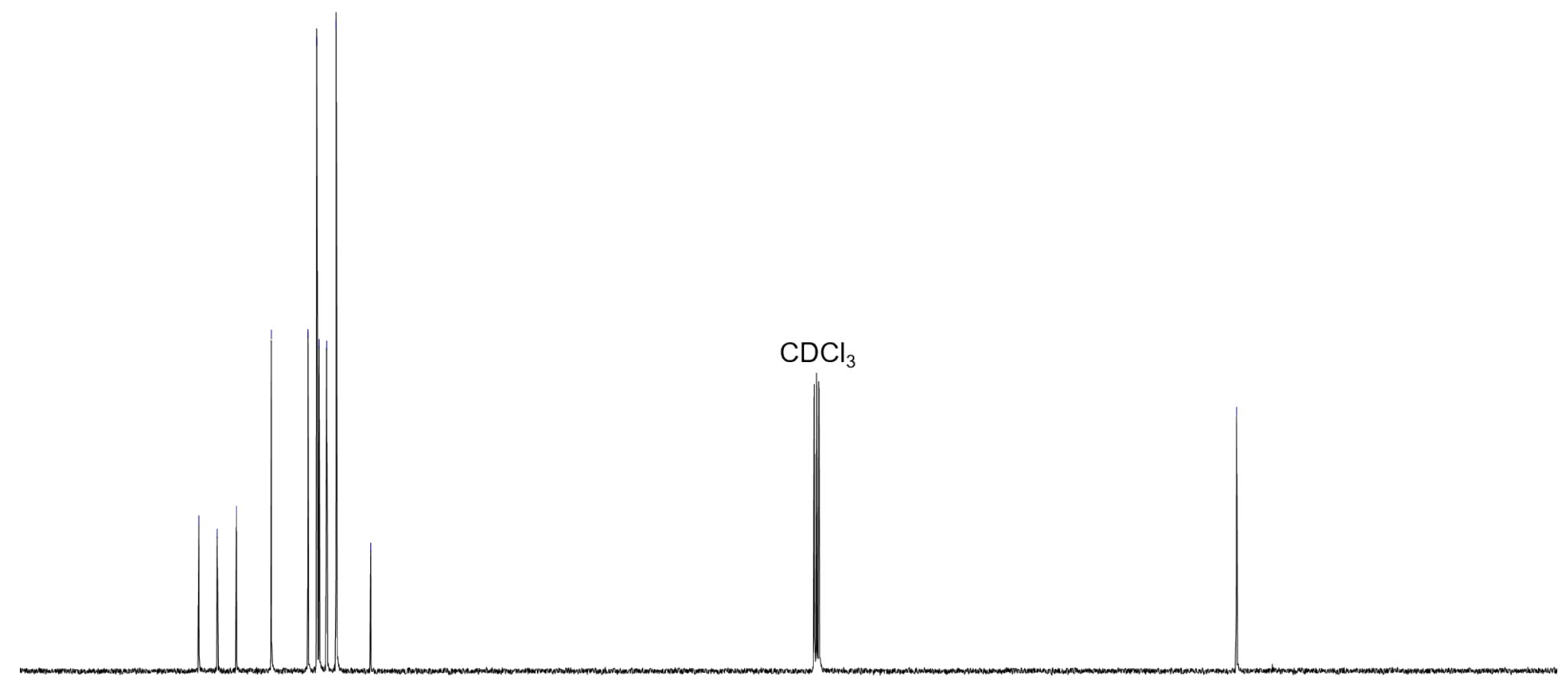

Figure S4. ${ }^{13} \mathrm{C}$ NMR spectrum of 2-bromo-5-phenylbenzyl bromide in $\mathrm{CDCl}_{3}$. 


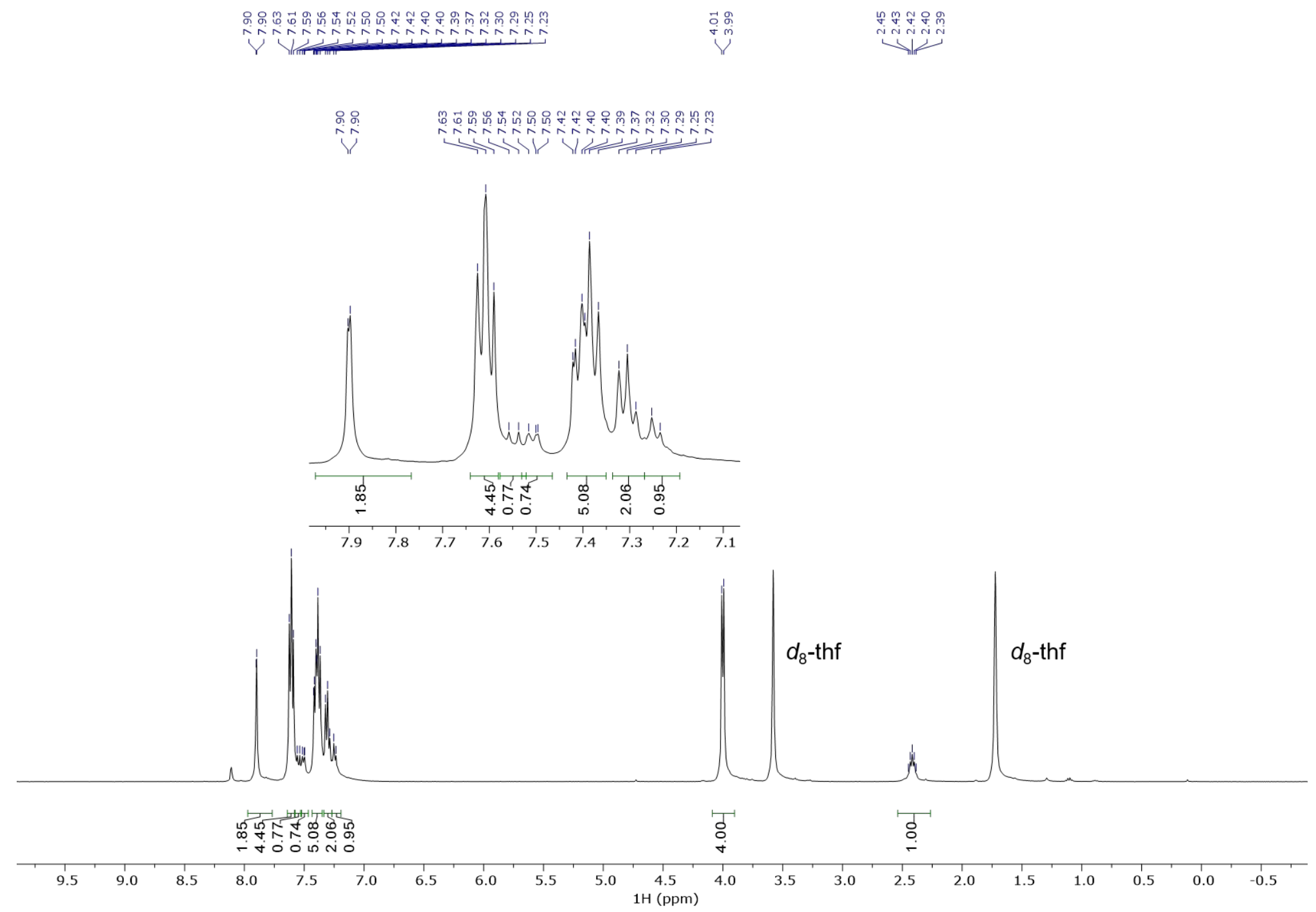

Figure S5. ${ }^{1} \mathrm{H}$ NMR spectrum of bis(2-bromo-5-phenyl)benzylamine in $d_{8}$-thf. 

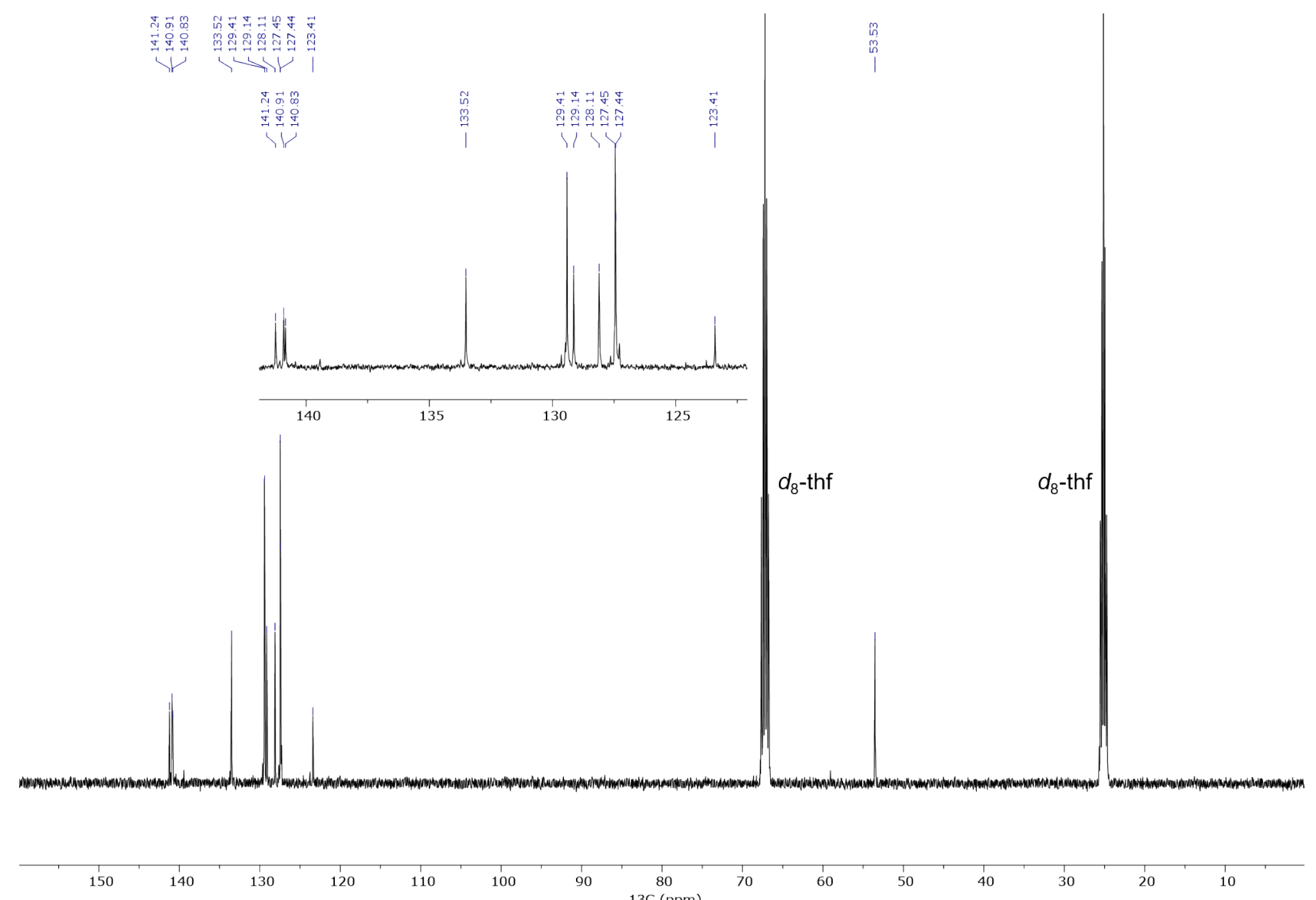

1
$60 \quad 50$

40

30

20 10

Figure S6. ${ }^{13} \mathrm{C}$ NMR spectrum of bis(2-bromo-5-phenyl)benzylamine in $d_{8}$-thf. 


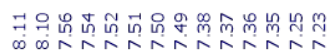

Y i r insin
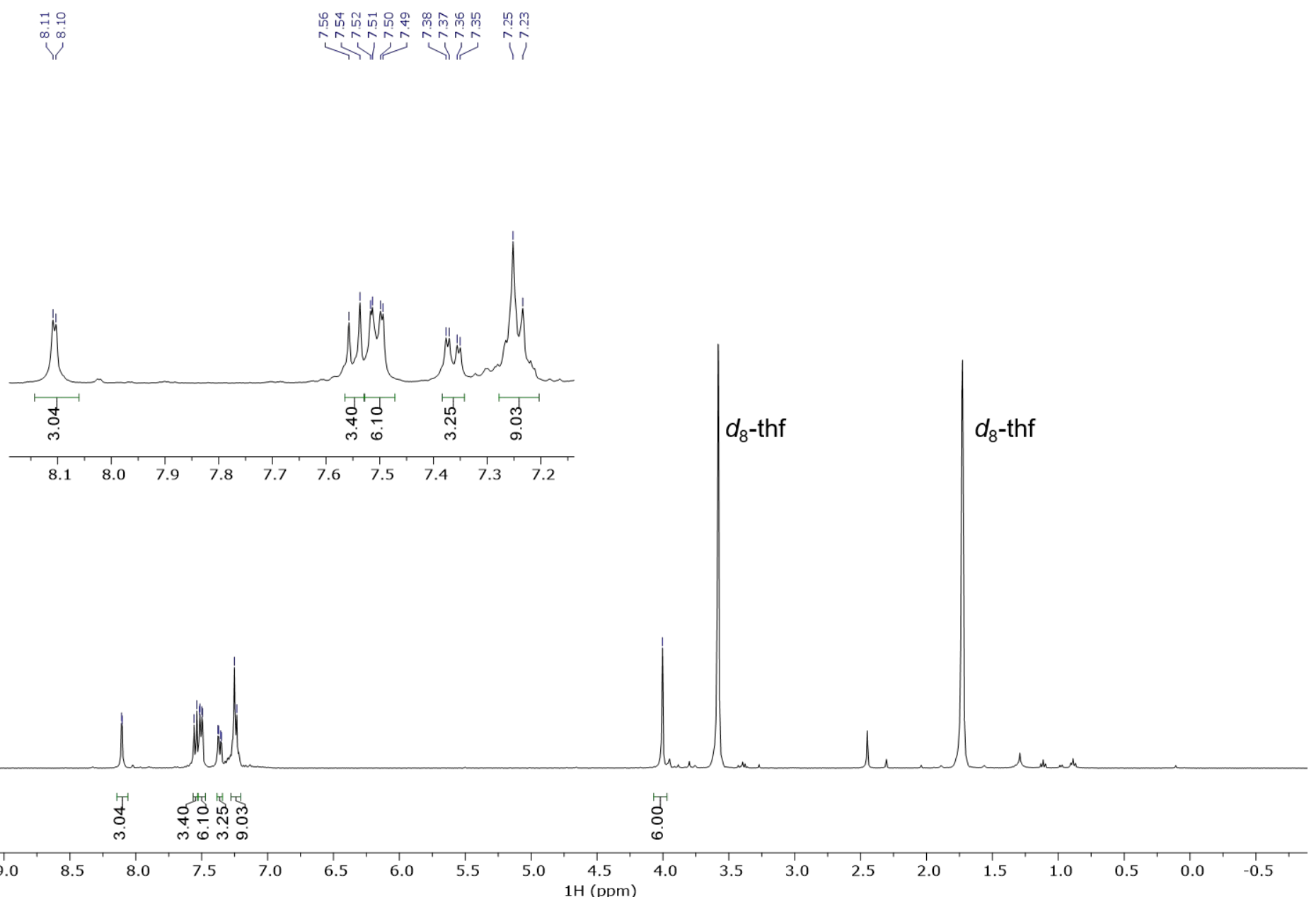

Figure S7. ${ }^{1} \mathrm{H}$ NMR spectrum of tris(2-bromo-5-phenyl)benzylamine in $d_{8}$-thf. 


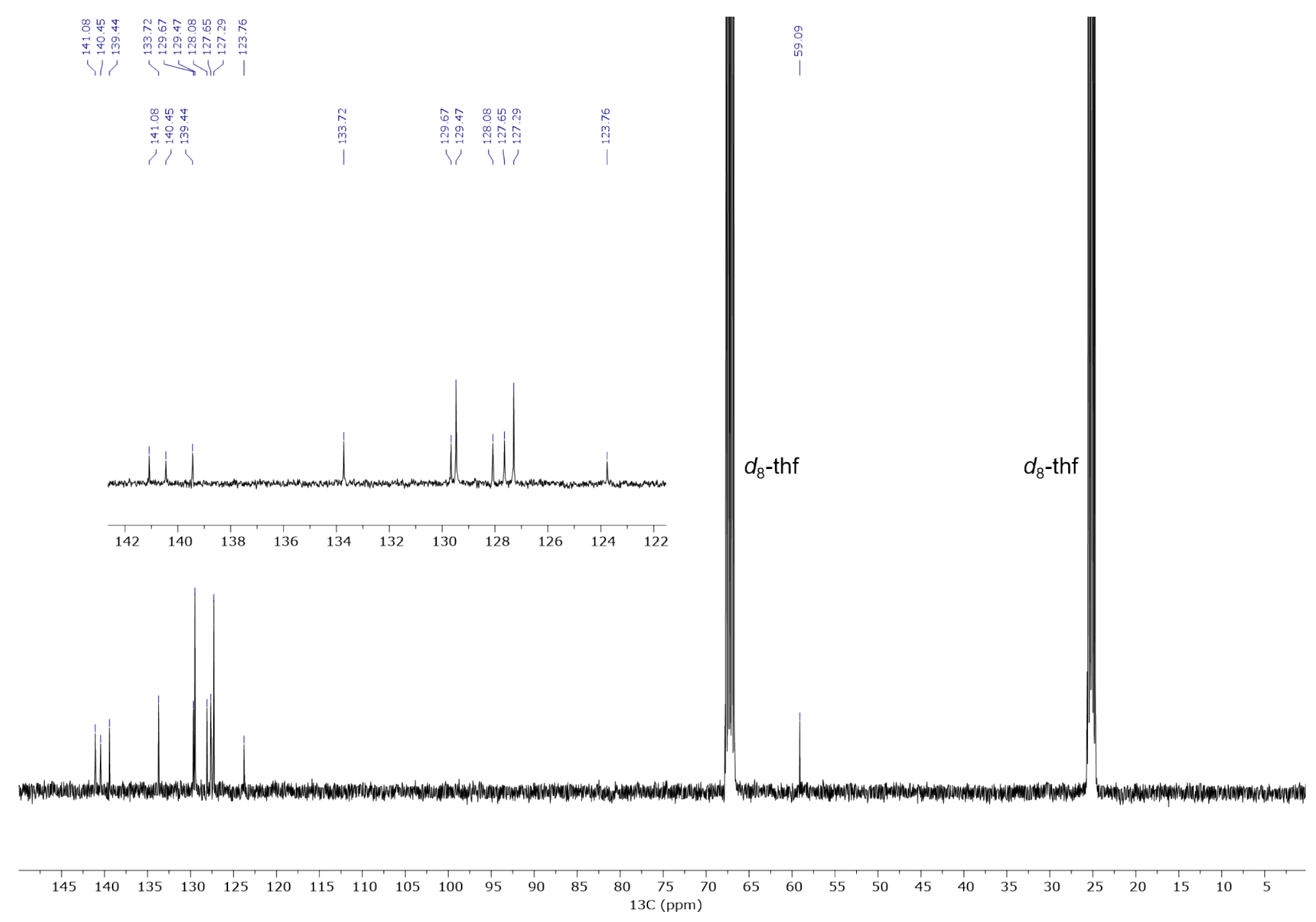

Figure S8. ${ }^{13} \mathrm{C}$ NMR spectrum of tris(2-bromo-5-phenyl)benzylamine in $d_{8}$-thf. 


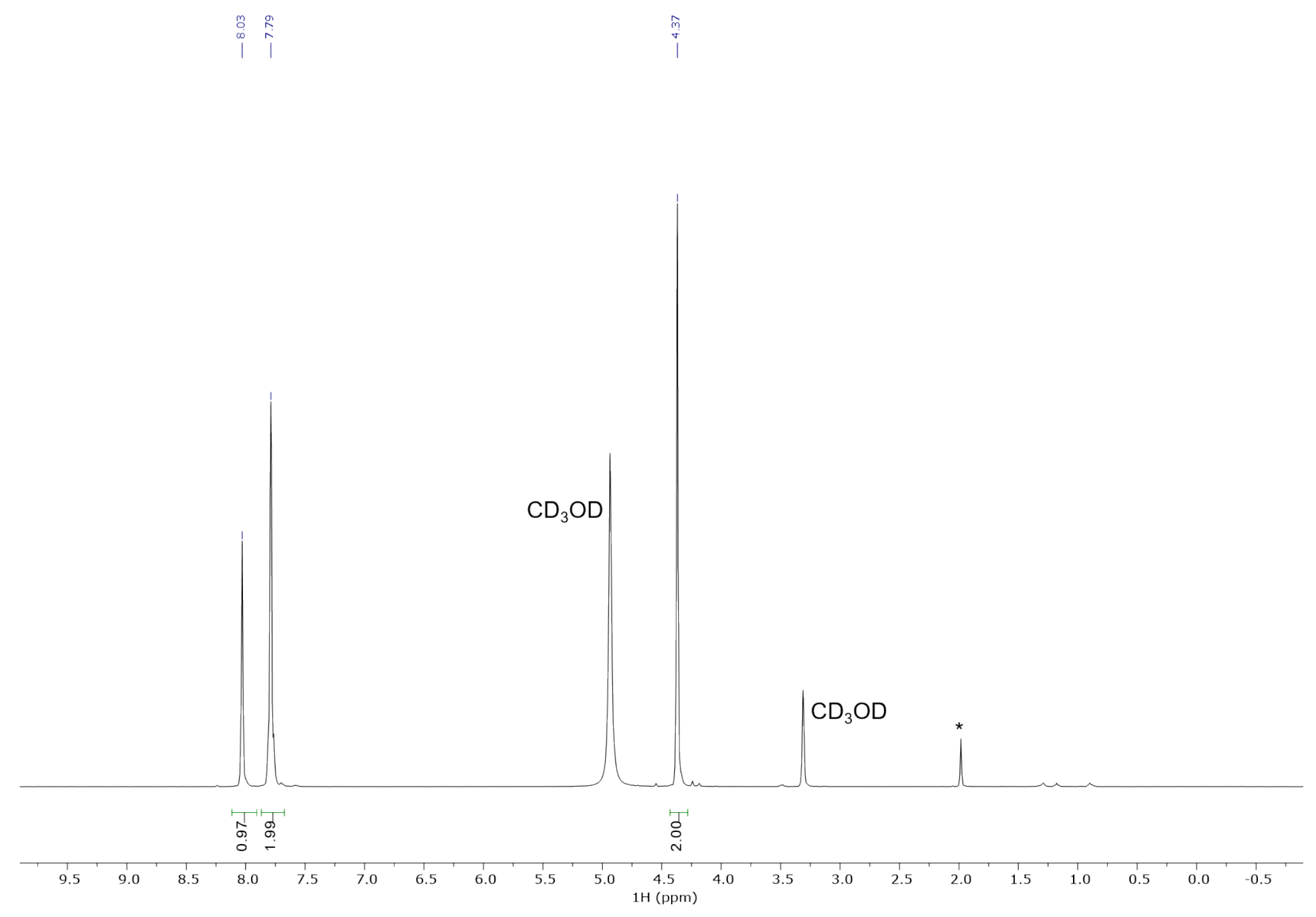

Figure S9. ${ }^{1} \mathrm{H}$ NMR spectrum of (2-bromo-4-trifluoromethyl)benzylamine in $\mathrm{CD}_{3} \mathrm{OD}$. ${ }^{*}$ indicates acetic acid impurity. 


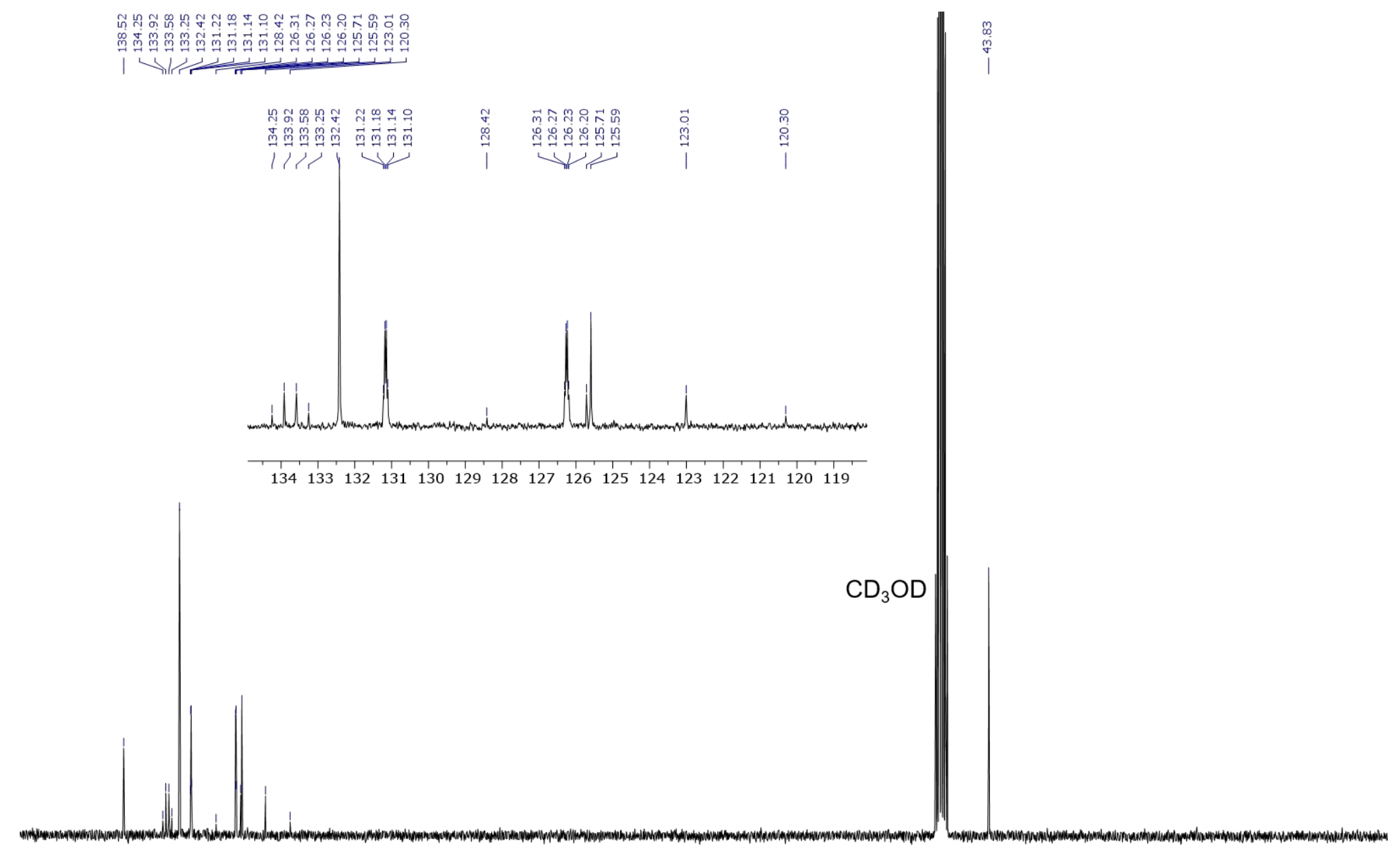

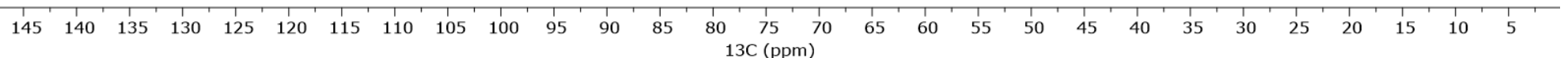

Figure S10. ${ }^{13} \mathrm{C}$ NMR spectrum of (2-bromo-4-trifluoromethyl)benzylamine in $\mathrm{CD}_{3} \mathrm{OD}$. 


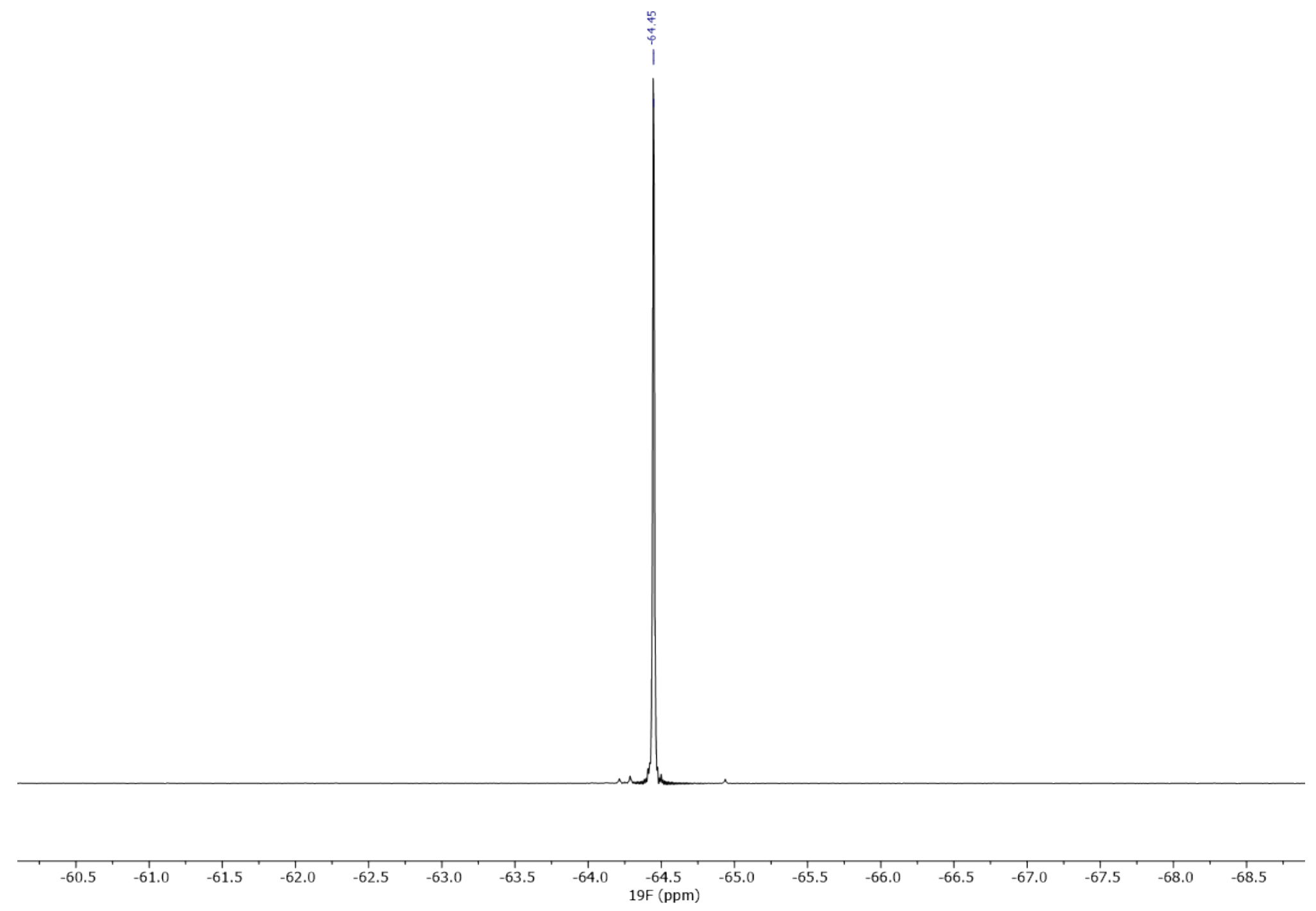

Figure S11. ${ }^{19} \mathrm{~F}$ NMR spectrum of (2-bromo-4-trifluoromethyl)benzylamine in $\mathrm{CD}_{3} \mathrm{OD}$. 


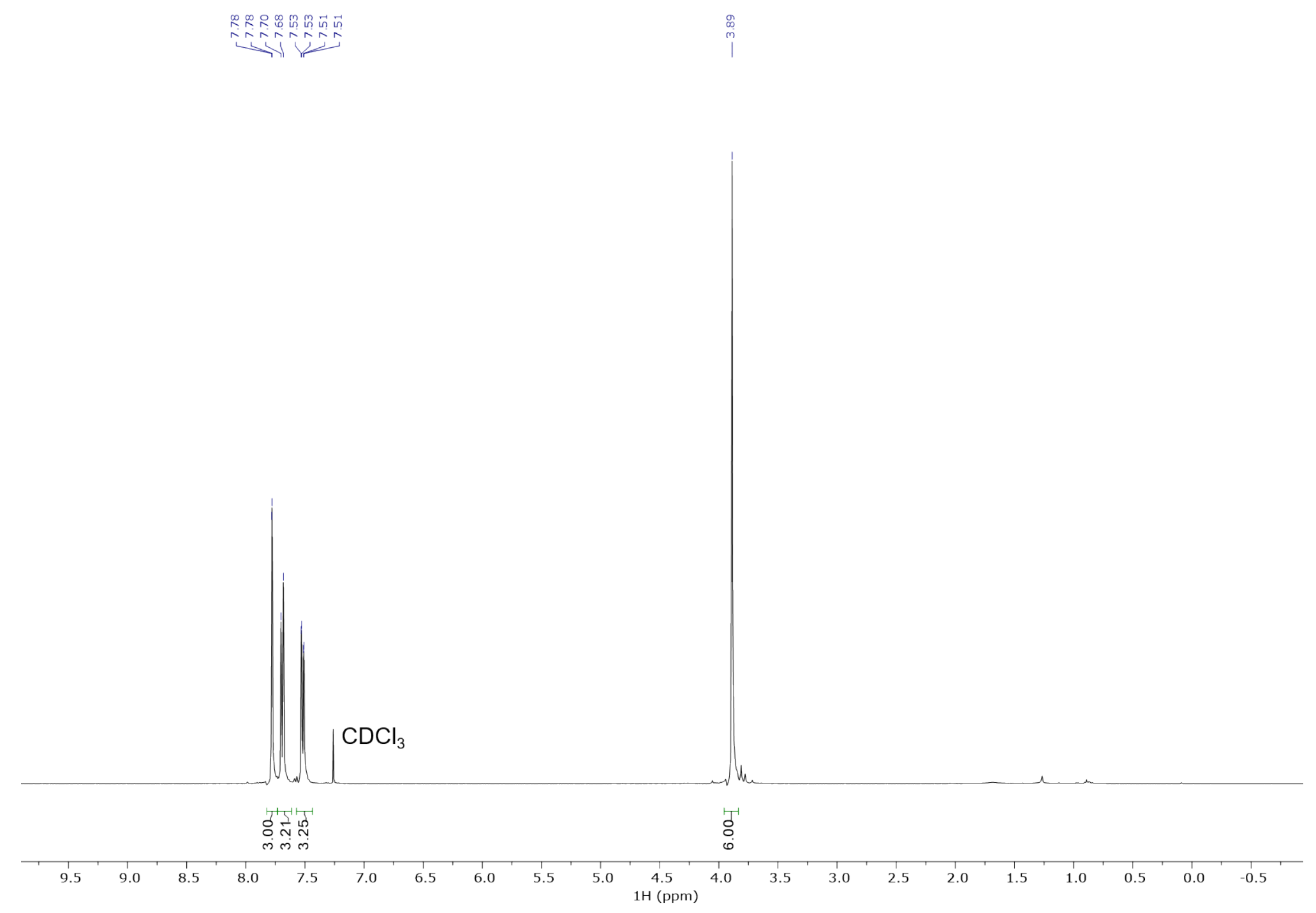

Figure S12. ${ }^{1} \mathrm{H}$ NMR spectrum of tris(2-bromo-4-trifluoromethyl)benzylamine in $\mathrm{CDCl}_{3}$. 

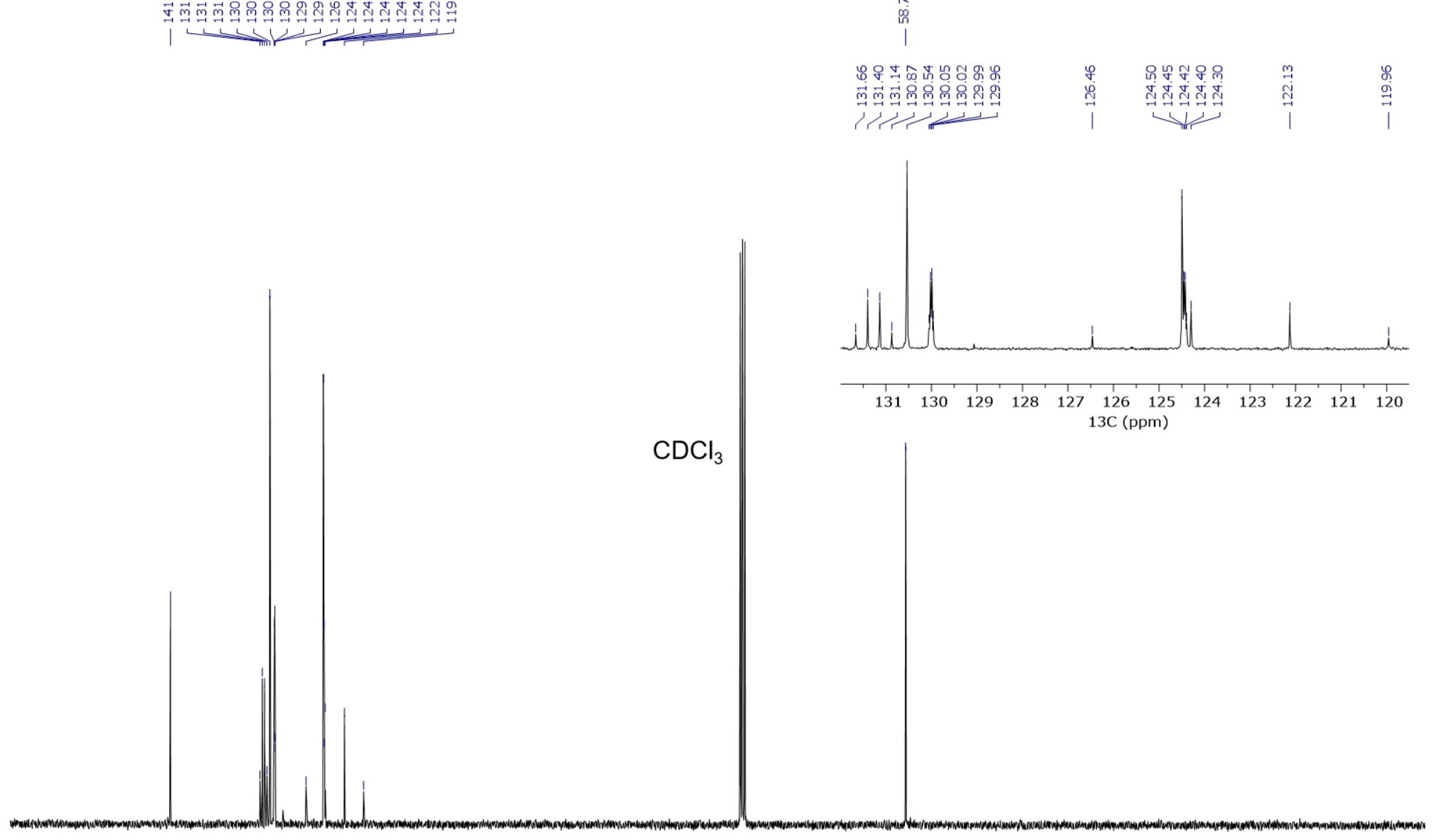

Figure S13. ${ }^{13} \mathrm{C}$ NMR spectrum of tris(2-bromo-4-trifluoromethyl)benzylamine in $\mathrm{CDCl}_{3}$. 


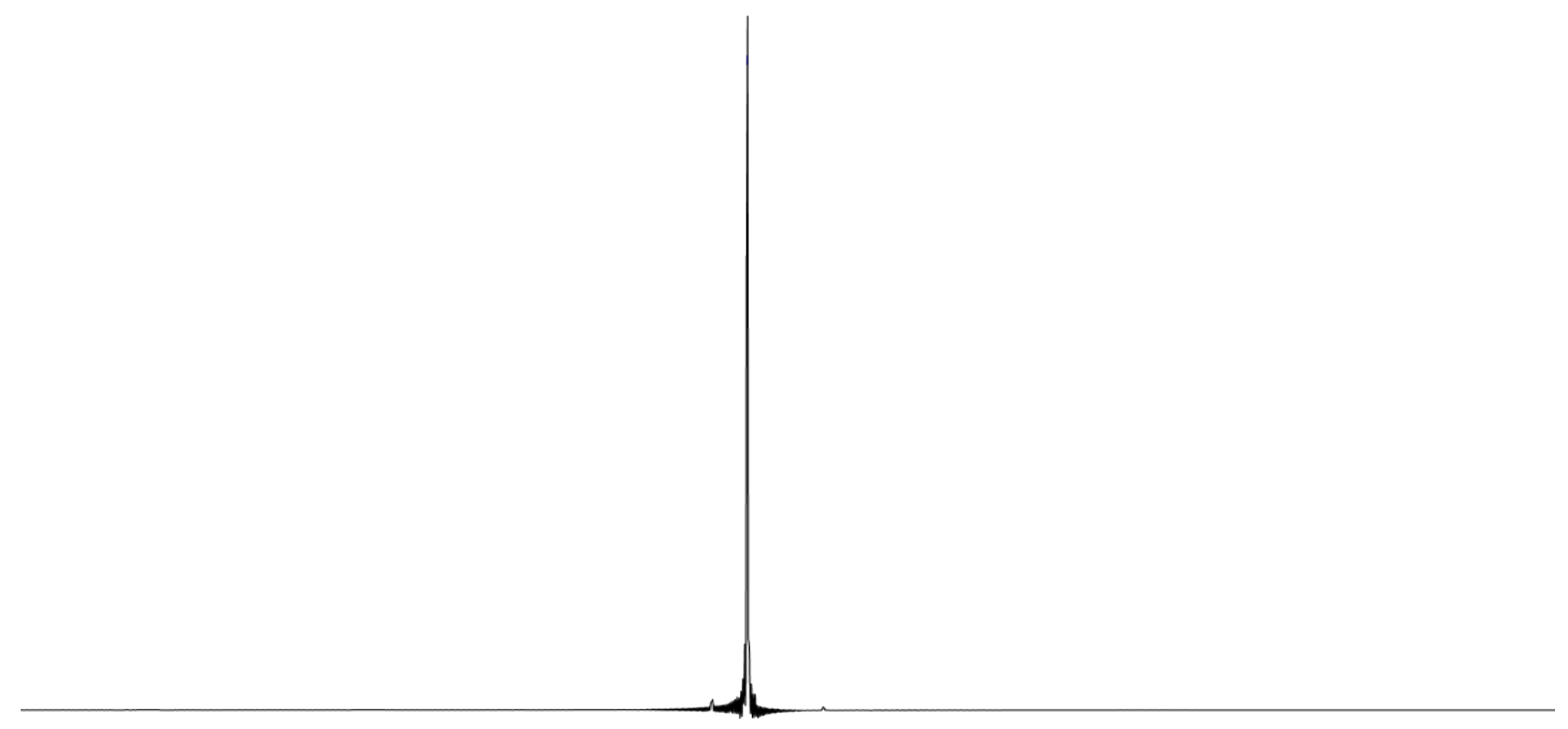

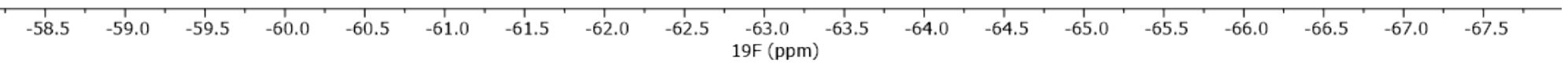

Figure S14. ${ }^{19} \mathrm{~F}$ NMR spectrum of tris(2-bromo-4-trifluoromethyl)benzylamine in $\mathrm{CDCl}_{3}$. 


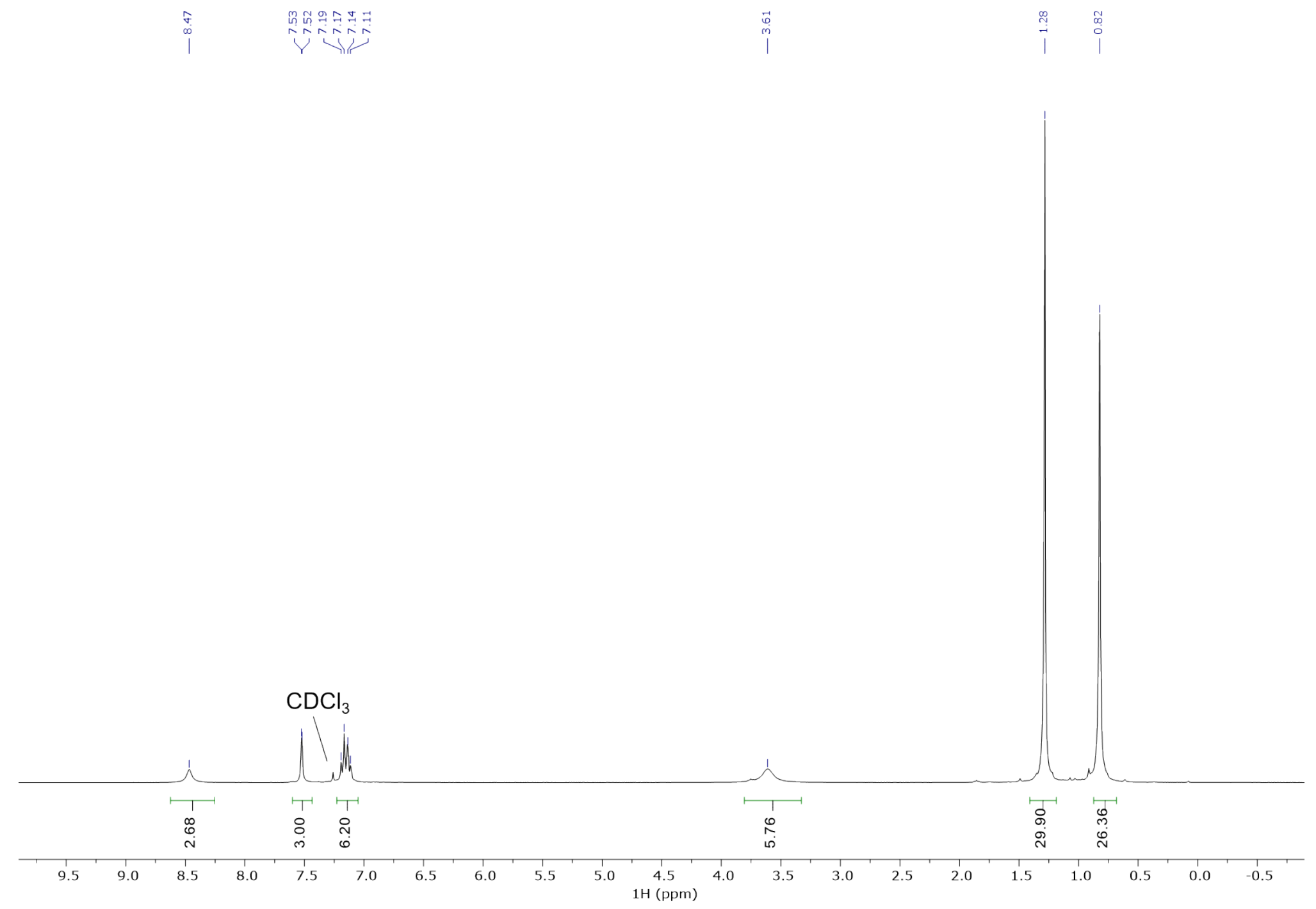

Figure S15. ${ }^{1} \mathrm{H}$ NMR spectrum of tris(2-tert-butylhydroxylamine-4-tertbutyl)benzylamine in $\mathrm{CDCl}_{3}$. 

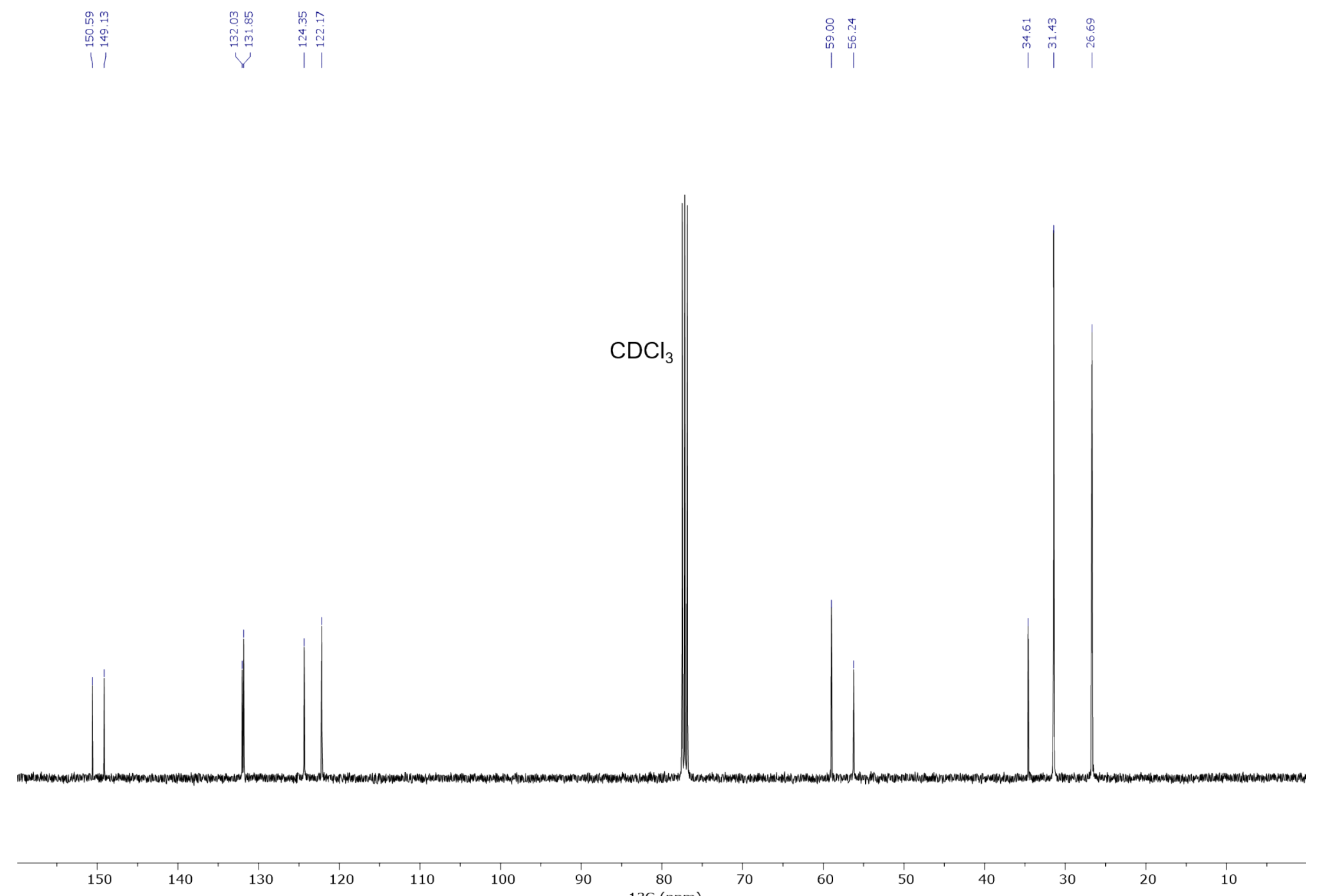

70

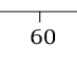

50

40

30

20

10

Figure S16. ${ }^{13} \mathrm{C}$ NMR spectrum of tris(2-tert-butylhydroxylamine-4-tertbutyl)benzylamine in $\mathrm{CDCl}_{3}$. 


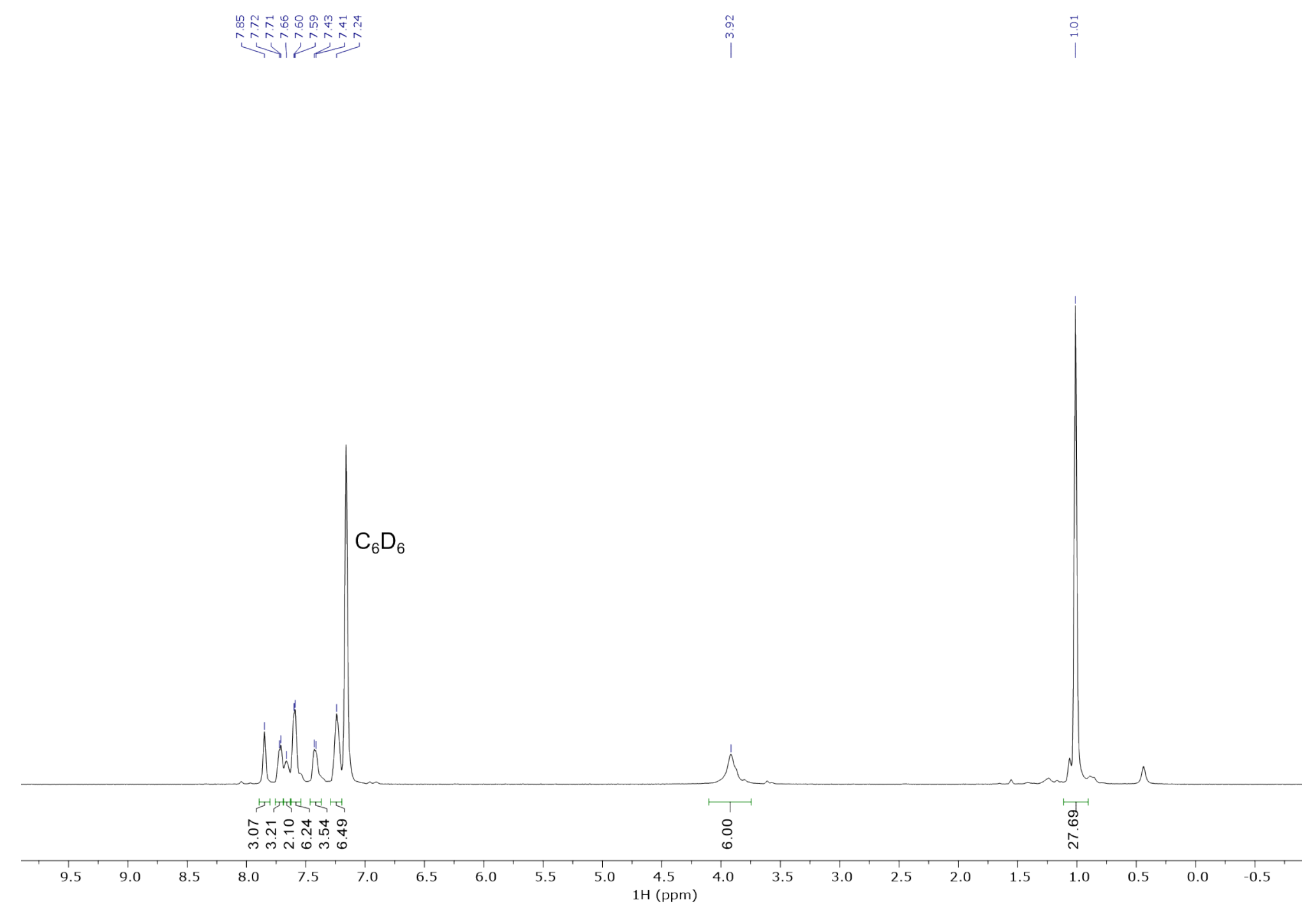

Figure S17. ${ }^{1} \mathrm{H}$ NMR spectrum of tris(2-tert-butylhydroxylamine-5-phenyl)benzylamine in $\mathrm{C}_{6} \mathrm{D}_{6}$. 


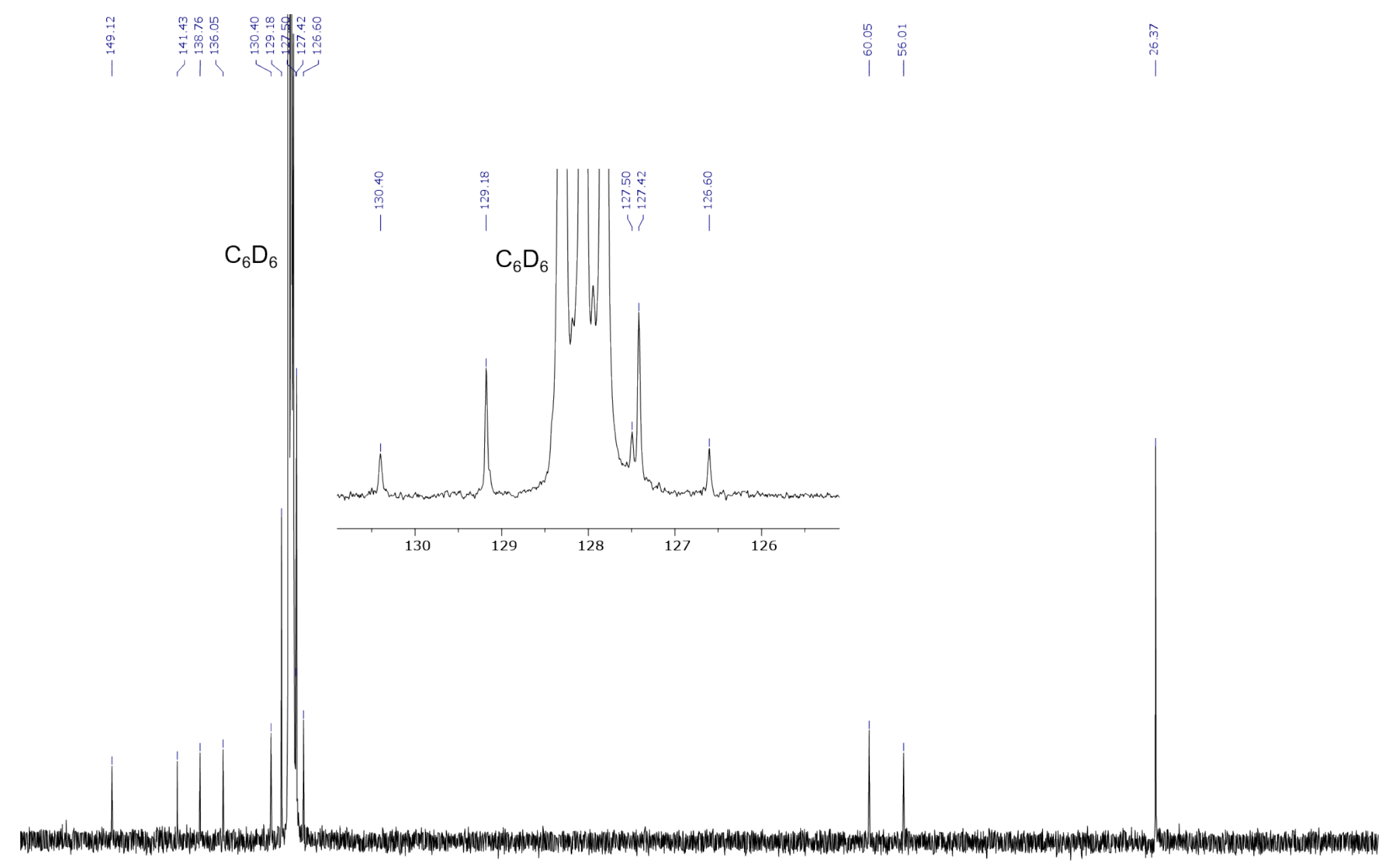

$\stackrel{80}{3 C}(\mathrm{ppm})$

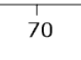

60

50

40

30

20

10

Figure S18. ${ }^{13} \mathrm{C}$ NMR spectrum of tris(2-tert-butylhydroxylamine-5-phenyl)benzylamine in $\mathrm{C}_{6} \mathrm{D}_{6}$. 


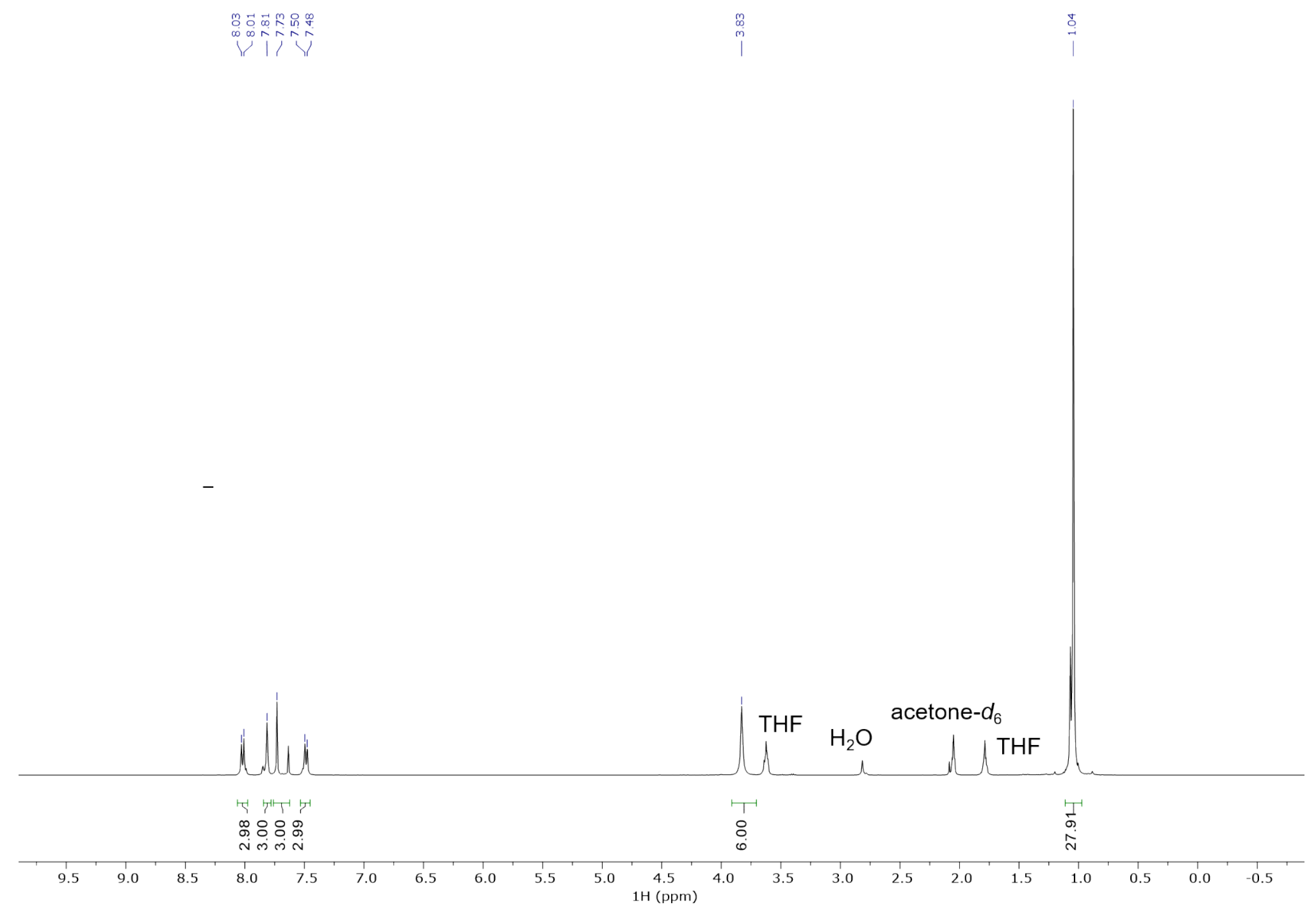

Figure S19. ${ }^{1} \mathrm{H}$ NMR spectrum of tris(2-tert-butylhydroxylamine-4-trifluoromethyl)benzylamine in acetone- $d_{6}$. 

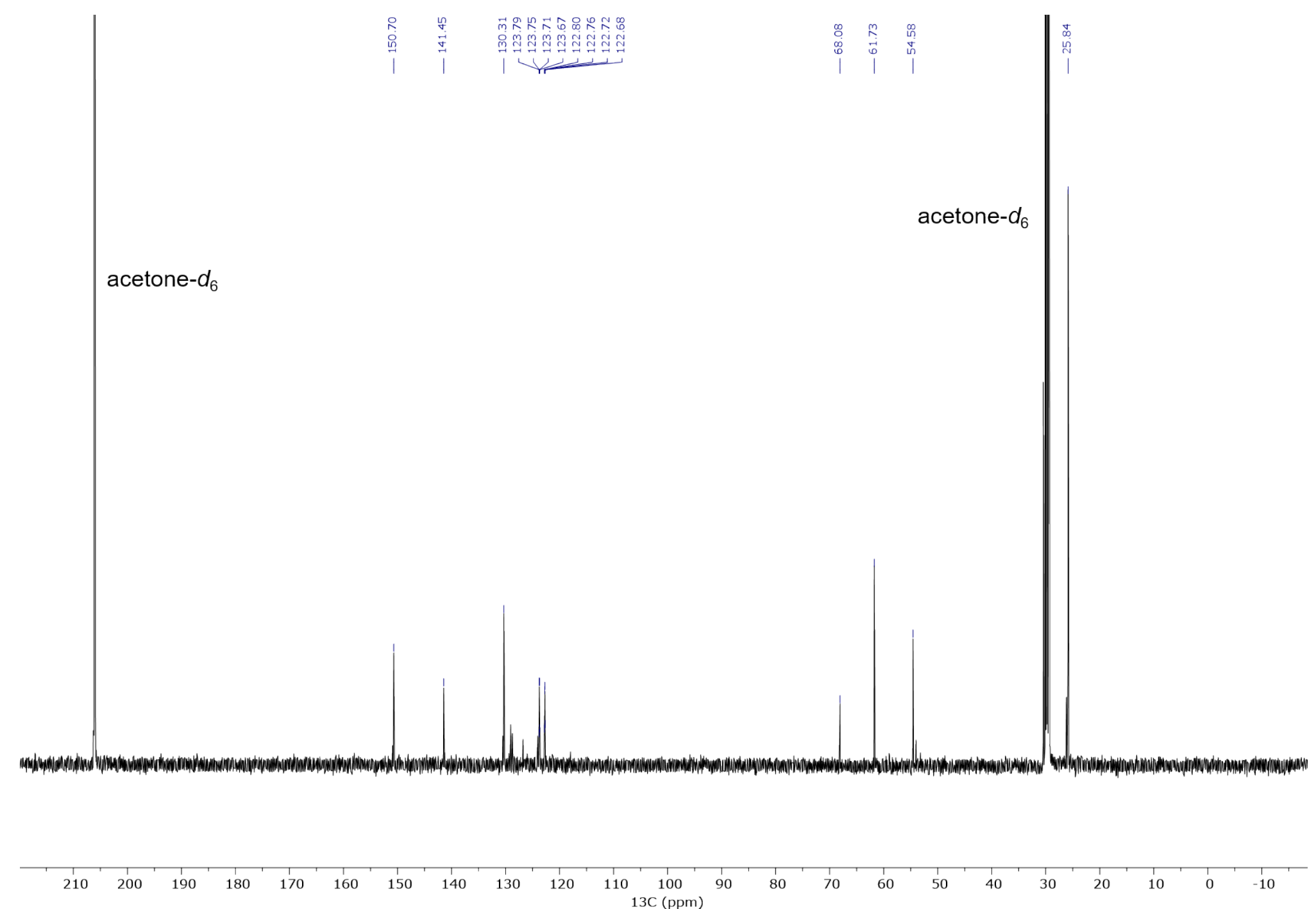

Figure S20. ${ }^{13} \mathrm{C}$ NMR spectrum of tris(2-tert-butylhydroxylamine-4-trifluoromethyl)benzylamine in acetone- $d_{6}$. 


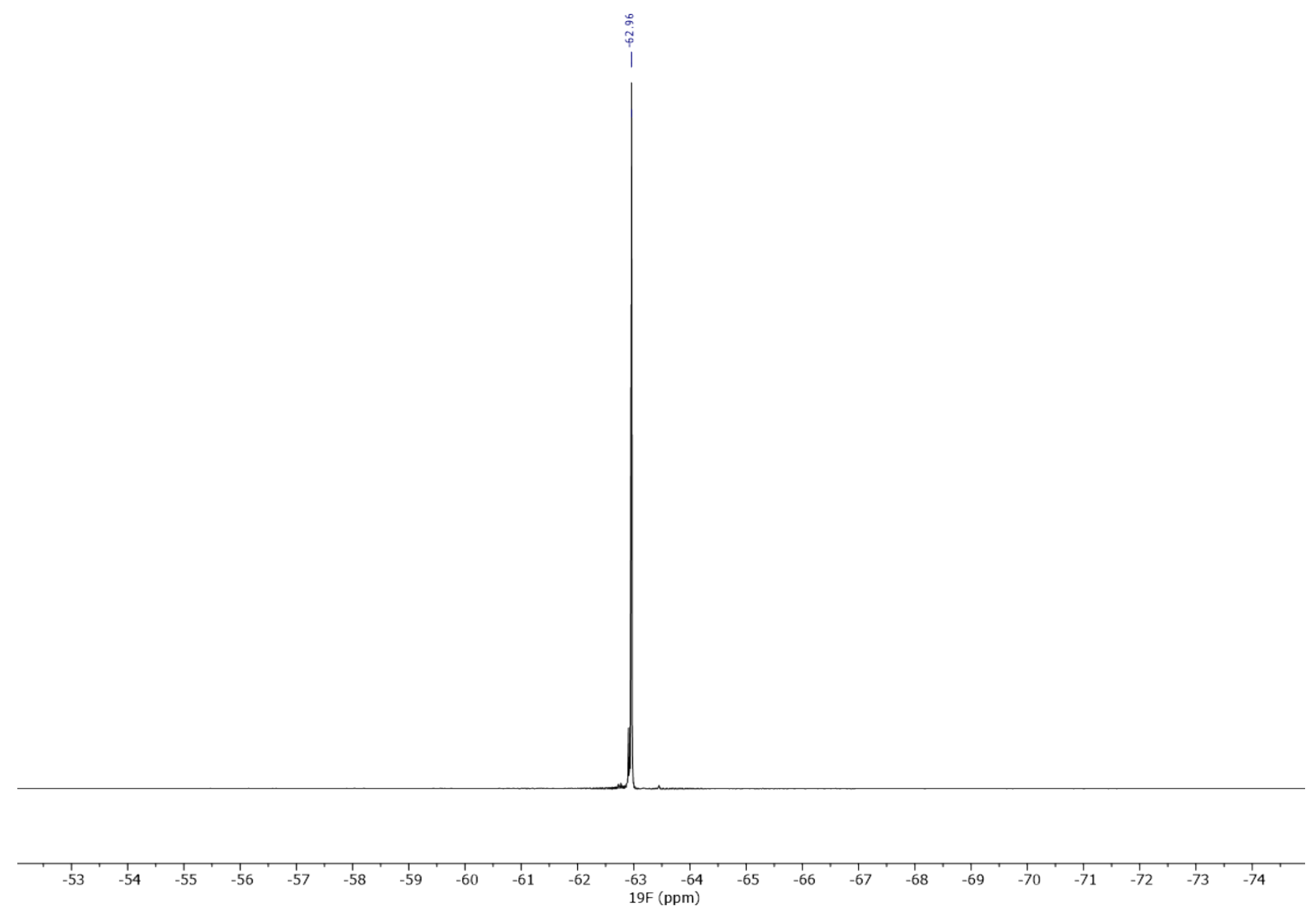

Figure S21. ${ }^{19} \mathrm{~F}$ NMR spectrum of tris(2-tert-butylhydroxylamine-4-trifluoromethyl)benzylamine in acetone- $d_{6}$. 


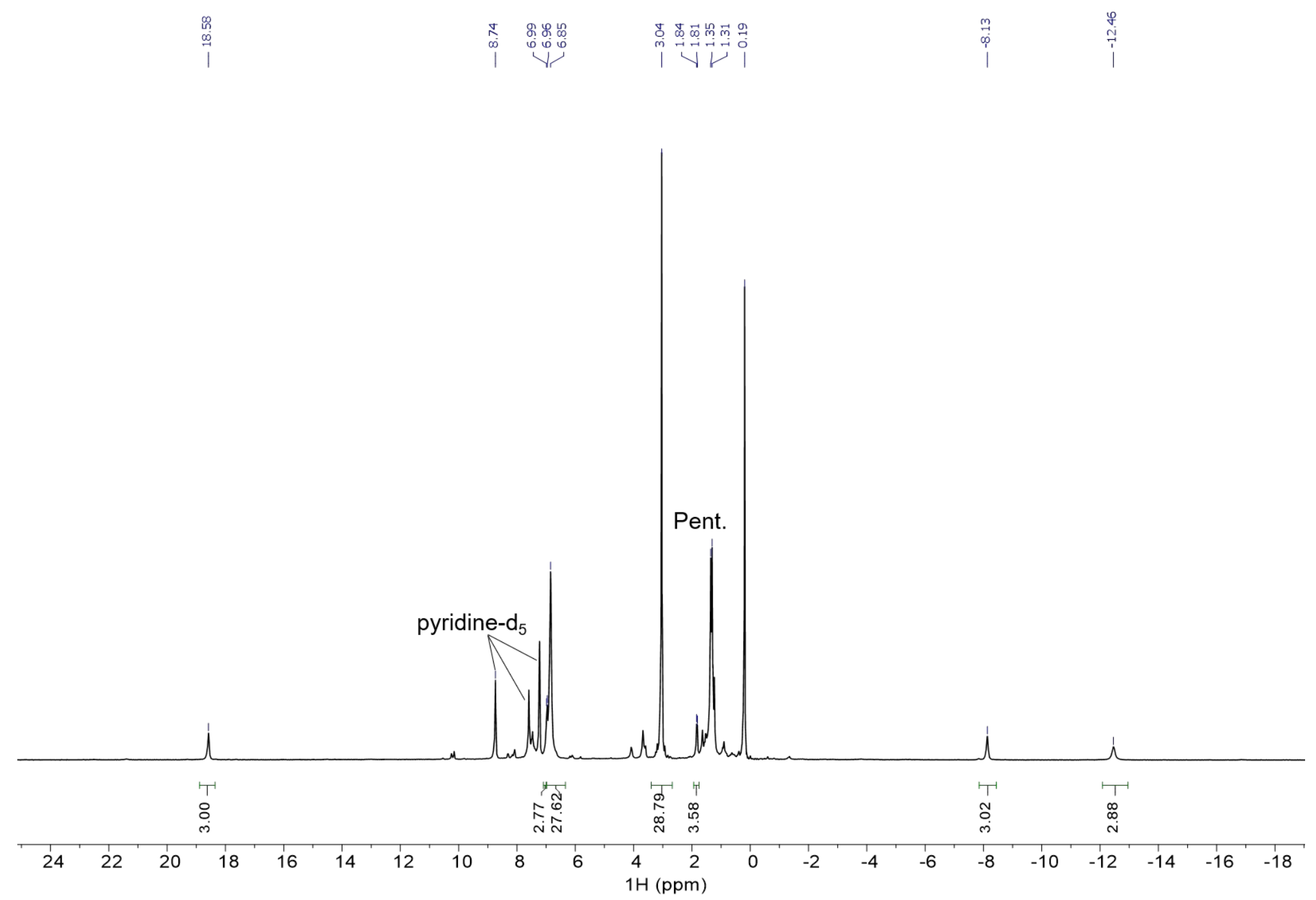

Figure S22. ${ }^{1} \mathrm{H}$ NMR spectrum of $\mathrm{Nd}\left(\operatorname{TriNOx}^{\mathrm{tBu}}\right)$ in pyridine- $d_{5}$. 


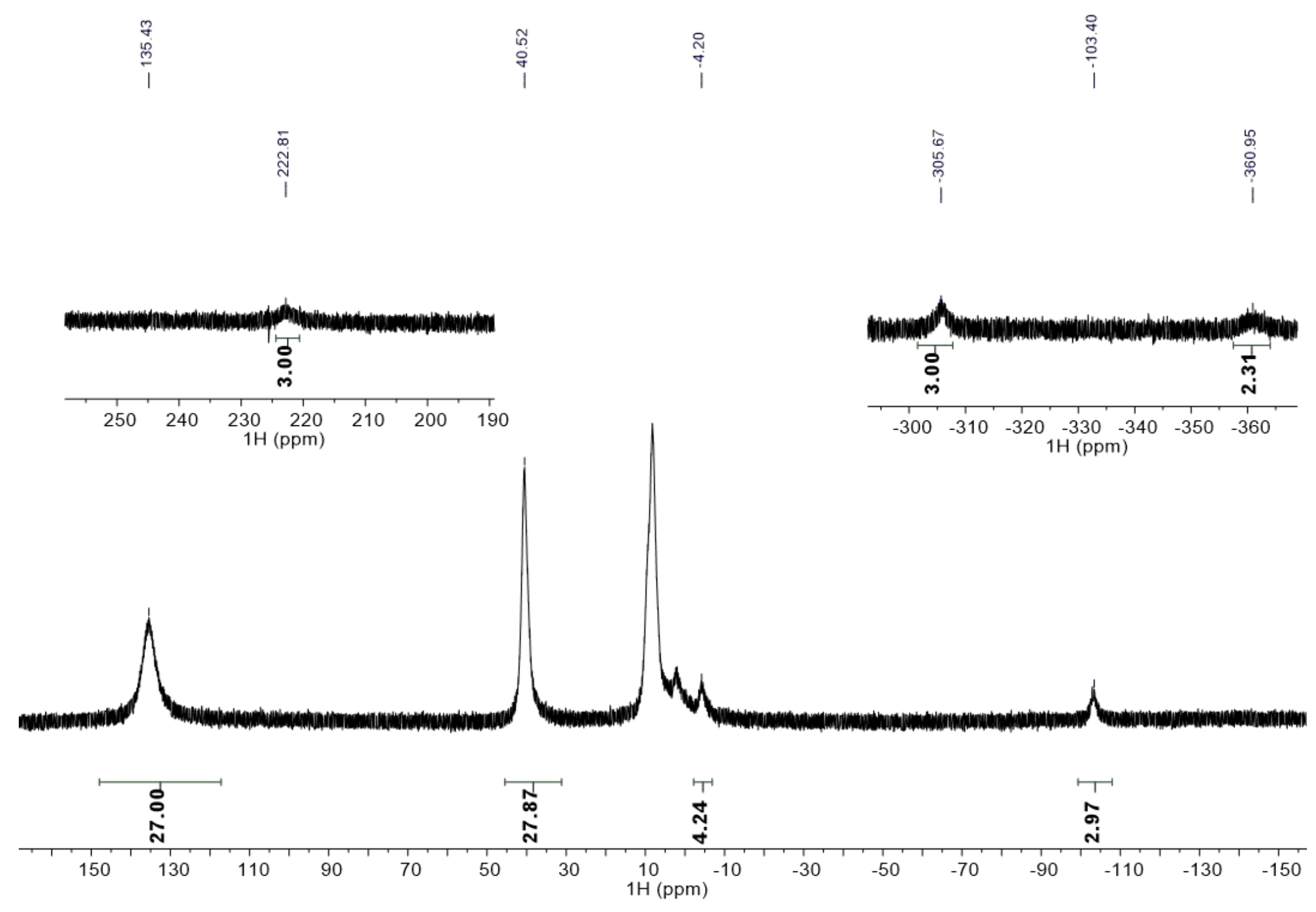

Figure S23. ${ }^{1} \mathrm{H}$ NMR spectrum of $\mathrm{Dy}\left(\mathrm{TriNOx}^{\mathrm{BBu}}\right)$ in pyridine- $d_{5}$. 


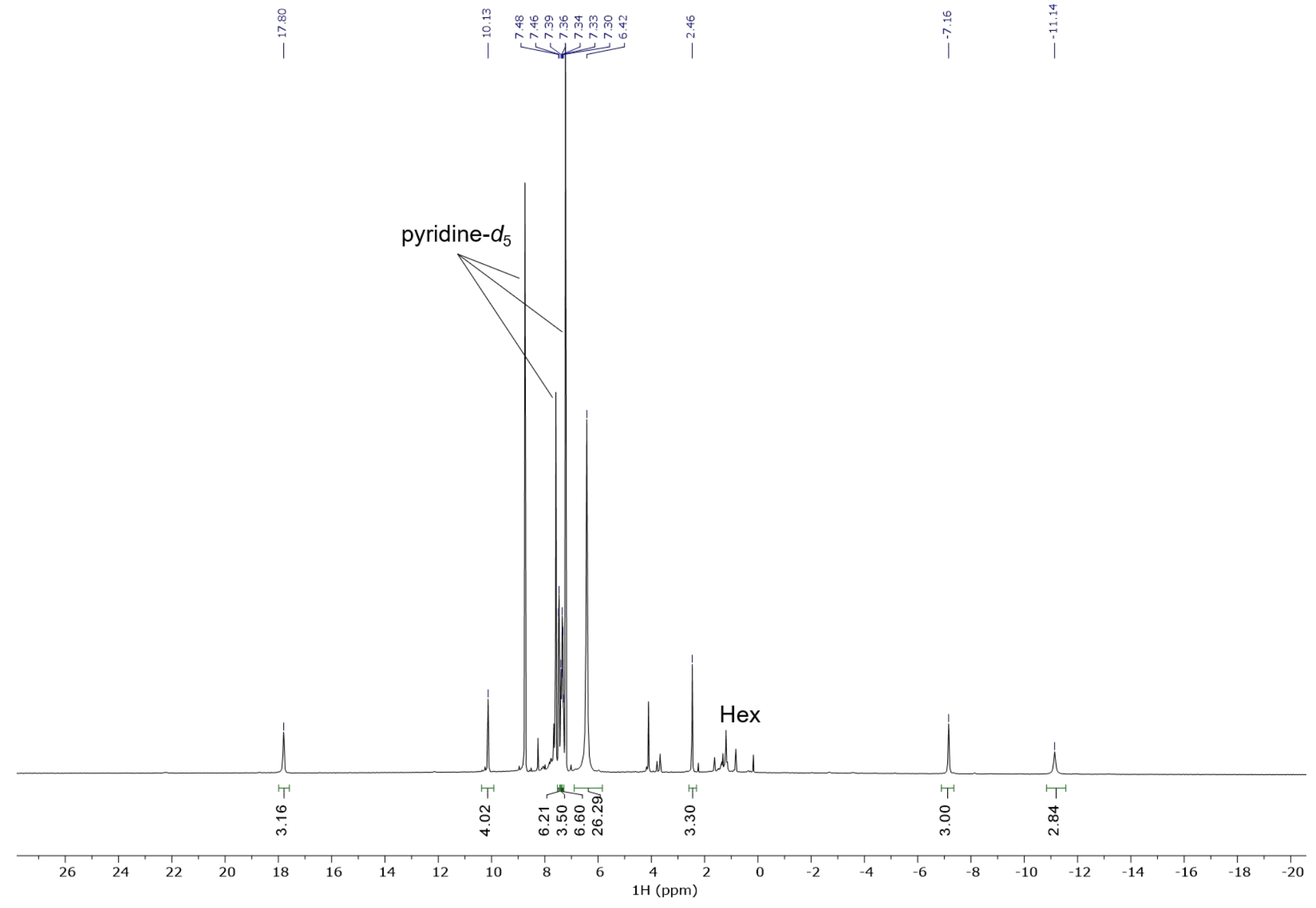

Figure S24. ${ }^{1} \mathrm{H}$ NMR spectrum of $\mathrm{Nd}\left(\mathrm{TrNOX}^{\mathrm{Ph}}\right)(\mathrm{THF})$ in pyridine- $d_{5}$. 


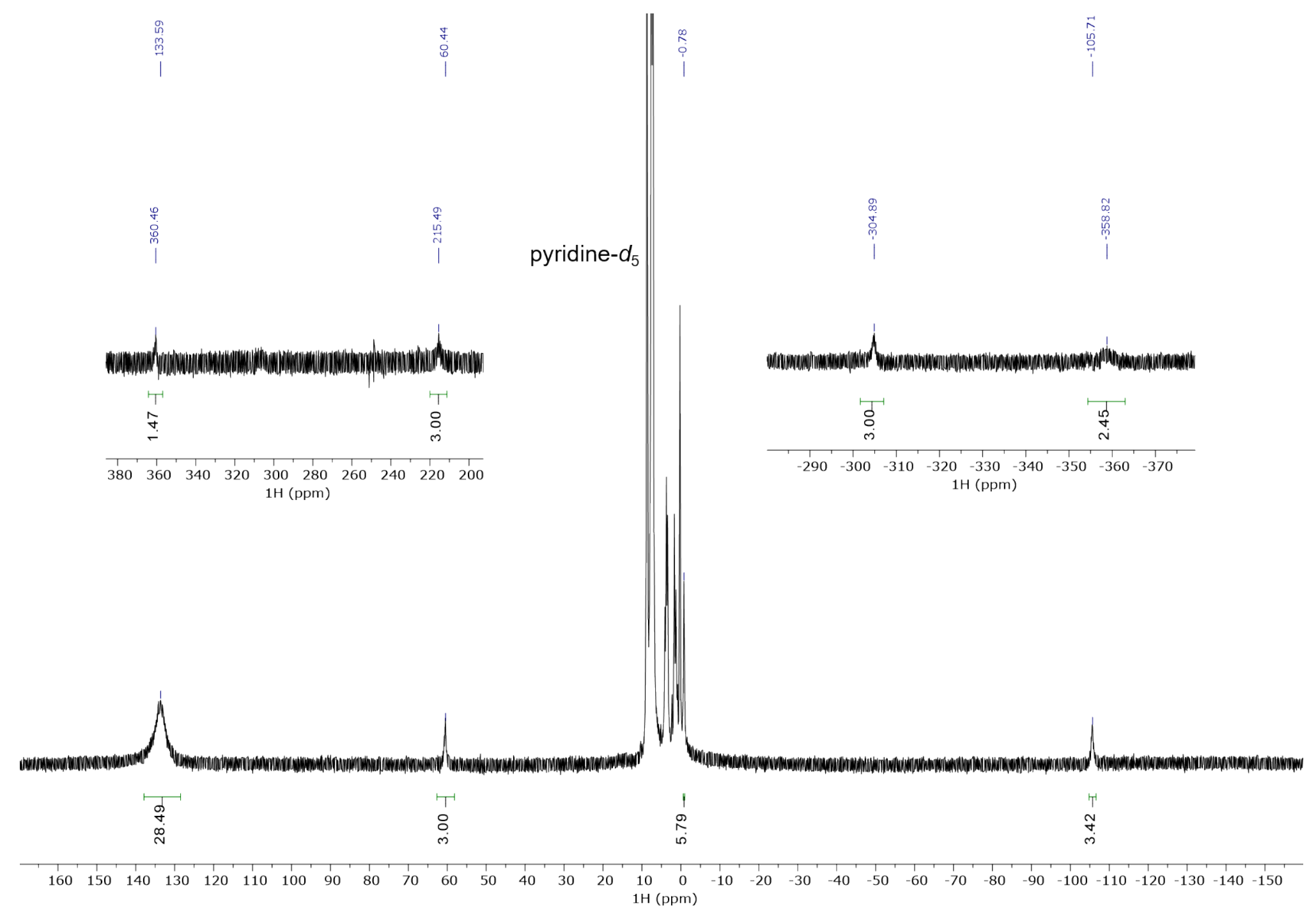

Figure S25. ${ }^{1} \mathrm{H}$ NMR spectrum of $\mathrm{Dy}\left(\mathrm{TriNOx}^{\mathrm{Ph}}\right)(\mathrm{THF})$ in pyridine- $d_{5}$. 


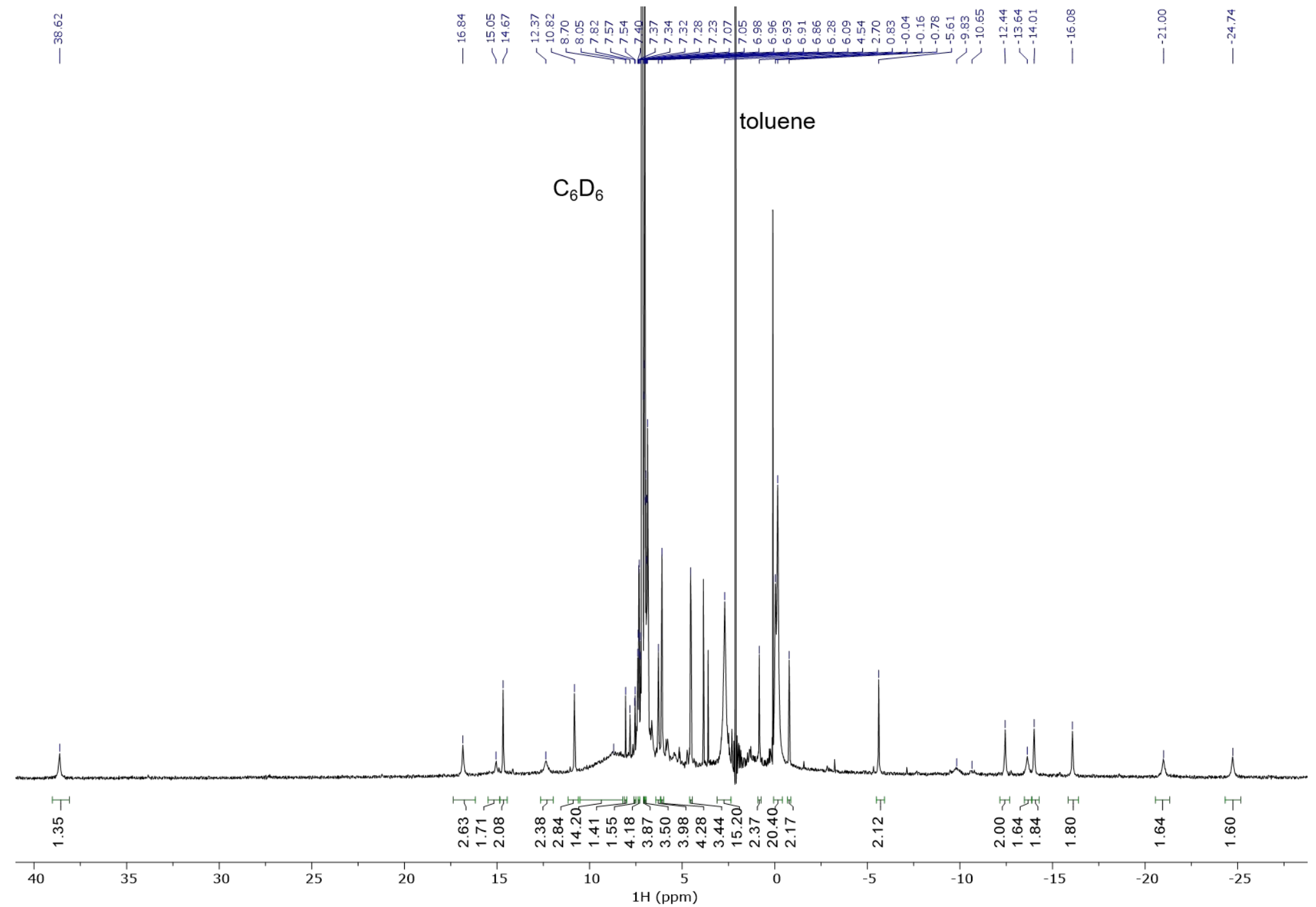

Figure S26. ${ }^{1} \mathrm{H}$ NMR spectrum of $\left[\mathrm{Nd}\left(\operatorname{TriNOx}{ }^{\mathrm{Ph}}\right)\right]_{2}$ in $\mathrm{C}_{6} \mathrm{D}_{6}$. 


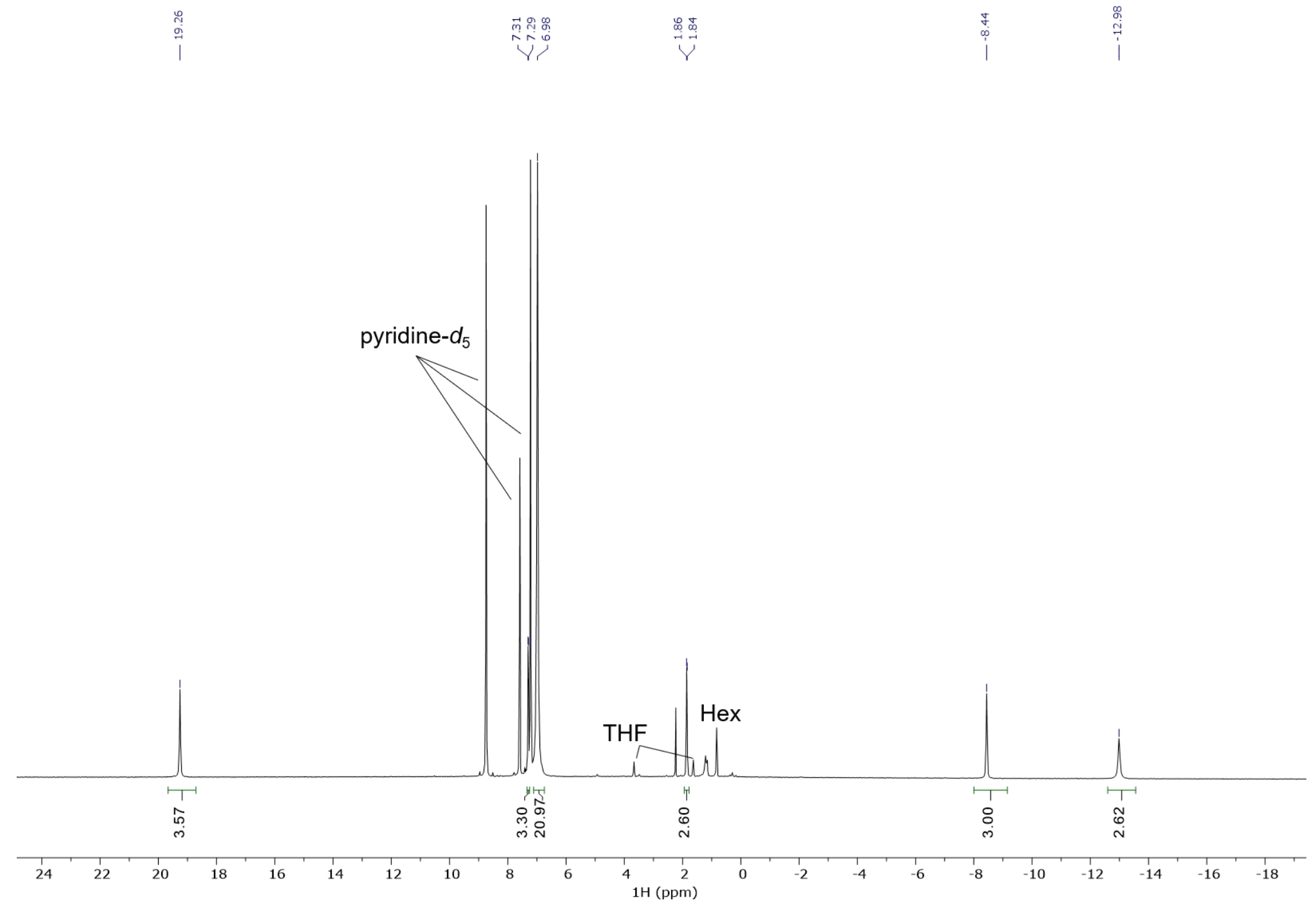

Figure S27. ${ }^{1} \mathrm{H}$ NMR spectrum of $\mathrm{Nd}\left(\mathrm{TriNOx}^{\mathrm{CF}} 3\right)(\mathrm{THF})$ in pyridine- $d_{5}$. 


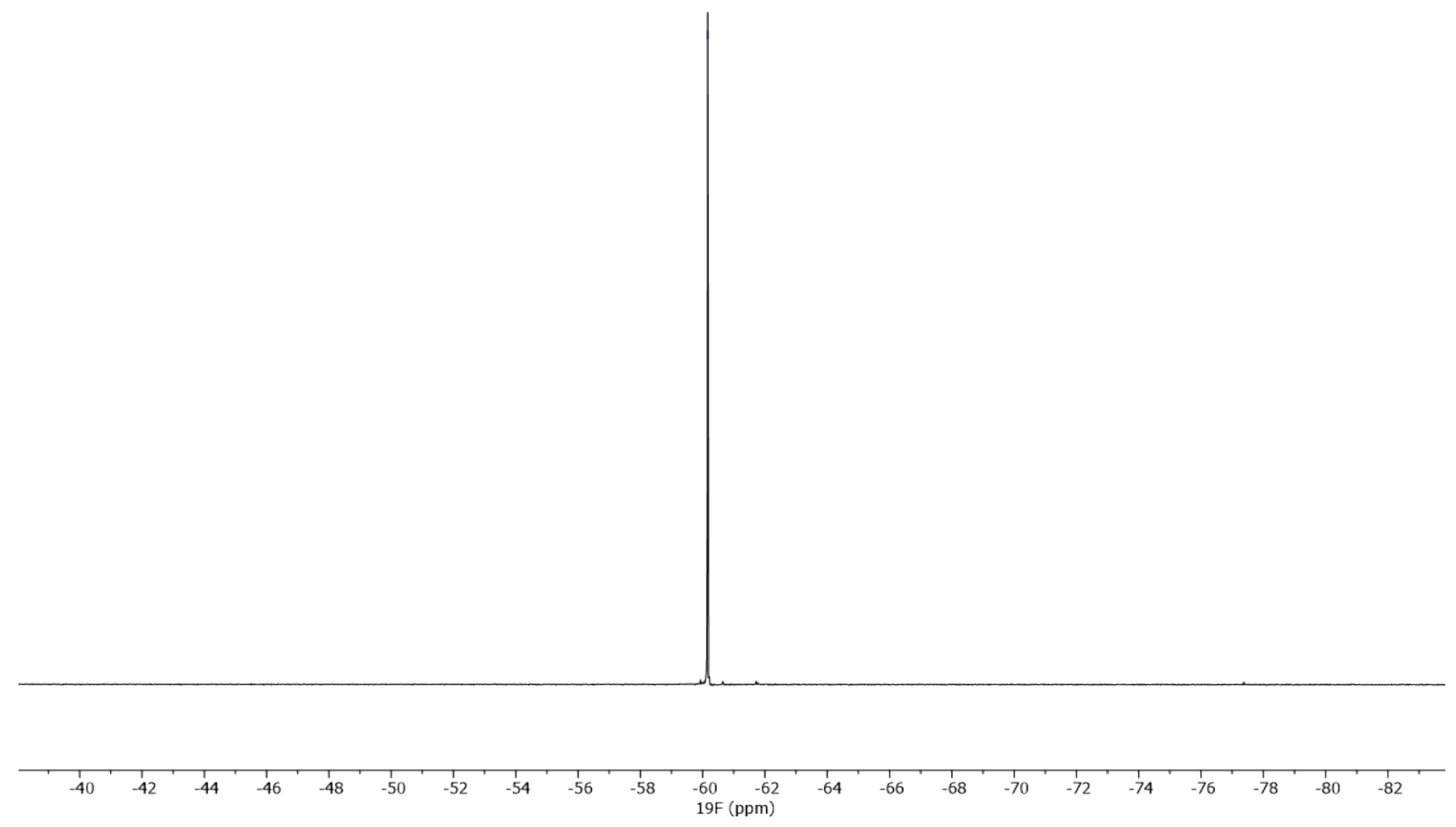

Figure S28. ${ }^{19} \mathrm{~F} \mathrm{NMR}$ spectrum of $\mathrm{Nd}\left(\mathrm{TriNOx}^{\mathrm{CF}}\right)(\mathrm{THF})$ in pyridine- $d_{5}$. 


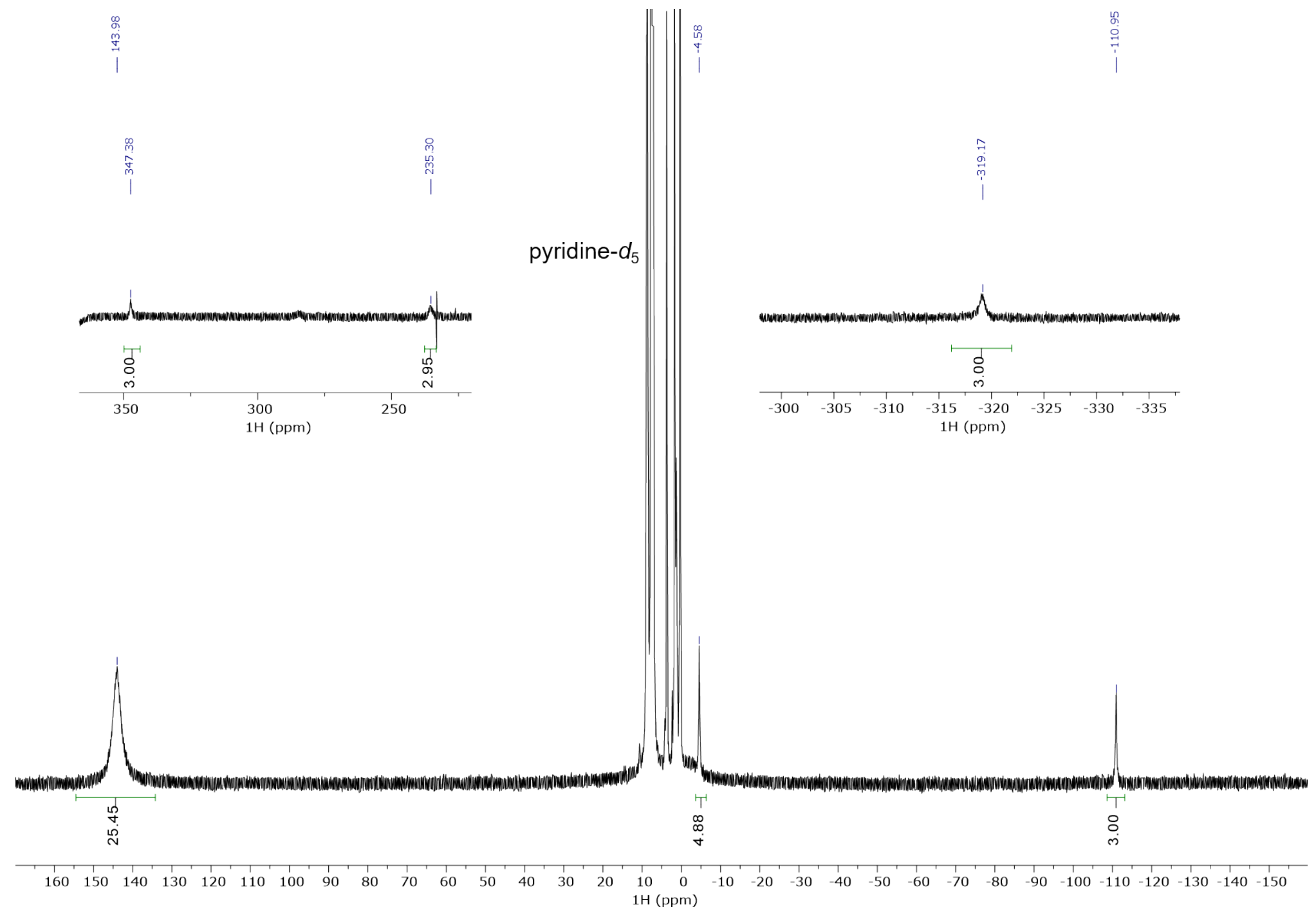

Figure S29. ${ }^{1} \mathrm{H}$ NMR spectrum of $\mathrm{Dy}\left(\mathrm{TriNOx}^{\mathrm{CF}} 3\right)(\mathrm{THF})$ in pyridine- $d_{5}$. 

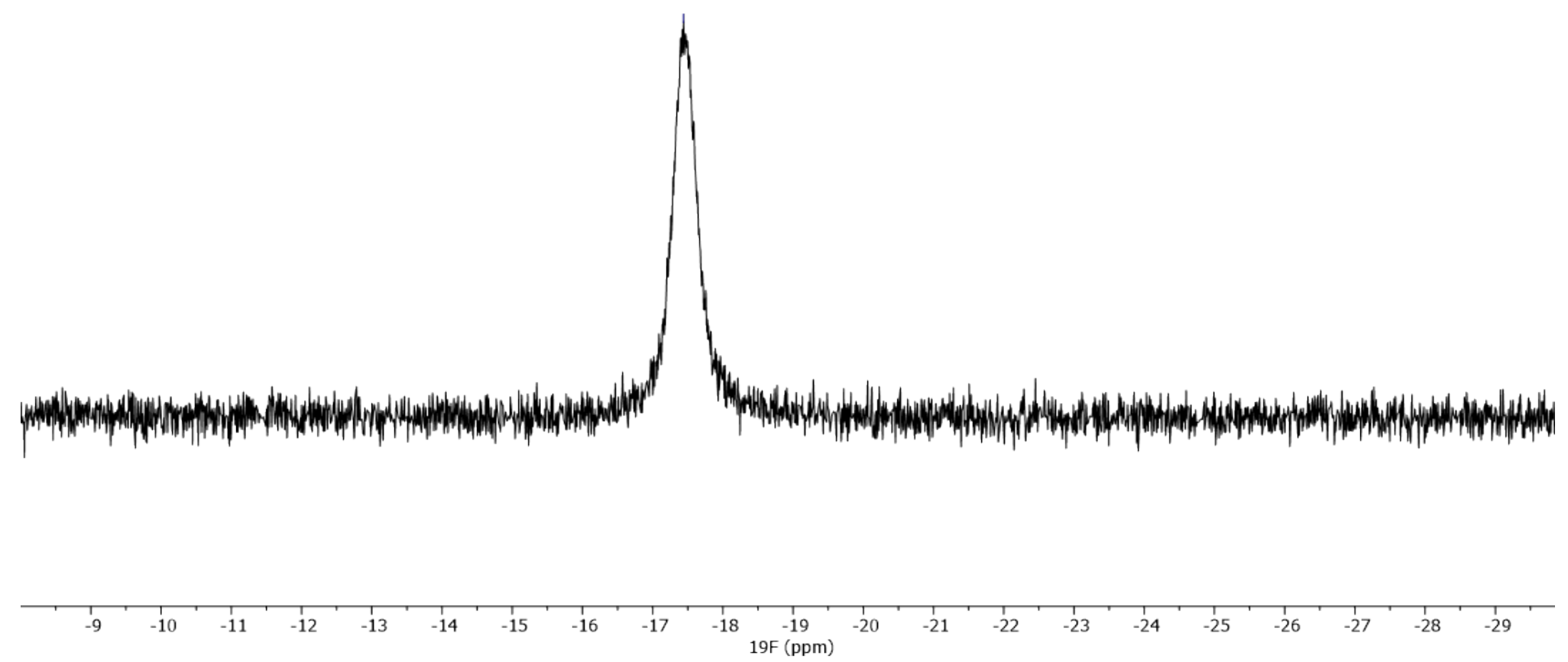

Figure S30. ${ }^{19} \mathrm{~F}$ NMR spectrum of $\mathrm{Dy}\left(\mathrm{TriNOx}^{\mathrm{CF}}\right)(\mathrm{THF})$ in pyridine- $d_{5}$. 


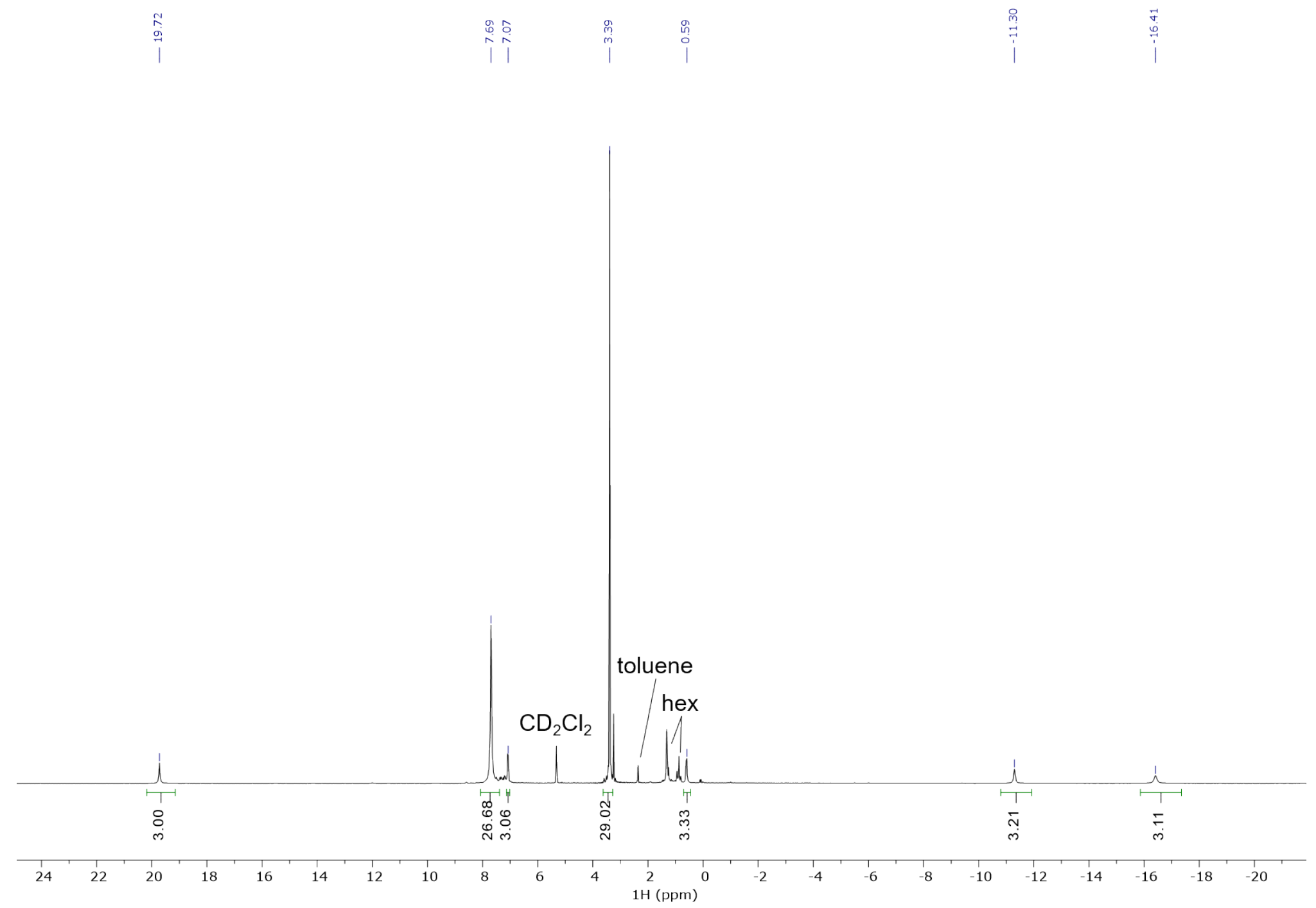

Figure S31. ${ }^{1} \mathrm{H}$ NMR spectrum of $\mathrm{Nd}\left(\right.$ TriNOx $\left.^{\mathrm{tBu}}\right)$ in $\mathrm{CD}_{2} \mathrm{Cl}_{2}$. No evidence of a dimeric species was observed. 


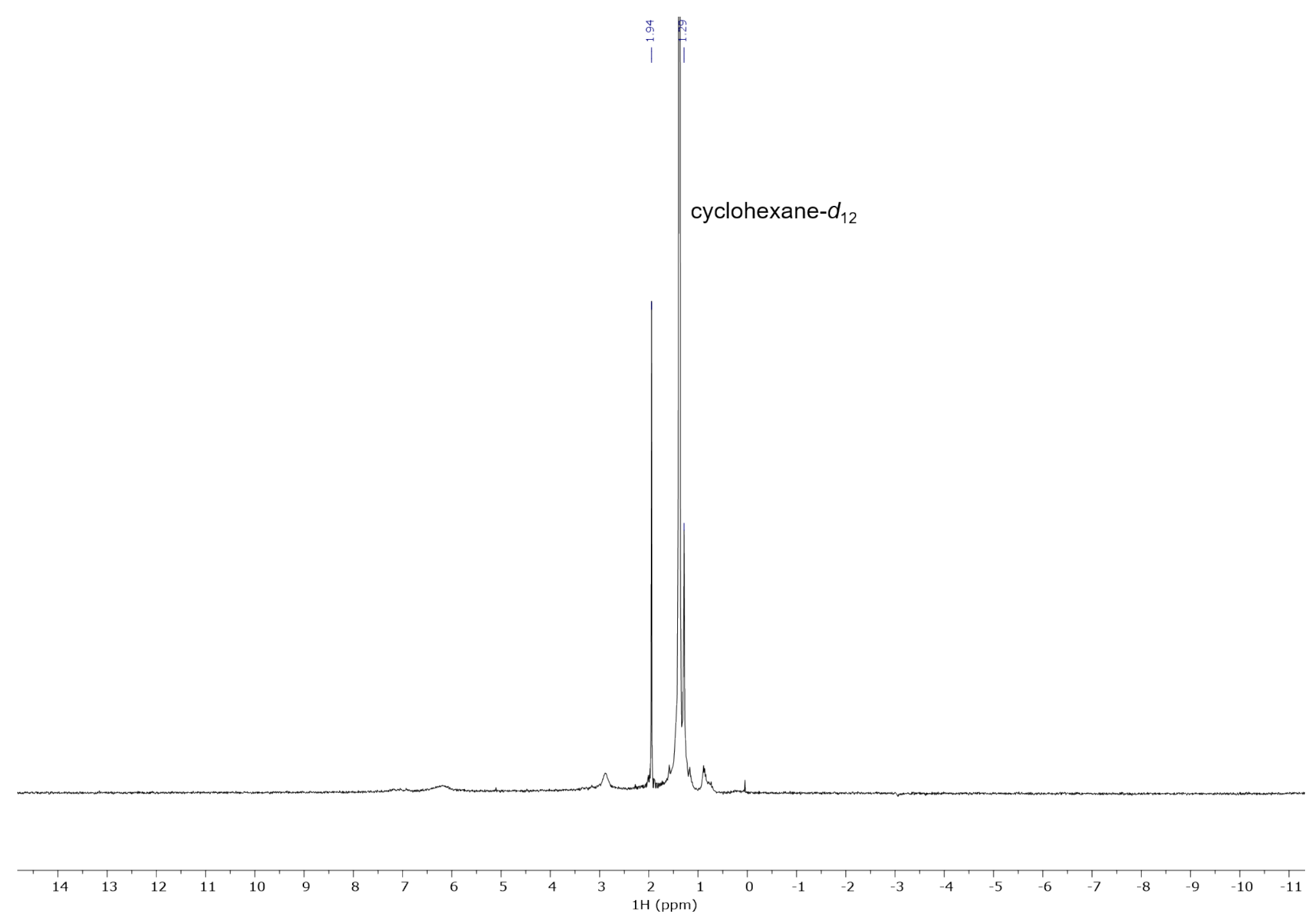

Figure S32. ${ }^{1} \mathrm{H}$ NMR spectrum of $\mathrm{Nd}\left(\right.$ TriNOx $\left.^{\mathrm{tBu}}\right)$ in cyclohexane- $d_{12}$. No evidence of a dimeric species was observed. 

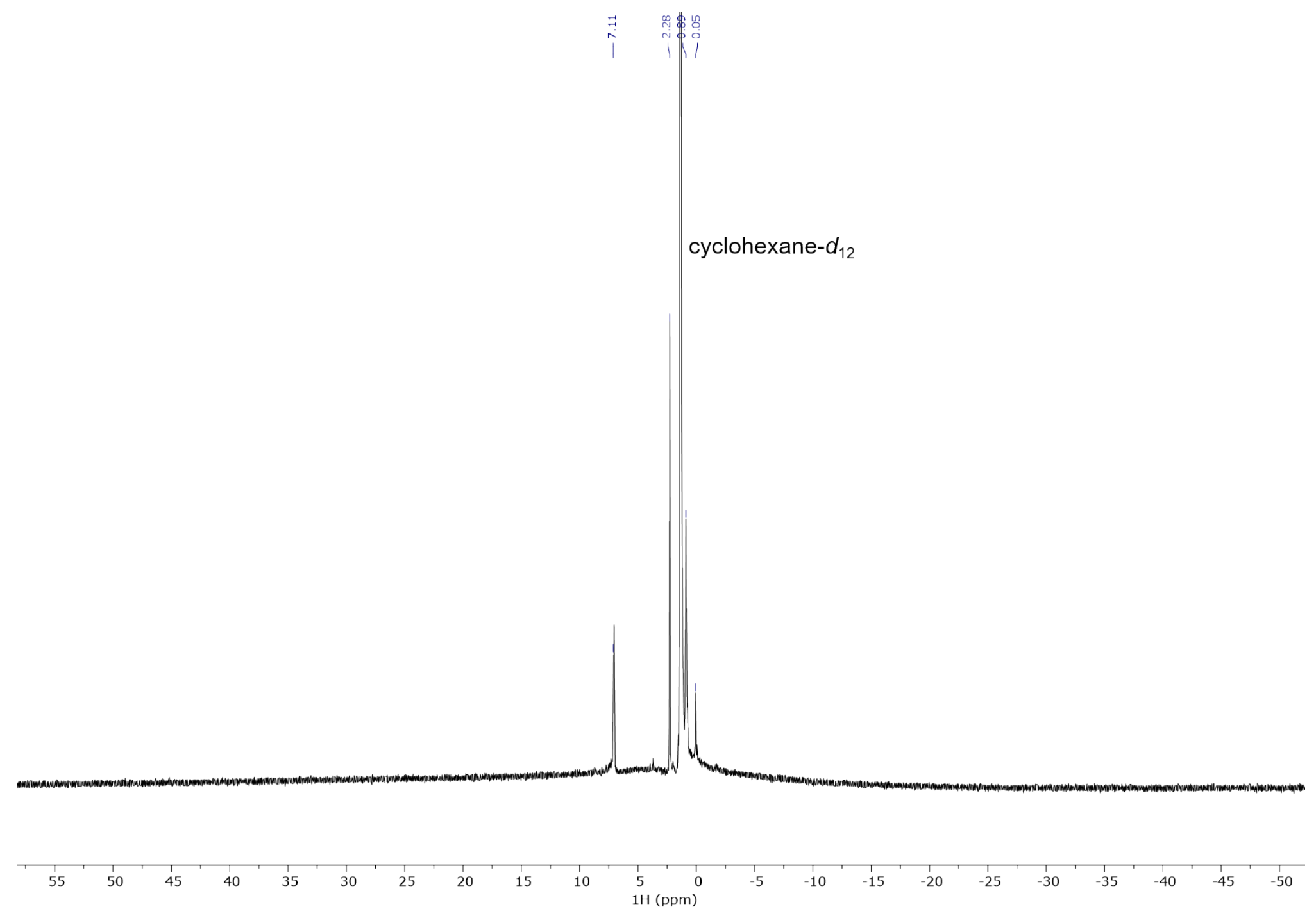

Figure S33. ${ }^{1} \mathrm{H}$ NMR spectrum of $\mathrm{Nd}\left(\mathrm{TriNOx}^{\mathrm{CF}} 3\right)(\mathrm{THF})$ in cyclohexane- $d_{12}$. No evidence of a dimeric species was observed. 


\section{Electrochemistry and Correlation Studies}

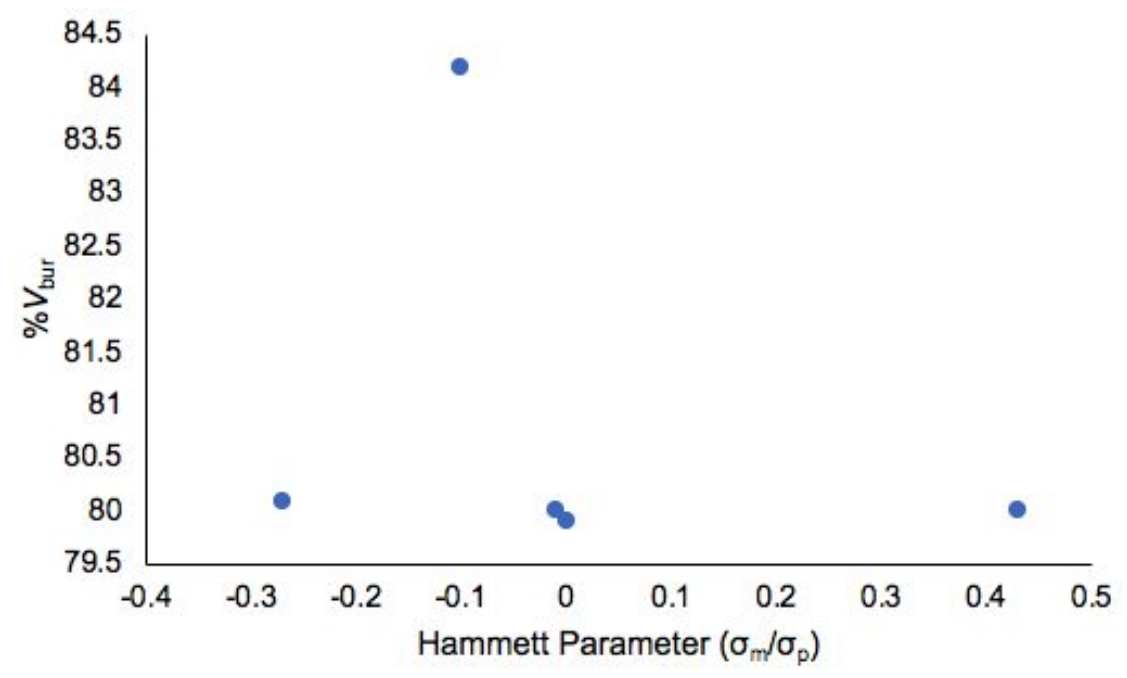

Figure S34. Comparison of the percent buried volume $\left(\% V_{\text {bur }}\right)$ of $\mathrm{Nd}\left(\mathrm{TriNOx}^{\mathrm{R}}\right)(\mathrm{THF})$ complexes against the Hammett parameter $\left(\sigma_{m}\right.$ or $\left.\sigma_{p}\right)$ of $R$. ( $\left.R=5-\mathrm{OMe},{ }^{-}{ }^{-} \mathrm{Bu}, 5-\mathrm{Ph}, \mathrm{H}, 4-\mathrm{CF}_{3}\right)$.

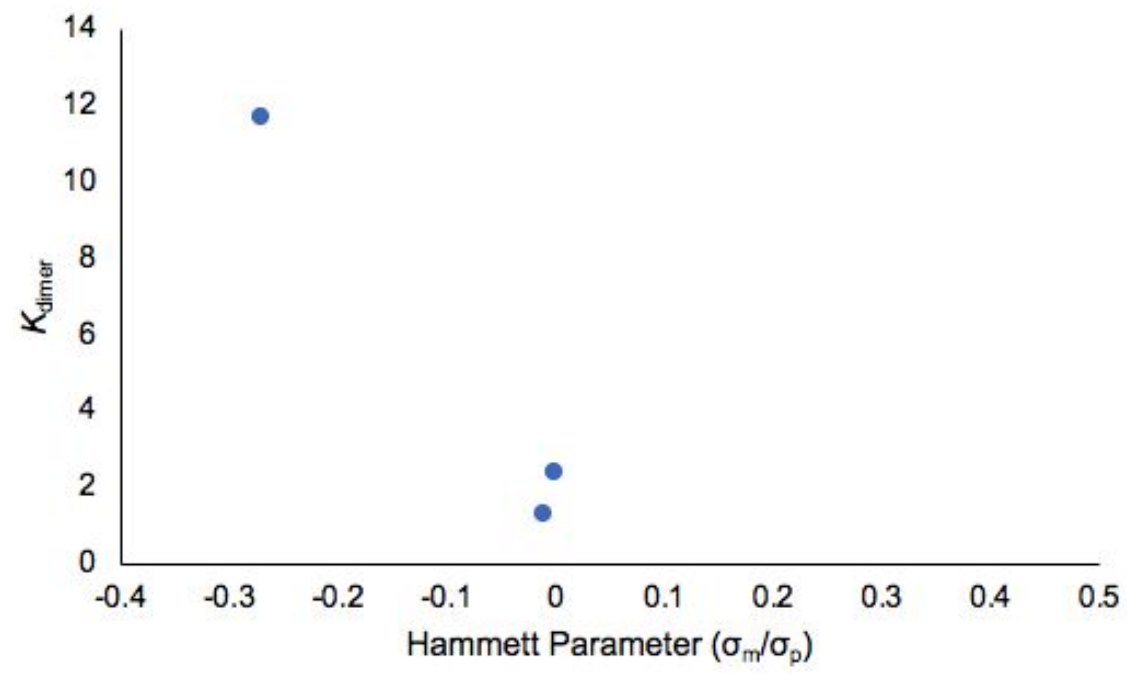

Figure S35. Comparison of the self-association constant $\left(K_{\text {dimer }}\right)$ of $\mathrm{Nd}\left(\mathrm{TriNOx}^{\mathrm{R}}\right)(\mathrm{THF})$ complexes against the Hammett parameter $\left(\sigma_{m}\right.$ or $\left.\sigma_{p}\right)$ of R. $(R=5-O M e, 5-P h, H)$. 


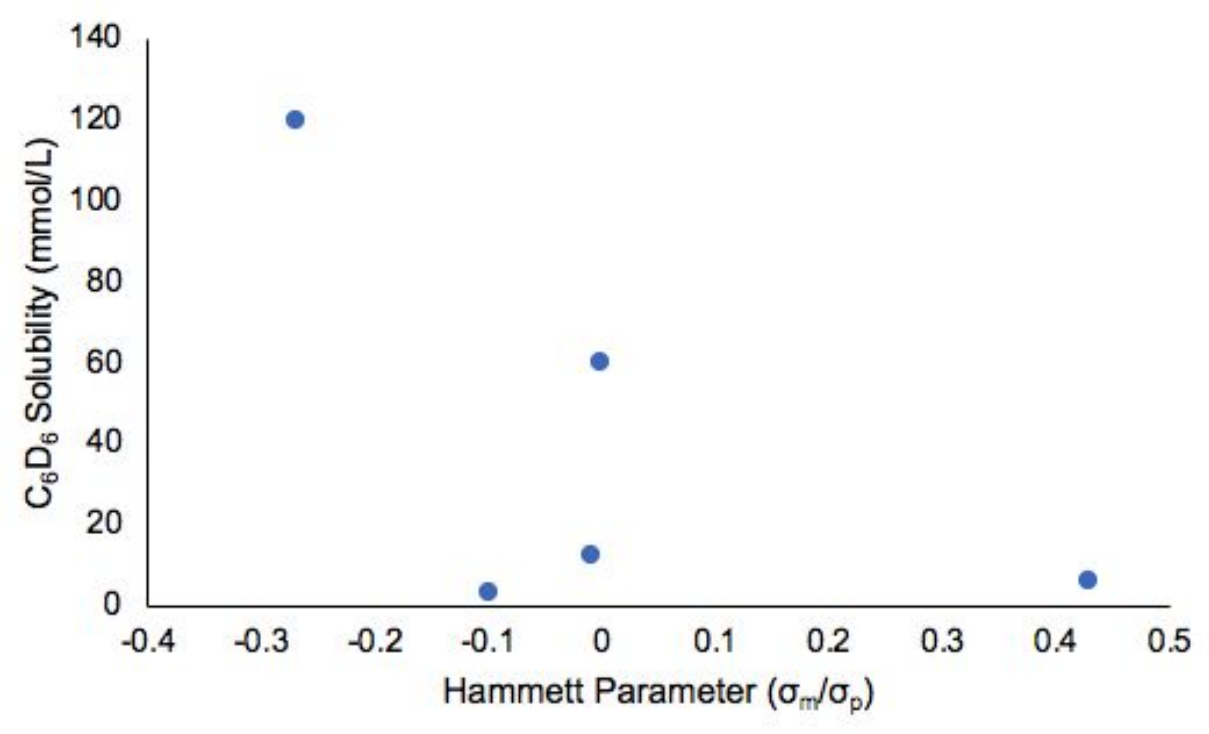

Figure S36. Comparison of the solubility (mmol/L) of $\mathrm{Nd}\left(\mathrm{TriNOx}^{\mathrm{R}}\right)(\mathrm{THF})$ complexes in $\mathrm{C}_{6} \mathrm{D}_{6}$ against the Hammett parameter $\left(\sigma_{m}\right.$ or $\left.\sigma_{p}\right)$ of $R$. ( $\left.R=5-\mathrm{OMe}, 4^{-} \mathrm{Bu}, 5-\mathrm{Ph}, \mathrm{H}, 4-\mathrm{CF}_{3}\right)$.

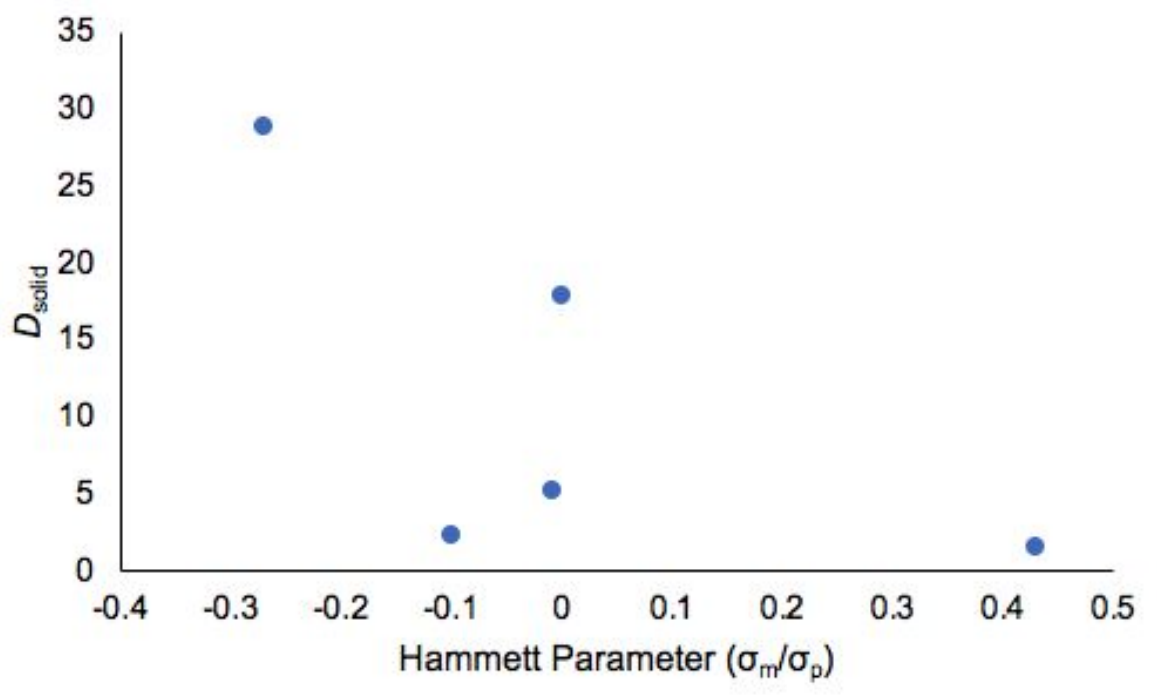

Figure S37. Comparison of the solid enrichment factor $\left(D_{\text {solid }}\right)$ in benzene against the Hammett parameter $\left(\sigma_{m}\right.$ or $\left.\sigma_{p}\right)$ of $R$. ( $R=5-\mathrm{OMe}$, 4-t $\left.\mathrm{Bu}, 5-\mathrm{Ph}, \mathrm{H}, 4-\mathrm{CF}_{3}\right)$. 


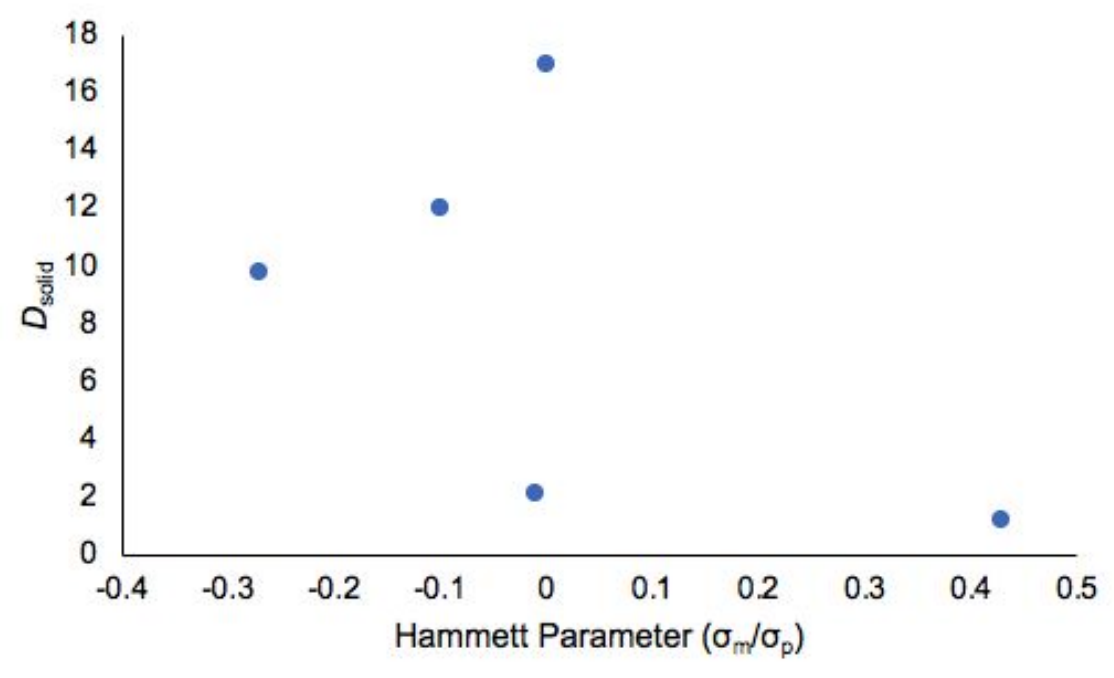

Figure S38. Comparison of the filtrate enrichment factor $\left(D_{\text {filtrate }}\right)$ in benzene against the Hammett parameter $\left(\sigma_{m}\right.$ or $\left.\sigma_{p}\right)$ of $R .\left(R=5-O M e, 4-{ }^{t} \mathrm{Bu}, 5-\mathrm{Ph}, \mathrm{H}, 4-\mathrm{CF}_{3}\right)$.

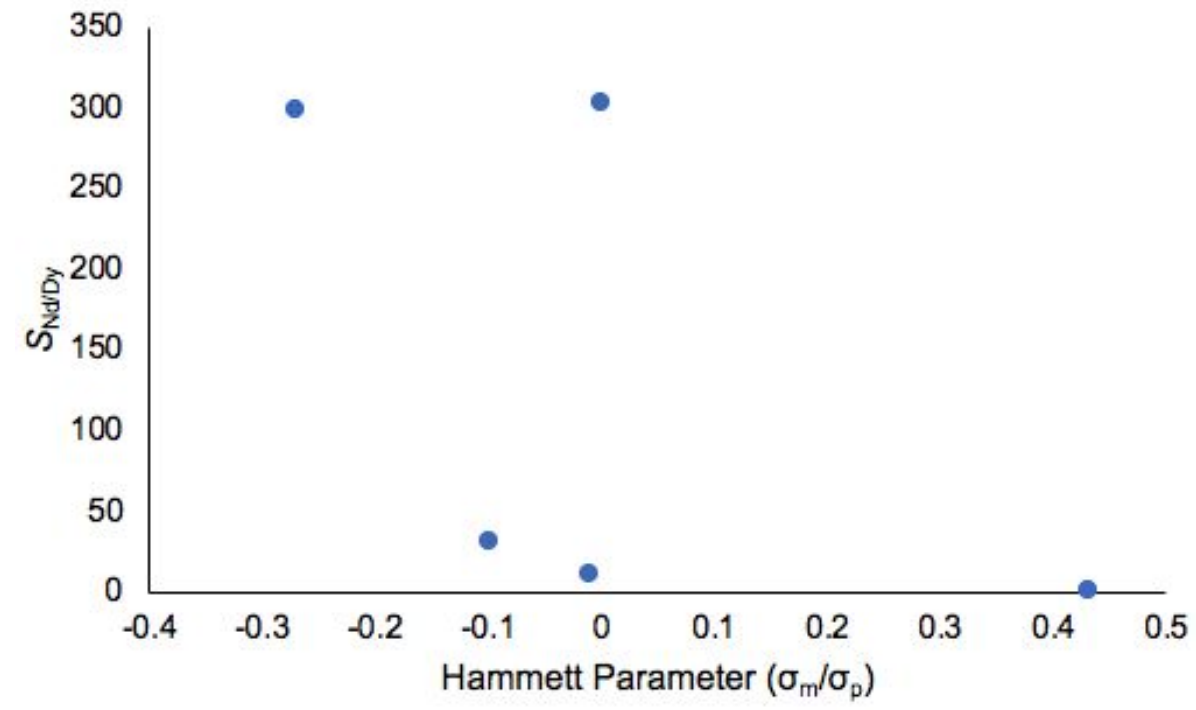

Figure S39. Comparison of the $\mathrm{Nd} / \mathrm{Dy}$ separation factor $\left(S_{\mathrm{Nd} / \mathrm{Dy}}\right)$ in benzene against the Hammett parameter $\left(\sigma_{m}\right.$ or $\left.\sigma_{p}\right)$ of $R .\left(R=5-O M e, 4-t B u, 5-P h, ~ H, 4-C F_{3}\right)$. 


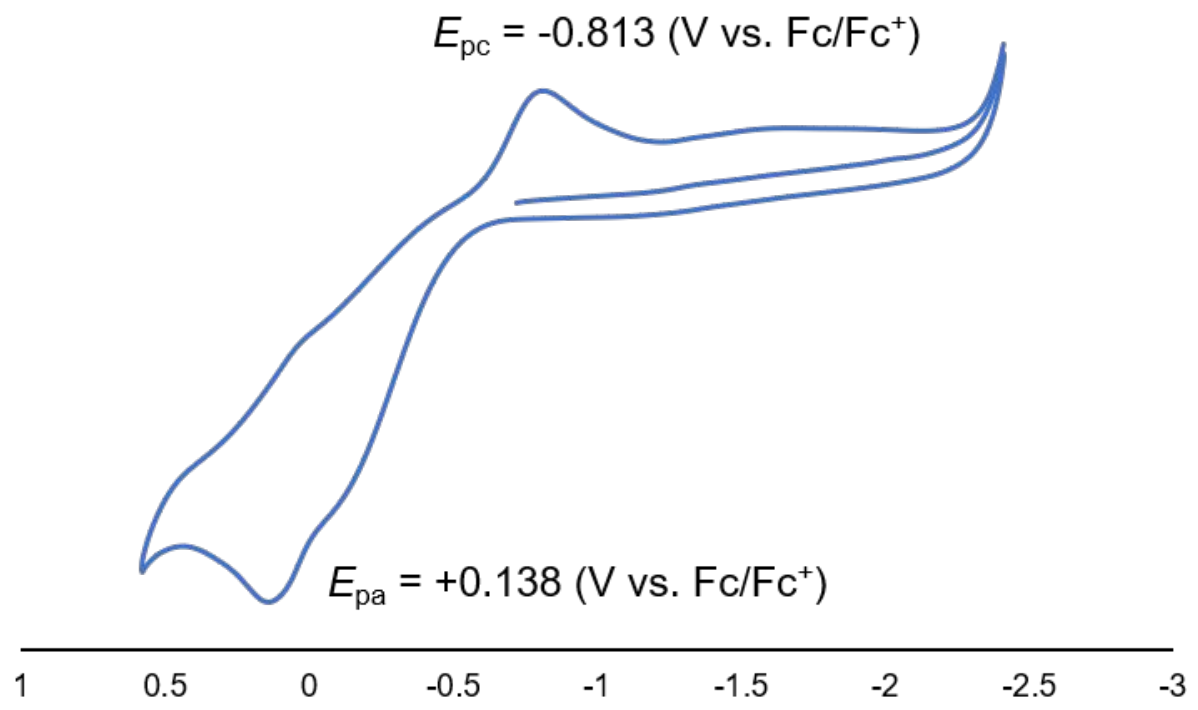

Figure S40. Cyclic voltammogram of $\mathrm{H}_{3}$ TriNOxOMe recorded at a scan rate of $100 \mathrm{mV} / \mathrm{s}$ in $0.1 \mathrm{M}$ $\left[{ }^{n} \mathrm{Pr}_{4} \mathrm{~N}\right]\left[\mathrm{BAr}_{4}\right]$ dichloromethane solution.

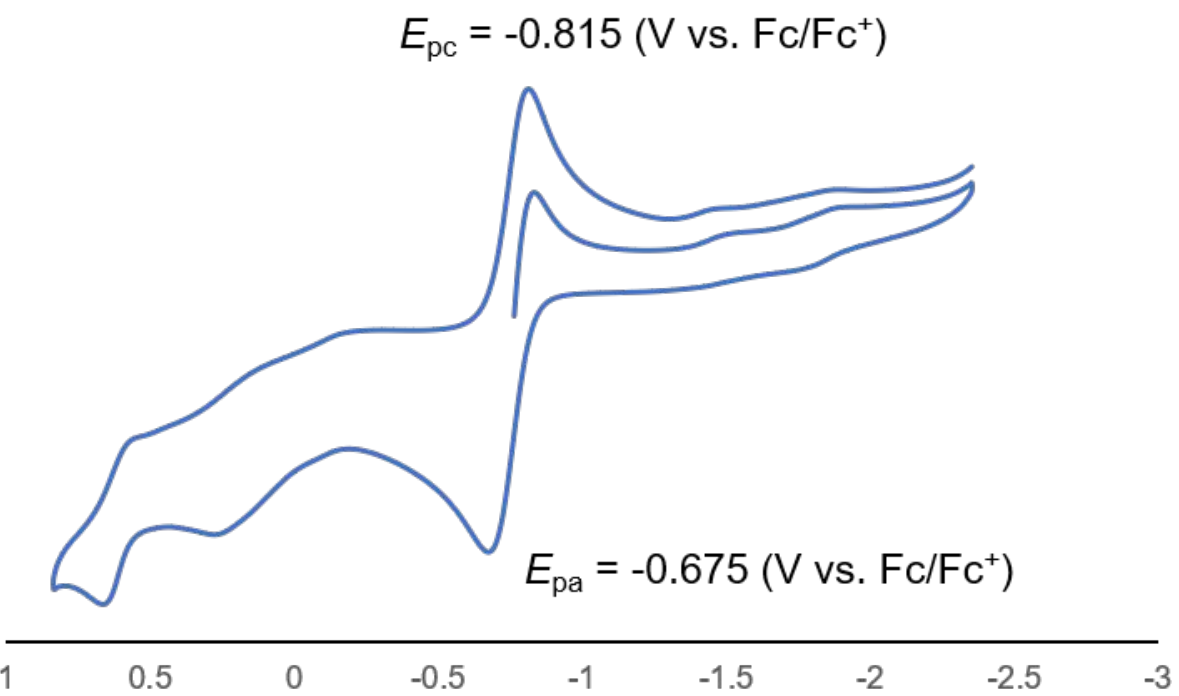

Figure S41. Cyclic voltammogram of $\mathrm{H}_{3}$ TriNOx ${ }^{\mathrm{tBu}}$ recorded at a scan rate of $100 \mathrm{mV} / \mathrm{s}$ in $0.1 \mathrm{M}$ $\left[{ }^{n} \mathrm{Pr}_{4} \mathrm{~N}\right]\left[\mathrm{BArF}_{4}\right]$ dichloromethane solution. 


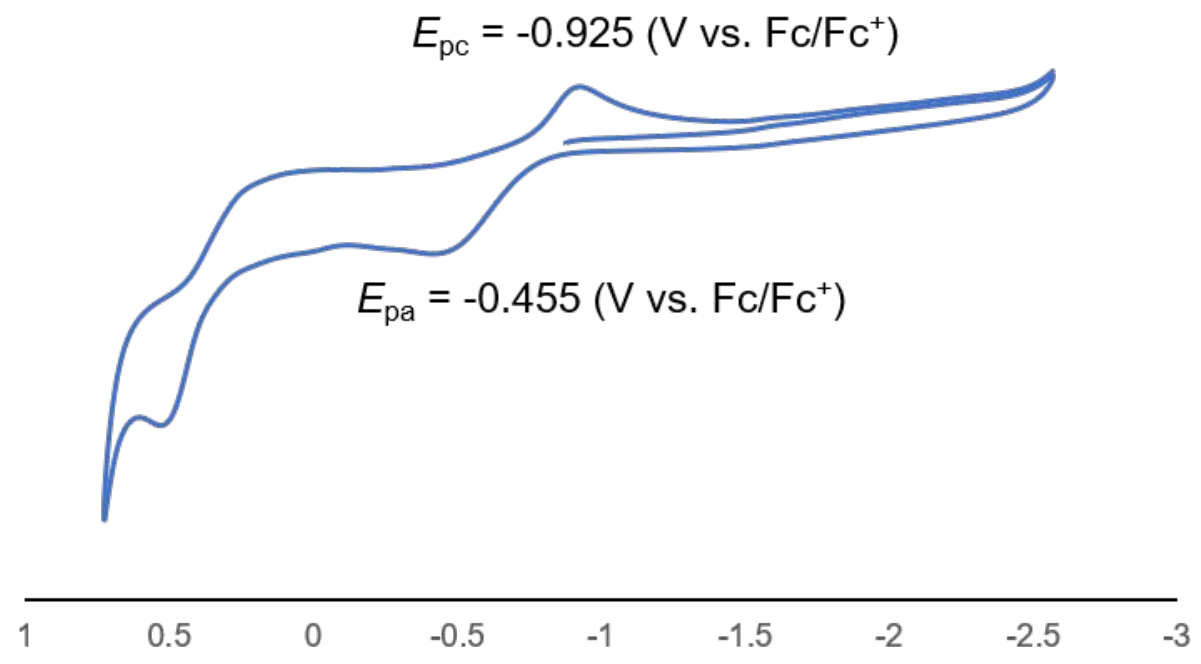

Figure S42. Cyclic voltammogram of $\mathrm{H}_{3}$ TriNOx $^{\mathrm{Ph}}$ recorded at a scan rate of $100 \mathrm{mV} / \mathrm{s}$ in $0.1 \mathrm{M}$ $\left[{ }^{n} \mathrm{Pr}_{4} \mathrm{~N}\right]\left[\mathrm{BArF}_{4}\right]$ dichloromethane solution.

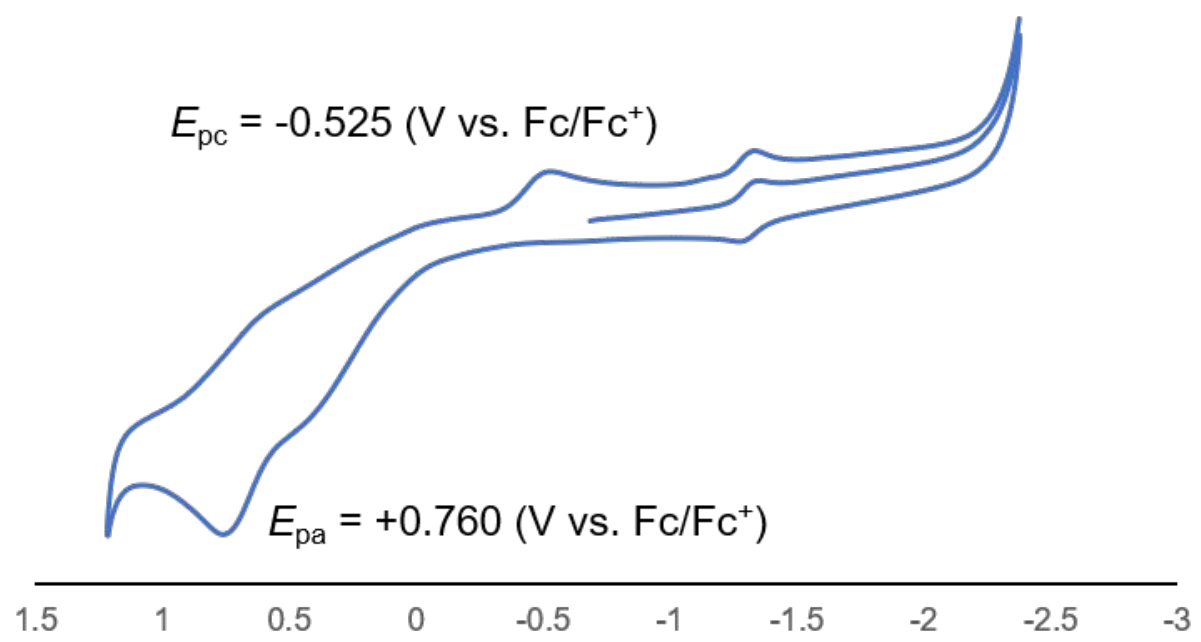

Figure S43. Cyclic voltammogram of $\mathrm{H}_{3} \mathrm{TriNOx} \mathrm{CF}_{3}$ recorded at a scan rate of $100 \mathrm{mV} / \mathrm{s}$ in $0.1 \mathrm{M}$ $\left[{ }^{n} \mathrm{Pr}_{4} \mathrm{~N}\right]\left[\mathrm{BAr}_{4}\right]$ dichloromethane solution. 


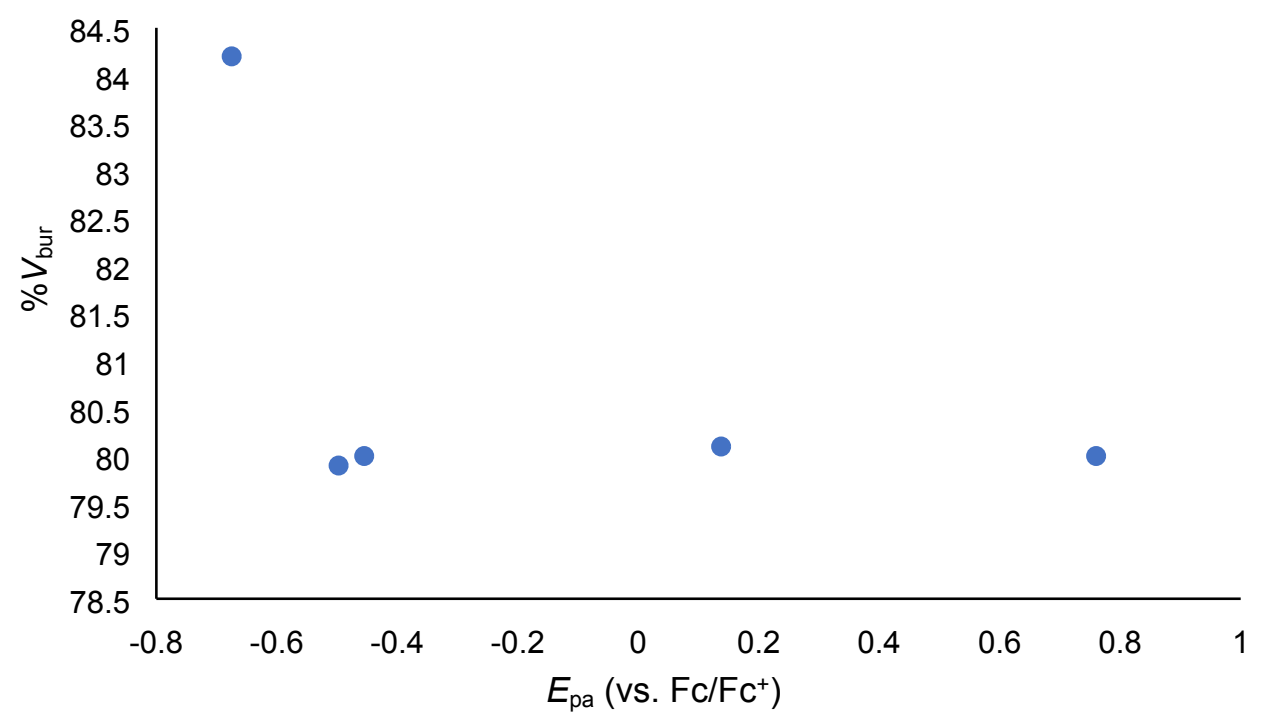

Figure S44. Comparison of the percent buried volume $\left(\% V_{\text {bur }}\right)$ of $\mathrm{Nd}\left(\mathrm{TriNOx}^{\mathrm{R}}\right)(\mathrm{THF})$ complexes against the anodic peak potential $\left(E_{\mathrm{pa}}\right)$ of $\mathrm{H}_{3} \operatorname{TriNOx}^{\mathrm{R}}$. $\left(\mathrm{R}=5-\mathrm{OMe}\right.$, 4-t $\left.\mathrm{Bu}, 5-\mathrm{Ph}, \mathrm{H}, 4-\mathrm{CF}_{3}\right)$.

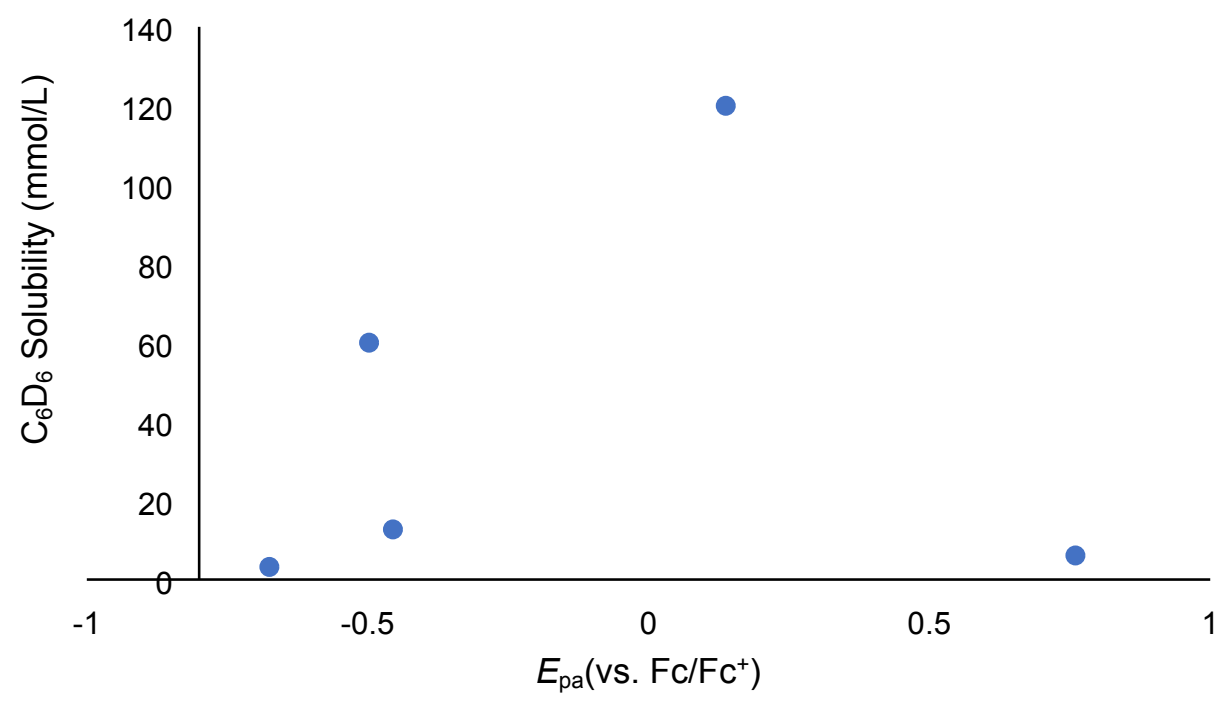

Figure S45. Comparison of the solubility (mmol/L) of $\mathrm{Nd}\left(\mathrm{TriNOx}^{\mathrm{R}}\right)(\mathrm{THF})$ complexes in $\mathrm{C}_{6} \mathrm{D}_{6}$ against the anodic peak potential $\left(E_{\mathrm{pa}}\right)$ of $\mathrm{H}_{3} \operatorname{TriNOx}^{\mathrm{R}}$. $\left(\mathrm{R}=5-\mathrm{OMe}, 4-{ }^{t} \mathrm{Bu}, 5-\mathrm{Ph}, \mathrm{H}, 4-\mathrm{CF}_{3}\right)$. 


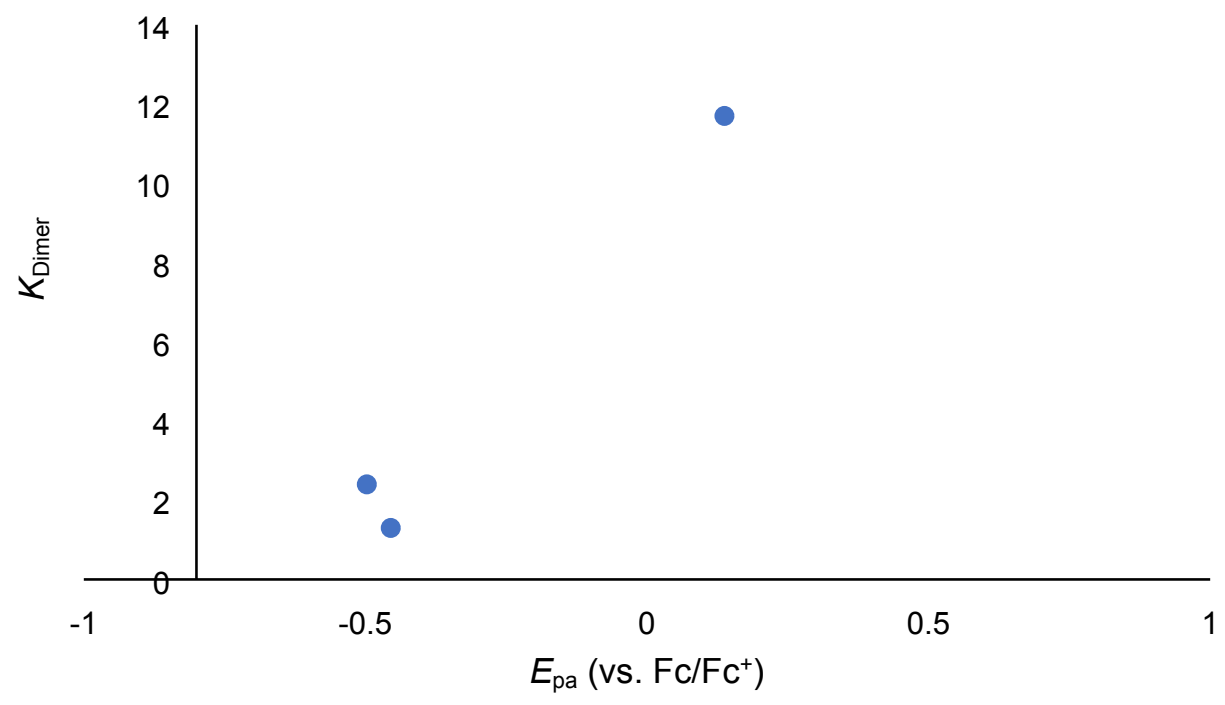

Figure S46. Comparison of the self-association constant $\left(K_{\text {dimer }}\right)$ of $\mathrm{Nd}\left(\mathrm{TriNOx}^{\mathrm{R}}\right)(\mathrm{THF})$ complexes against the anodic peak potential $\left(E_{\mathrm{pa}}\right)$ of $\mathrm{H}_{3} \operatorname{TriNOx}^{\mathrm{R}}$. $\left(\mathrm{R}=5-\mathrm{OMe}\right.$, 4- $\left.{ }^{\mathrm{B} u}, 5-\mathrm{Ph}, \mathrm{H}, 4-\mathrm{CF}_{3}\right)$.

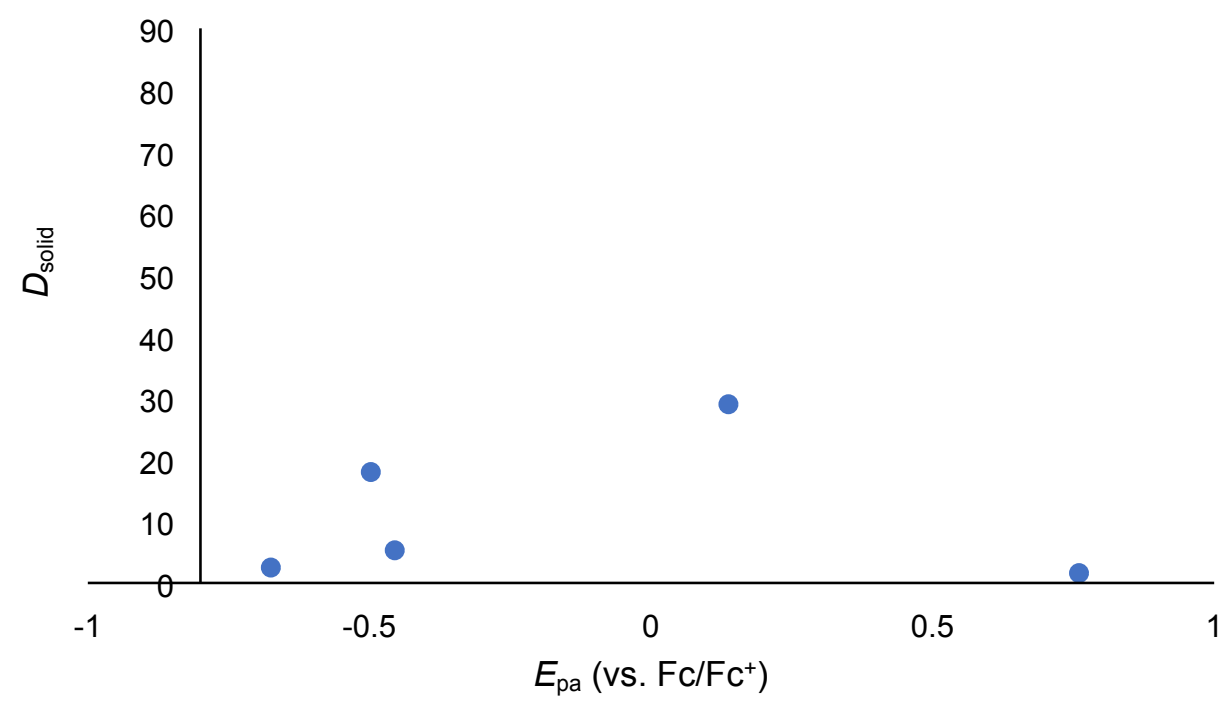

Figure S47. Comparison of the solid enrichment factor $\left(D_{\text {solid }}\right)$ in benzene against the anodic peak potential $\left(E_{\mathrm{pa}}\right)$ of $\mathrm{H}_{3}$ TriNOx$^{\mathrm{R}}$. $\left(\mathrm{R}=5-\mathrm{OMe}\right.$, 4-'Bu, 5-Ph, $\left.\mathrm{H}, 4-\mathrm{CF}_{3}\right)$. 


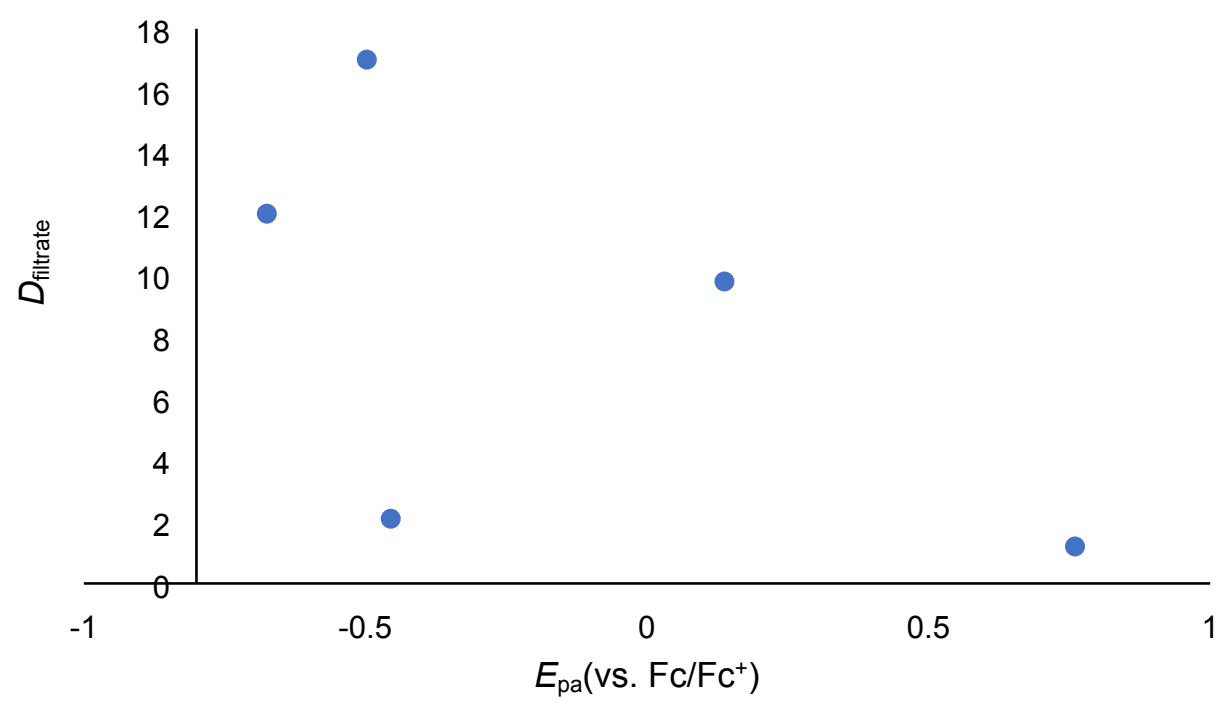

Figure S48. Comparison of the filtrate enrichment factor $\left(D_{\text {filtrate }}\right)$ in benzene against the anodic peak potential $\left(E_{\mathrm{pa}}\right)$ of $\mathrm{H}_{3}$ TriNOx $^{\mathrm{R}}$. ( $\mathrm{R}=5-\mathrm{OMe}$, 4- $\left.{ }^{\mathrm{t}} \mathrm{Bu}, 5-\mathrm{Ph}, \mathrm{H}, 4-\mathrm{CF}_{3}\right)$.

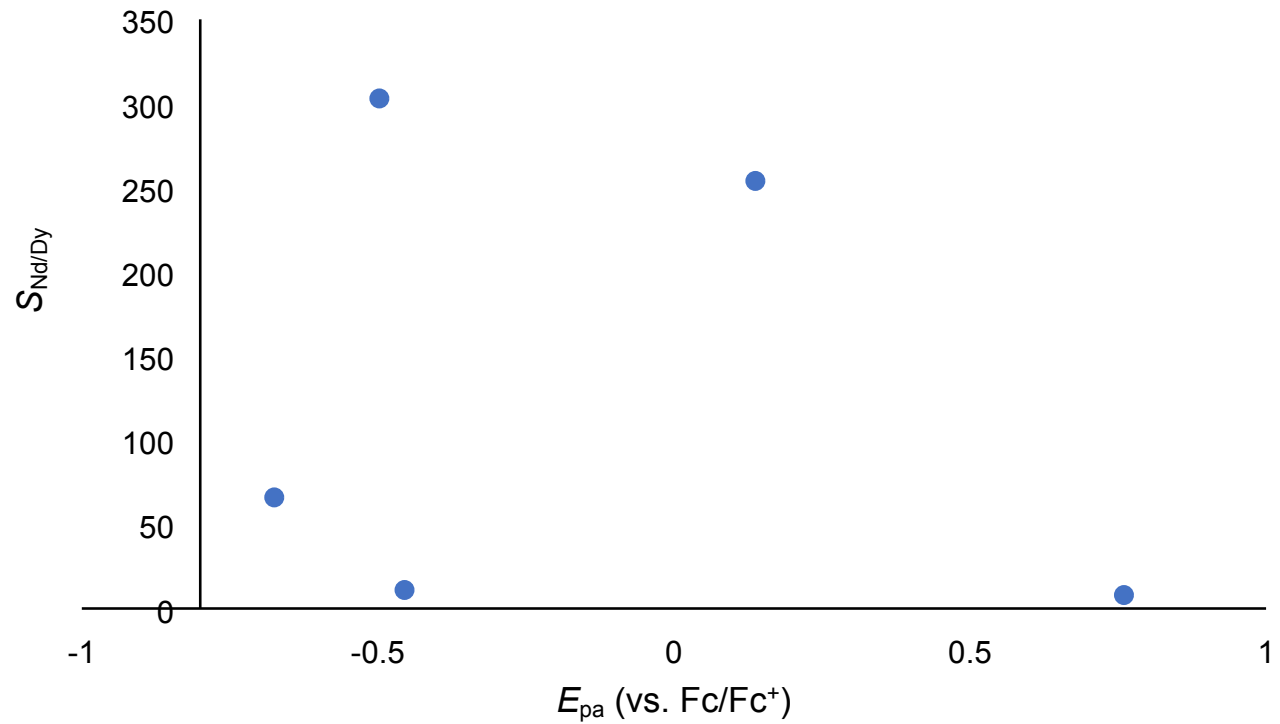

Figure S49. Comparison of the $\mathrm{Nd} / \mathrm{Dy}$ separation factor $\left(S_{\mathrm{Nd} / \mathrm{Dy}}\right)$ in benzene against the anodic peak potential $\left(E_{\mathrm{pa}}\right)$ of $\mathrm{H}_{3}$ TriNOx $^{\mathrm{R}}$. $\left(\mathrm{R}=5-\mathrm{OMe},{ }^{-}{ }^{-} \mathrm{Bu}, 5-\mathrm{Ph}, \mathrm{H}, 4-\mathrm{CF}_{3}\right)$. 


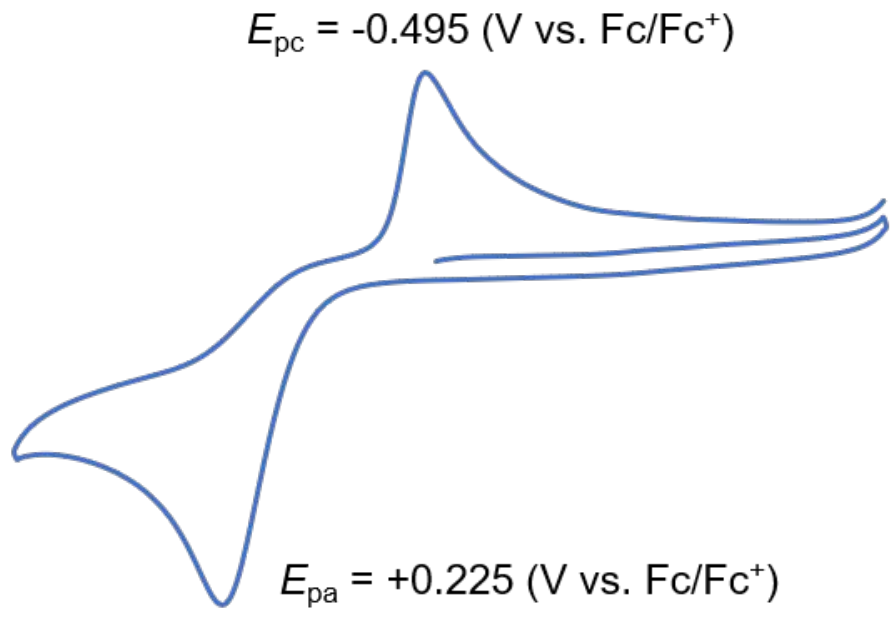

1.5

1

0.5

$-0.5$

$-1$

$-1.5$

$-2 \quad-2.5$

Figure S50. Cyclic voltammogram of $\mathrm{Dy}\left(\right.$ TriNOx $\left.^{\mathrm{OMe}}\right)$ recorded at a scan rate of $100 \mathrm{mV} / \mathrm{s}$ in 0.1 $\mathrm{M}\left[{ }^{n} \mathrm{Pr}_{4} \mathrm{~N}\right]\left[\mathrm{BAr}_{4}\right]$ dichloromethane solution.

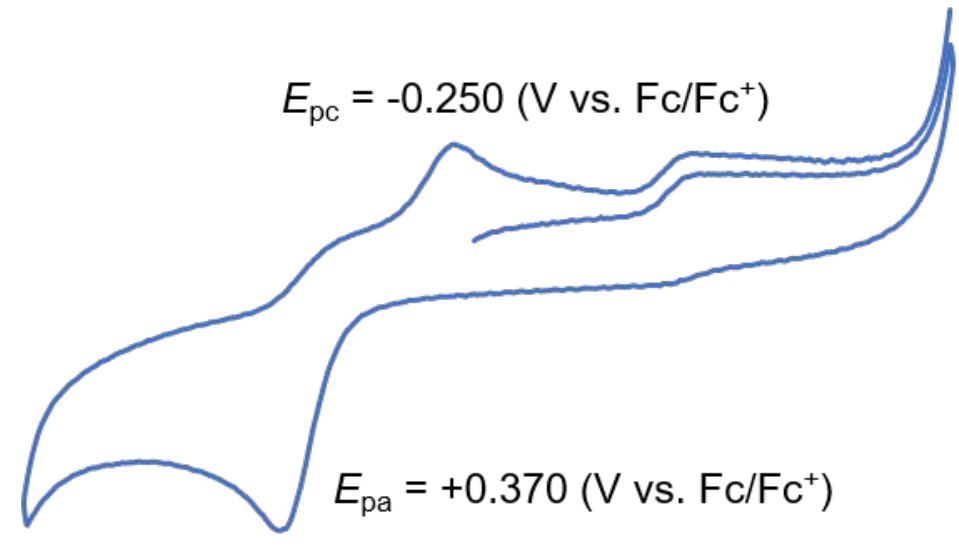

0

$-0.5$

$-1 \quad-1.5$

$-2$

$-2.5$

Figure S51. Cyclic voltammogram of $\mathrm{Dy}\left(\right.$ TriNOx $\left.^{\mathrm{tBu}}\right)$ recorded at a scan rate of $100 \mathrm{mV} / \mathrm{s}$ in $0.1 \mathrm{M}$ $\left[{ }^{n} \mathrm{Pr}_{4} \mathrm{~N}\right]\left[\mathrm{BAr}_{4}\right]$ dichloromethane solution. 


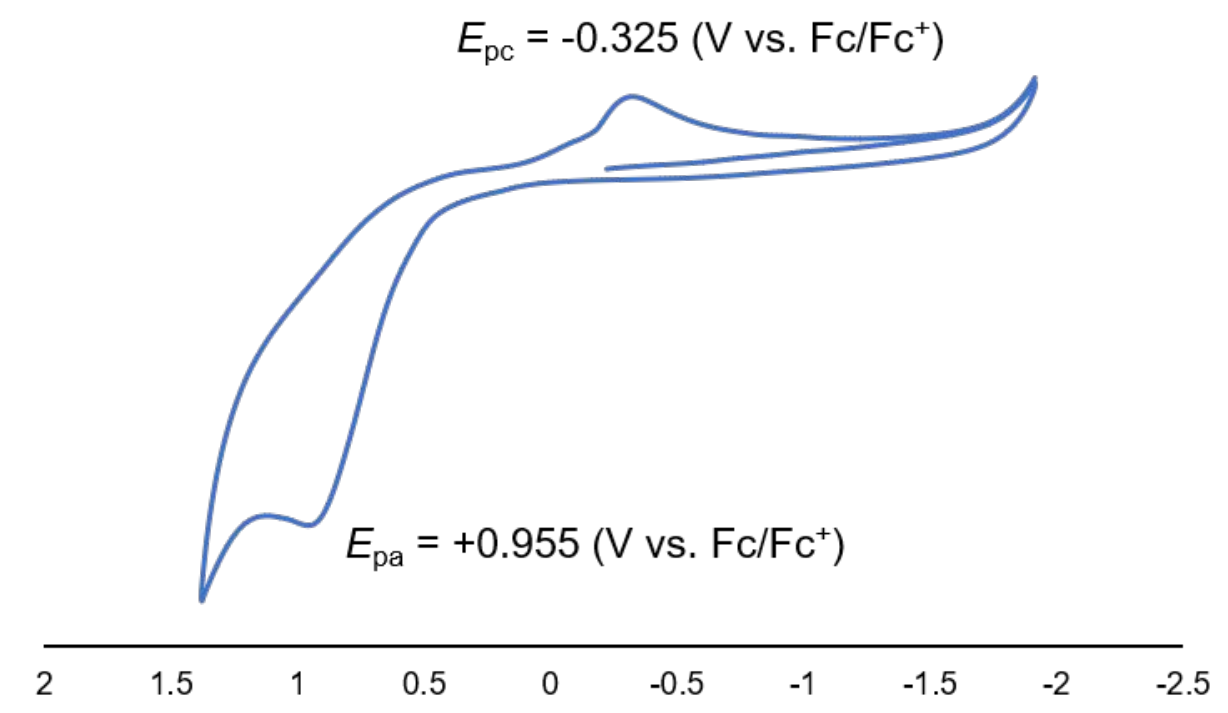

Figure S52. Cyclic voltammogram of Dy $\left(\right.$ TriNOx $\left.^{\mathrm{Ph}}\right)$ recorded at a scan rate of $100 \mathrm{mV} / \mathrm{s}$ in $0.1 \mathrm{M}$ $\left[{ }^{n} \mathrm{Pr}_{4} \mathrm{~N}\right]\left[\mathrm{BAr}_{4}\right]$ dichloromethane solution.

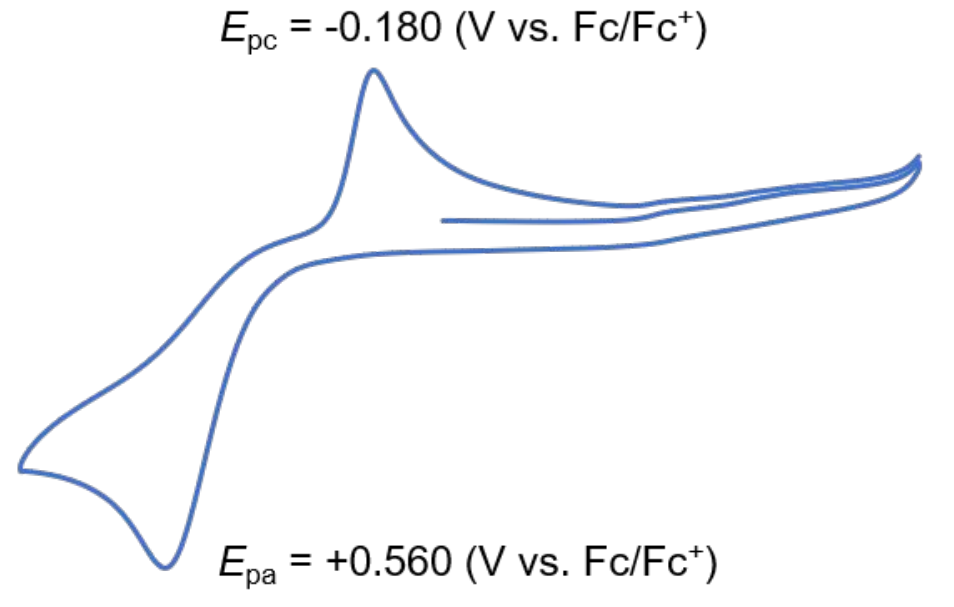

\begin{tabular}{lllllllll}
\hline 1.5 & 1 & 0.5 & 0 & -0.5 & -1 & -1.5 & -2 & -2.5
\end{tabular}

Figure S53. Cyclic voltammogram of $\mathrm{Dy}\left(\mathrm{TriNOx}^{\mathrm{CF}}{ }_{3}\right)$ recorded at a scan rate of $100 \mathrm{mV} / \mathrm{s}$ in $0.1 \mathrm{M}$ $\left[{ }^{n} \mathrm{Pr}_{4} \mathrm{~N}\right]\left[\mathrm{BAr}_{4}\right]$ dichloromethane solution. 


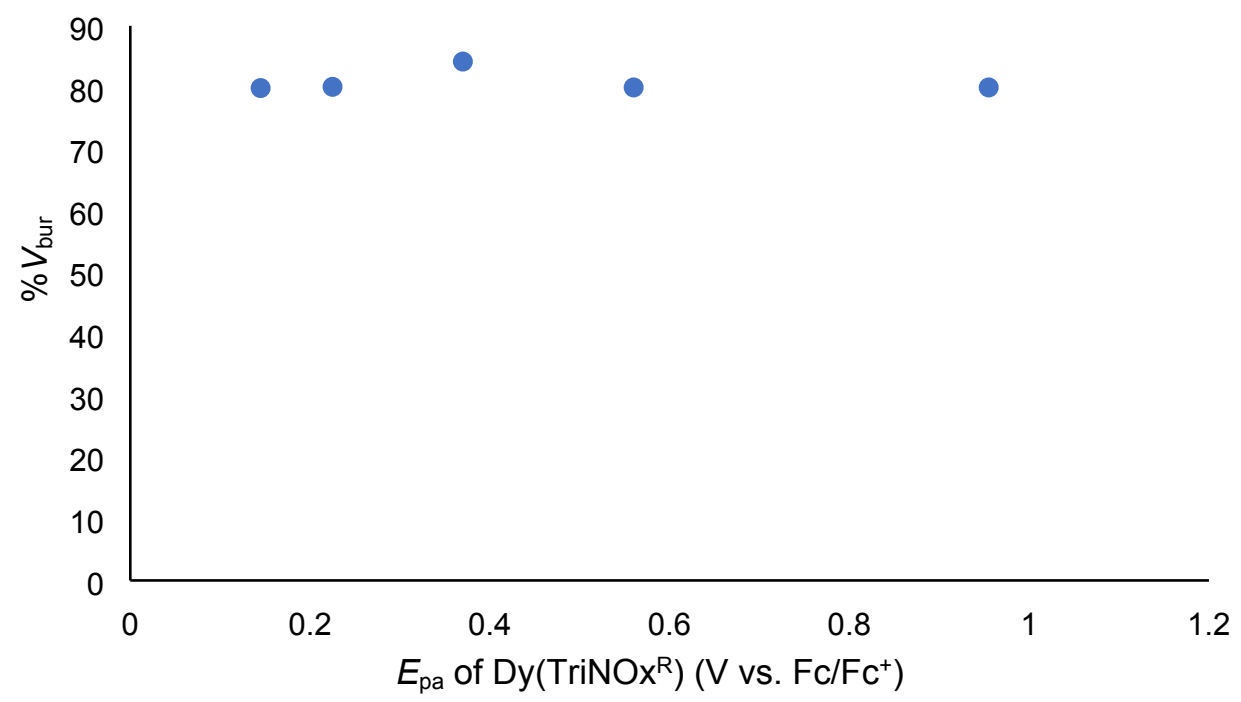

Figure S54. Comparison of the percent buried volume $\left(\% V_{\text {bur }}\right)$ of $\mathrm{Nd}\left(\mathrm{TriNOx}^{\mathrm{R}}\right)(\mathrm{THF})$ complexes against the anodic peak potential $\left(E_{\mathrm{pa}}\right)$ of DyTriNOx${ }^{\mathrm{R}}$. $\left(\mathrm{R}=5-\mathrm{OMe}, 4-{ }^{\mathrm{t}} \mathrm{Bu}, 5-\mathrm{Ph}, \mathrm{H}, 4-\mathrm{CF}_{3}\right)$.

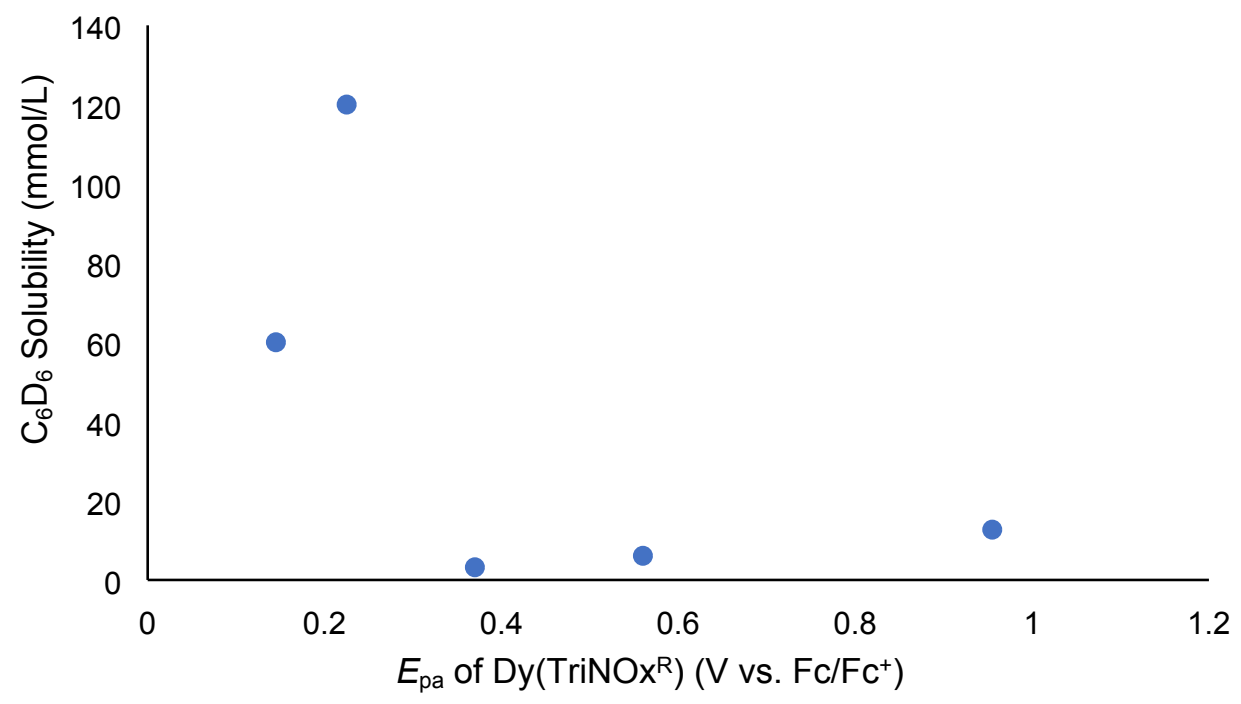

Figure S55. Comparison of the solubility (mmol/L) of $\mathrm{Nd}\left(\operatorname{TriNOx}^{\mathrm{R}}\right)(\mathrm{THF})$ complexes in $\mathrm{C}_{6} \mathrm{D}_{6}$ against the anodic peak potential $\left(E_{\mathrm{pa}}\right)$ of DyTriNOx ${ }^{\mathrm{R}}$. ( $\left.\mathrm{R}=5-\mathrm{OMe}, 4-{ }^{-} \mathrm{Bu}, 5-\mathrm{Ph}, \mathrm{H}, 4-\mathrm{CF}_{3}\right)$. 


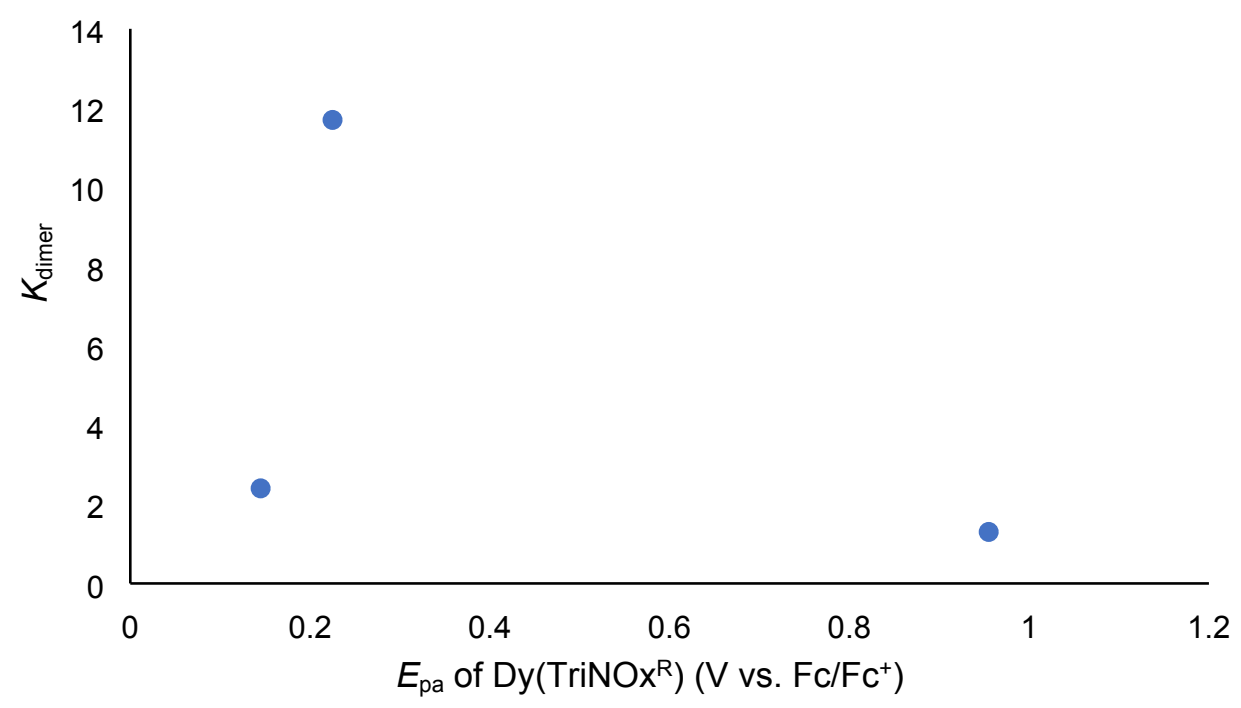

Figure S56. Comparison of the self-association constant $\left(K_{\text {dimer }}\right)$ of $\mathrm{Nd}\left(\mathrm{TriNOx}^{\mathrm{R}}\right)(\mathrm{THF})$ complexes against the anodic peak potential $\left(E_{\mathrm{pa}}\right)$ of $\mathrm{H}_{3} \operatorname{TriNOx}^{\mathrm{R}}$. ( $\mathrm{R}=5-\mathrm{OMe}$, 4- $\left.{ }^{\mathrm{B}} \mathrm{Bu}, 5-\mathrm{Ph}, \mathrm{H}, 4-\mathrm{CF}_{3}\right)$.

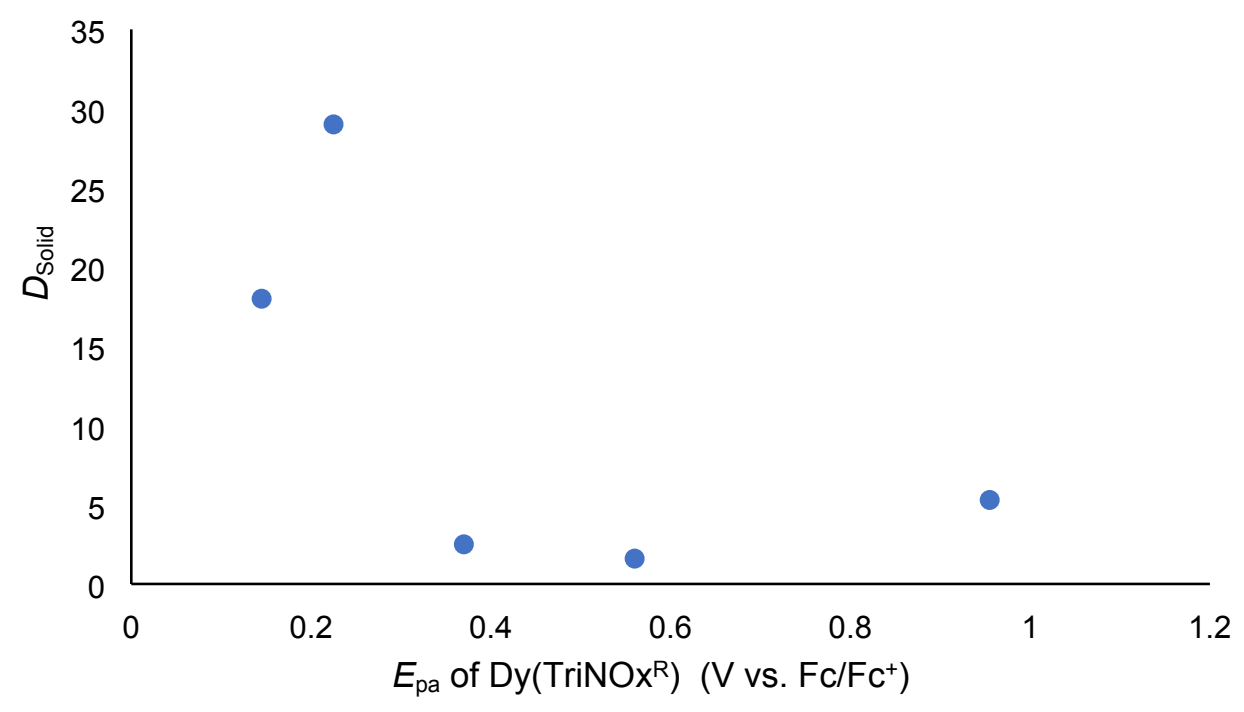

Figure S57. Comparison of the solid enrichment factor $\left(D_{\text {solid }}\right)$ in benzene against the anodic peak potential $\left(E_{\mathrm{pa}}\right)$ of DyTriNOx ${ }^{\mathrm{R}}$. $\left(\mathrm{R}=5-\mathrm{OMe}\right.$, 4- $\left.\mathrm{Bu}, 5-\mathrm{Ph}, \mathrm{H}, 4-\mathrm{CF}_{3}\right)$. 


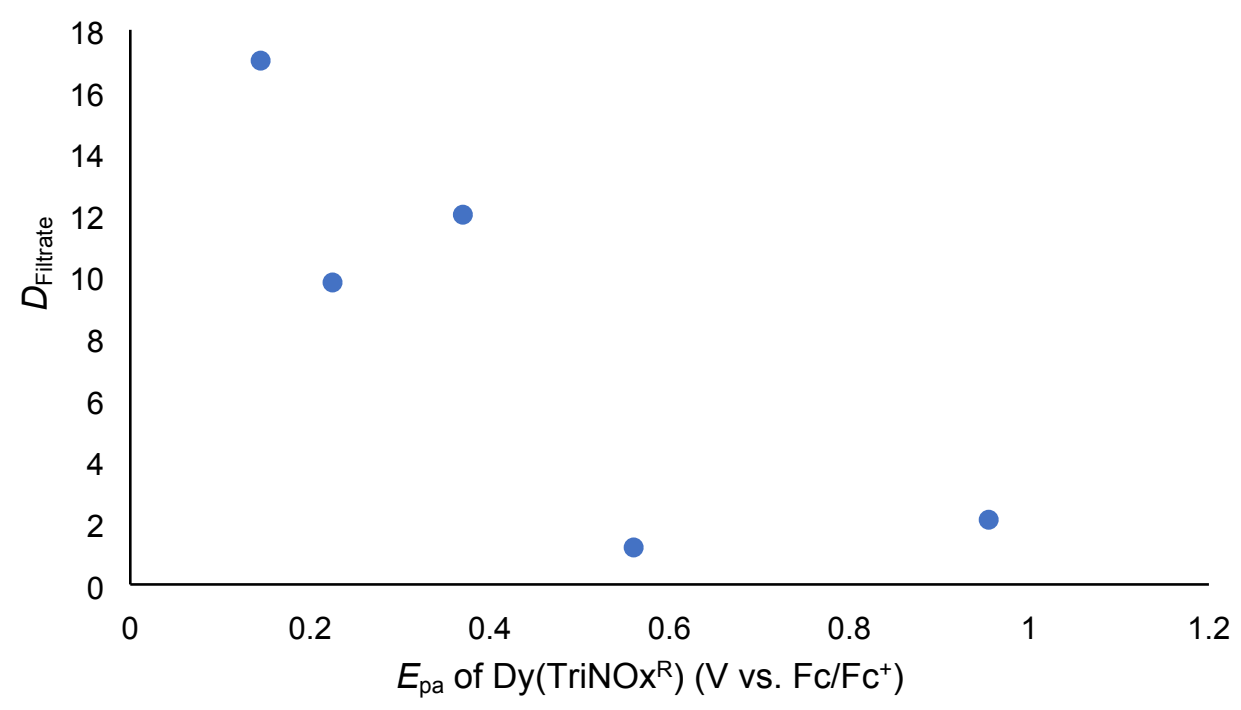

Figure S58. Comparison of the filtrate enrichment factor $\left(D_{\text {filtrate }}\right)$ in benzene against the anodic peak potential $\left(E_{\mathrm{pa}}\right)$ of DyTriNOx ${ }^{\mathrm{R}}$. $\left(\mathrm{R}=5-\mathrm{OMe}\right.$, 4- $\left.{ }^{\mathrm{B}} \mathrm{Bu}, 5-\mathrm{Ph}, \mathrm{H}, 4-\mathrm{CF}_{3}\right)$.

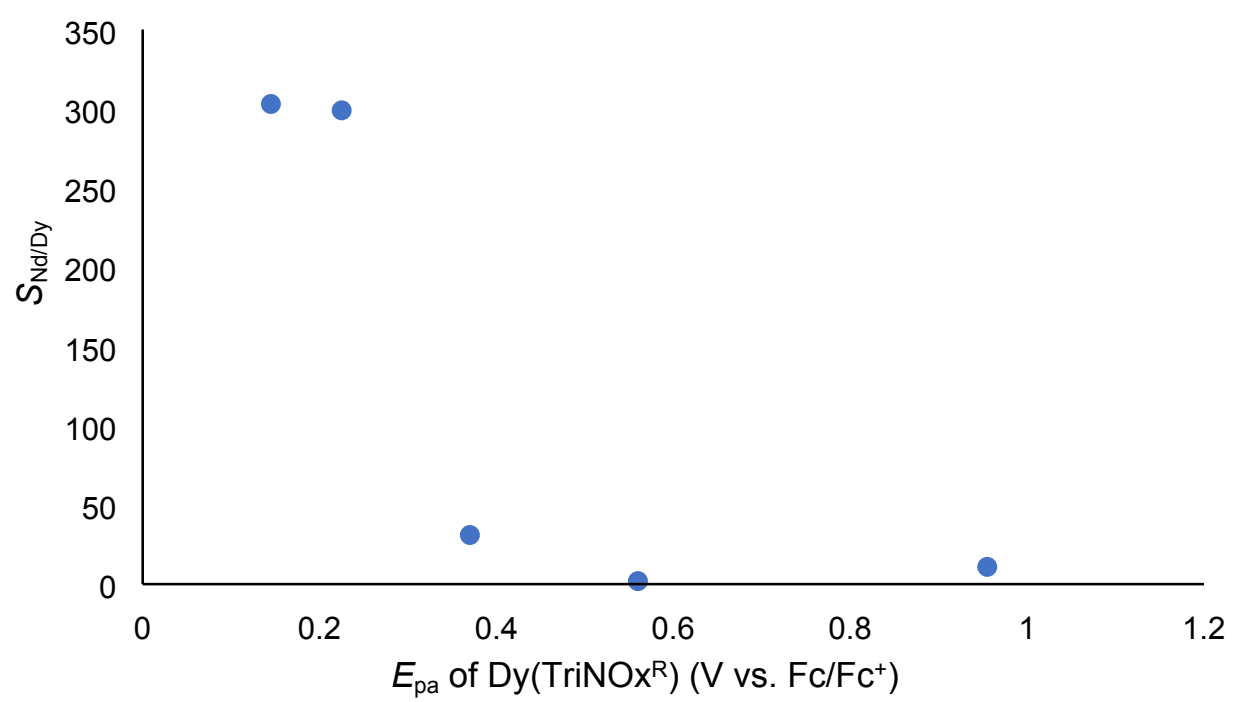

Figure S59. Comparison of the $\mathrm{Nd} / \mathrm{Dy}$ separation factor $\left(S_{\mathrm{Nd} / \mathrm{Dy}}\right)$ in benzene against the anodic peak potential $\left(E_{\mathrm{pa}}\right)$ of $\mathrm{H}_{3} \operatorname{TriNOx}^{\mathrm{R}}$. ( $\mathrm{R}=5-\mathrm{OMe}$, 4- $\left.{ }^{\mathrm{t}} \mathrm{Bu}, 5-\mathrm{Ph}, \mathrm{H}, 4-\mathrm{CF}_{3}\right)$. 


\section{References}

1. Bradley, D. C.; Ghotra, J. S.; Hart, F. A. Low Coordination Numbers in Lanthanide and Actinide Compounds .Part 1. Preparation and Characterization of Tris $\{\mathrm{Bis}($ Trimethylsilyl)Amido\}Lanthanides. J. Chem. Soc., Dalton Trans. 1973, 1021-1027, DOI: 10.1039/DT9730001021.

2. $\quad$ Bruker APEX3, 1-0; Bruker AXS, Inc.: Madison, WI, 2015.

3. Bruker APEX2, 11-0; Bruker-AXS: Madison, WI, 2014.

4. Bruker SAINT, 8.37A; Bruker-AXS: Madison, WI, 2014.

5. Krause, L.; Herbst-Irmer, R.; Sheldrick, G. M.; Stalke, D. Comparison of silver and molybdenum microfocus X-ray sources for single-crystal structure determination. J. Appl. Cryst. 2015, 48, 3-10, DOI: 10.1107/S1600576714022985.

6. Sheldrick, G. M. SHELXT - Integrated space-group and crystal-structure determination. Acta Cryst. 2015, A71, 3-8, DOI: 10.1107/S2053273314026370.

7. Sheldrick, G. M. A short history of SHELX. Acta Cryst. 2008, A64, 112-122, DOI: 10.1107/S0108767307043930.

8. Sheldrick, G. M. Crystal structure refinement with SHELXL. Acta Cryst. 2015, C71, 3-8, DOI: $10.1107 /$ S2053229614024218.

9. Winge, R. K.; Peterson, V. J.; Fassel, V. A. Inductively Coupled Plasma-Atomic EmissionSpectroscopy - Prominent Lines. Appl. Spectrosc. 1979, 33, 206-219.

10. Mallory, F. B.; Butler, K. E.; Berube, A.; Luzik, E. D.; Mallory, C. W.; Brondyke, E. J.; Hiremath, R.; Ngo, P.; Carroll, P. J. Phenacenes: a family of graphite ribbons. Part 3: Iterative strategies for the synthesis of large phenacenes. Tetrahedron 2001, 57, 3715-3724, DOI: 10.1016/S0040-4020(01)00240-X.

11. Chen, Q.; Buss, C. E.; Young, V. G.; Fox, S. Synthesis and structural studies of tris-2chlorobenzylamine and tris-2-bromobenzylamine. J. Chem. Crystallogr. 2005, 35, 177-181, DOI: 10.1007/s10870-005-2954-5.

12. Dressler, J. J.; Miller, S. A.; Meeuwsen, B. T.; Riel, A. M. S.; Dahl, B. J. Synthesis of dilactone bridged terphenyls with crankshaft architectures. Tetrahedron 2015, 71, 283-292, DOI: 10.1016/j.tet.2014.11.055.

13. Duggan, K. A. Compositions for the Treatment of Fibrosis and Fibrosis-Related Conditions. 2016. U.S. Patent No. US 9,458,093 B2.

14. Tang, R. J.; Milcent, T.; Crousse, B. Regioselective Halogenation of Arenes and Heterocycles in Hexafluoroisopropanol. J. Org. Chem. 2018, 83, 930-938, DOI: 10.1021/acs.joc.7b02920.

15. Dahl, T.; Tornoe, C. W.; Bang-Andersen, B.; Nielsen, P.; Jorgensen, M. Palladiumcatalyzed three-component approach to promazine with formation of one carbon-sulfur and two carbon-nitrogen bonds. Angew. Chem. Int. Ed. 2008, 47, 1726-1728, DOI: 10.1002/anie.200705209.

16. Rauniyar, V.; Hall, D. G. Rationally Improved Chiral Bronsted Acid for Catalytic Enantioselective Allylboration of Aldehydes with an Expanded Reagent Scope. J. Org. Chem. 2009, 74, 4236-4241, DOI: 10.1021/jo900553f. 